\title{
WestVirginiaUniversity
}

THE RESEARCH REPOSITORY @ WVU

Graduate Theses, Dissertations, and Problem Reports

2010

\section{Musculoskeletal injuries in tactical law enforcement}

\author{
Nathan T. Roberts \\ West Virginia University
}

Follow this and additional works at: https://researchrepository.wvu.edu/etd

\section{Recommended Citation}

Roberts, Nathan T., "Musculoskeletal injuries in tactical law enforcement" (2010). Graduate Theses, Dissertations, and Problem Reports. 4647.

https://researchrepository.wvu.edu/etd/4647

This Thesis is protected by copyright and/or related rights. It has been brought to you by the The Research Repository @ WVU with permission from the rights-holder(s). You are free to use this Thesis in any way that is permitted by the copyright and related rights legislation that applies to your use. For other uses you must obtain permission from the rights-holder(s) directly, unless additional rights are indicated by a Creative Commons license in the record and/ or on the work itself. This Thesis has been accepted for inclusion in WVU Graduate Theses, Dissertations, and Problem Reports collection by an authorized administrator of The Research Repository @ WVU. For more information, please contact researchrepository@mail.wvu.edu. 


\title{
Musculoskeletal Injuries in Tactical Law Enforcement
}

\author{
Nathan T. Roberts BS, LAT, ATC \\ Thesis submitted to the College of Physical Activity and Sport Sciences \\ at West Virginia University \\ in partial fulfillment of the requirements \\ for the degree of
}

Master of Science in Athletic Training

Michelle A. Sandrey, PhD, ATC

Chris Courtney, D.O. Ruth Kershner, EdD, RN, CHES

College of Physcial Activity and Sport Sciences

Morgantown, WV

2010

Key Words: Musculoskeletal Disorders, Tactical Team, Injuries, Law Enforcement 


\title{
ABSTRACT \\ Musculoskeletal Injuries in Tactical Law Enforcement
}

\author{
Nathan T. Roberts, BS, LAT, ATC
}

Context: Tactical law enforcement combines special law enforcement tactics and elite level athletic movements. There is a lack of research surrounding the frequency and types of musculoskeletal injuries incurred by tactical law enforcement officers. It is postulated that the musculoskeletal injuries seen in the military and among elite level athletes are similar to those sustained by tactical officers. Objective: The primary purpose of this study is to determine how often tactical officers experience musculoskeletal injuries, what types are most common, and when they are occurring. The secondary purpose of this study is to determine how often tactical officers have access to medical professionals, and who is managing/treating their musculoskeletal injuries. Design: The design of this study was a prospective descriptive study using questionnaire analysis. Setting: West Virginia University. Patients or Other Participants: Members of the National Tactical Officers Association and members of various state tactical organizations. Fifty two responses were collected, and 40 (76.9\%) participants answered the questionnaire in its entirety. Interventions: A single questionnaire was used in this study. It contained questions about the types of injuries sustained, the frequency at which they occurred, and tactical unit primary medical care providers. An initial letter was emailed to the National Tactical Officers Association (NTOA) and 25 other state and regional tactical organizations to gain approval to send the questionnaire to their members. This questionnaire cover letter contained the link to the Tactical Officer Questionnaire (TOQ). After three weeks a follow up letter was sent out to remind participants that they had three weeks left to participate in the study. Main Outcomes Measures: The expectation of this study was to determine the musculoskeletal injuries most commonly occurring in tactical law enforcement, who is treating them, and when they are occurring. Results: The mean age of participants was 39.6 \pm 6.5 . Most participants were part time tactical officers $(78 \%, \mathrm{n}=39)$. The majority of tactical officers $(38.5 \%, \mathrm{n}=20)$ have been employed as such for more than 10 years. The majority of tactical officers polled $(76.9 \%, \mathrm{n}=40)$ spent less than 5 hours per week on call outs, and $45.1 \%(\mathrm{n}=23)$ spent less than 5 hours training per week. Most indicated that their tactical unit employed the Tactical Emergency Medical Support (TEMS) system (78.8\%, $\mathrm{n}=41$ ). The most popular medical coverage was to use an outside medical professional with tactical training and TEMS certification as the TEMS provider $(70.0 \%, \mathrm{n}=28)$. When TEMS was not available an EMT in emergency situations only $(61.1 \%, \mathrm{n}=11)$ was the most common. Only $13.3 \%(n=4)$ could consider a medical provider having a full time commitment to the tactical unit. Most tactical officers claimed not having any previous injuries that were exacerbated by their tactical officer duties $(71.2 \%, \mathrm{n}=37)$. An even greater number admitted to experiencing some kind of musculoskeletal injury as a direct result of being employed as a tactical officer $(80.8 \%, n=42)$, and only $67.3 \%(n=35)$ admitted to sustaining some kind of musculoskeletal injury while employed as a tactical officer as a result of non-work related activities. Common Lower extremity injuries were ankle ligament sprains $(63.2 \%, \mathrm{n}=12)$, knee tears/ruptures $(68.8 \%, \mathrm{n}=11)$, and general pain and discomfort of the knee $(41.7 \%, \mathrm{n}=5)$. The most common upper extremity injuries were shoulder dislocations $(60.0 \%, \mathrm{n}=6)$ and elbow tendinitis $(62.5 \%, \mathrm{n}=5)$. The most common trunk injuries were back muscle strains $(42.1 \%, \mathrm{n}=8)$ and vertebral disc involvement in the back $(77.8 \%, \mathrm{n}=7)$. Multiple ligament sprains $(81.5 \%, \mathrm{n}=13)$, Muscle strains $(50.0 \%, \mathrm{n}=9)$, dislocations $(62.5 \%, \mathrm{n}=5)$, tendinitis $(55.5 \%, \mathrm{n}=5)$, tears/ruptures $(50 \%, \mathrm{n}=7)$, vertebral disc involvement $(55.5 \%, \mathrm{n}=5)$, and general pain/discomfort $(66.7 \%, \mathrm{n}=8)$ were reported prior to tactical officer employment. Multiple cases of ligament sprains $(73.7 \%, \mathrm{n}=14)$, muscle strains $(89.5 \%, \mathrm{n}=17)$, fractures $(58.3 \%, \mathrm{n}=7)$, dislocations $(55.5 \%, \mathrm{n}=5)$, tendinitis $(75.0 \%, \mathrm{n}=6)$, tears/ruptures $(66.7 \%$, $\mathrm{n}=10)$, vertebral disc involvement $(80.0 \%, \mathrm{n}=8)$, contusions $(91.0 \%, \mathrm{n}=10)$, lacerations $(84.7 \%, \mathrm{n}=11)$, and general pain/discomfort $(83.2 \%, \mathrm{n}=10)$ were reported as a result of work related activities. Multiple ligament sprains $(66.8 \%, n=10)$, muscle strains $(73.6 \%, n=14)$, tendinitis $(57.2 \%, n=4)$, tears/ruptures $(53.9 \%, n=7)$, contusions $(55.5 \%, \mathrm{n}=5)$, and general pain/discomfort $(54.6 \%, \mathrm{n}=6)$ were reported while engaging in outside of work activities. Physicians treated the majority of all injuries regardless of when they occurred whether prior to tactical officer employment injuries $(74.2 \%, \mathrm{n}=23)$, work related injuries $(82.9 \%, \mathrm{n}=29)$, and outside of work injuries $(78.1 \%$, $\mathrm{n}=25)$. Most responded that injuries sustained pre-tactical officer employment $(82.4 \%, \mathrm{n}=28)$ and those sustained outside of work related activities $(65.7 \%, \mathrm{n}=23)$ resulted in no time lost from work due to injuries. While $63.2 \%$ $(n=24)$ reported missing time from work due to injuries sustained on the job, with $34.3 \%(n=12)$ reporting missing 2-6 weeks of work due to injury. Conclusion: Ankle sprains, knee sprains, back strains, shoulder dislocations, elbow tendinitis, knee tears/ruptures, vertebral disc involvement of the back, hand lacerations, and general knee pain were the most commonly injured body parts in tactical officers. Work related injuries seemed to be the most prevalent. 
The information gained through this study represents a small population of tactical officers and the injuries experienced during their careers. This provides valuable information about common musculoskeletal injuries and when they are occurring. A more focused study with a larger sample size is needed to improve the validity and power of this information. 


\section{ACKNOWLEDGEMENTS}

First and foremost I would like to thank my parents for all their love and support during the good times and the bad and for encouraging me to continue my education.

Thank you to Bob Cable for giving me an opportunity to be admitted into the Graduate Athletic Training Program at WVU. Thank you for everything that you have done for me in the past two years and the experiences you have provided. Thank you and your family for your support during the loss of family. Thank you for being a great friend and mentor.

Dr. Sandrey, thank you for allowing me to be part of the Graduate Athletic Training Program at WVU and gain clinical experience at Fairmont State University. Thank you for all of your suggestions throughout this process.

Dr. Kershner, thank you for your willingness to be a part of this committee. I appreciate all of your time, guidance and expert opinions.

Dr. Courtney, thank you for taking the time to be a part of this committee. Thank you for being a part of Fairmont State Sports Medicine, you have really helped to take FSU to the top.

Thank you to Special Agent Walsh and Special Agent Egan for providing your personal expertise about tactical law enforcement, and tanking the time to review this study.

Thank you to Doug Kleiner for your presentation at the 2009 NATA clinical symposium encouraging more research in this area, and for striking my interest in tactical law enforcement.

Thank you to all of the tactical officers who help make our communities a safer place to live, and thank you to those who participated in this study.

To my friends and classmates, thank you for being there to get a little crazy and relieve the stresses of graduate school. I wish you all the best and the greatest success in your careers. 


\section{TABLE OF CONTENTS}

Page

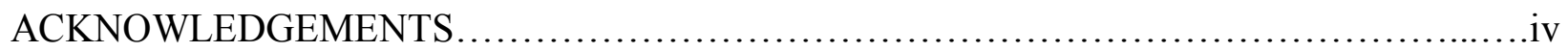

LIST OF TABLES...............................................................

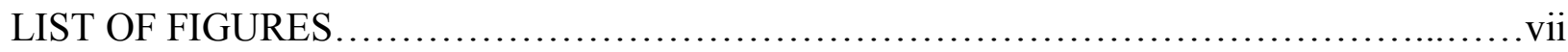

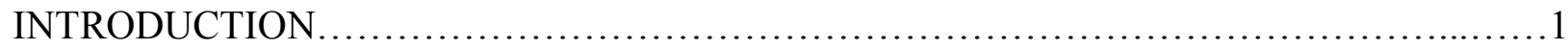

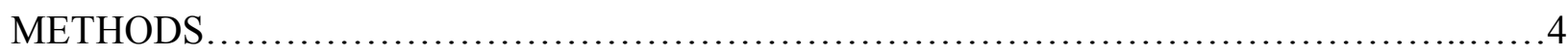

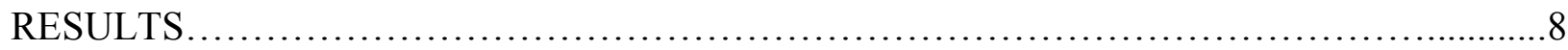

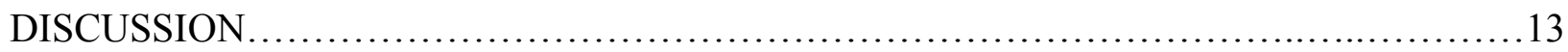

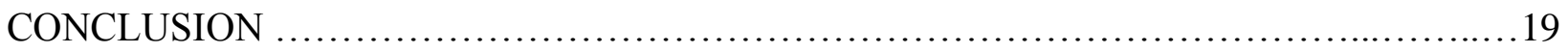

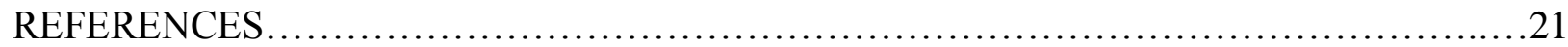

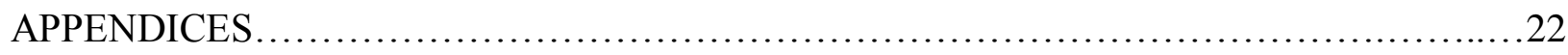

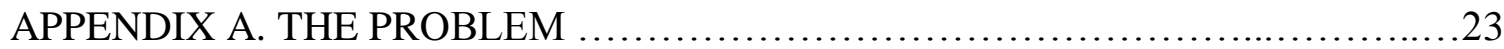

APPENDIX B. LITERATURE REVIEW .....................................28

APPENDIX C. ADDITIONAL METHODS ........................................59

APPENDIX D. ADDITIONAL RESULTS .......................................68

APPENDIX E. RECOMMENDATIONS FOR FUTURE RESEARCH $\ldots \ldots \ldots \ldots \ldots . . . . .86$

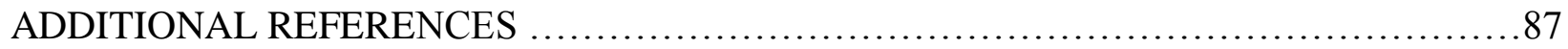




\section{LIST OF TABLES}

Table

Page

B1. Vertebral Column Musculature .............................................33

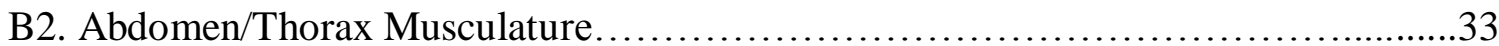

B3. Carpal Bones........................................................ 34

B4. Forearm Musculature......................................................

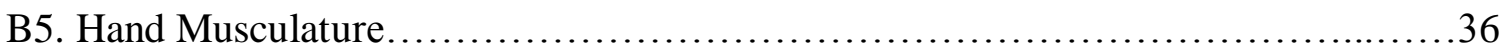

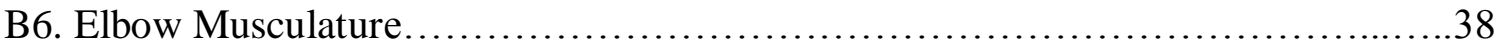

B7. Shoulder Girdle/Complex Musculature......................................41

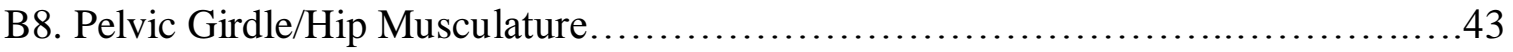

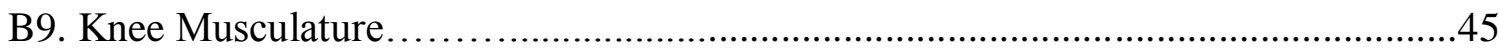

B10. Foot/Ankle Musculature..............................................47

C1. Association Letter of Interest................................................... 59

C2. Questionnaire Cover Letter......................................................................6

C3. Follow Up Cover Letter.......................................................61

C4. Tactical Officer Questionnaire...............................................62

D1. Pre-Tactical Officer Employment Injuries..................................68

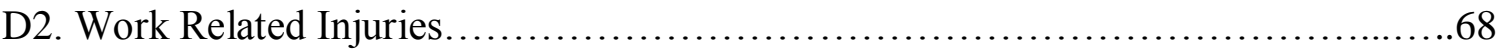

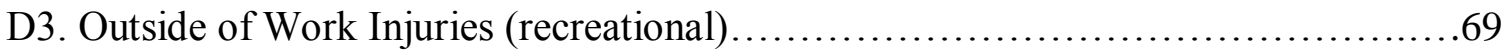




\section{LIST OF FIGURES}

$\begin{array}{lll}\text { Figure } & \text { Page }\end{array}$

D1. Role within Tactical Team..................................................69

D2. Employment Status................................................ 70

D3.Years of Employment....................................................... 70

D4. Hours Spent on Call Outs per Week......................................... 71

D5. Hours Spent Training per Week......................................... 71

D6.Tactical Emergency Medical Support (TEMS)............................................. 72

D7. TEMS Personnel................................................... 72

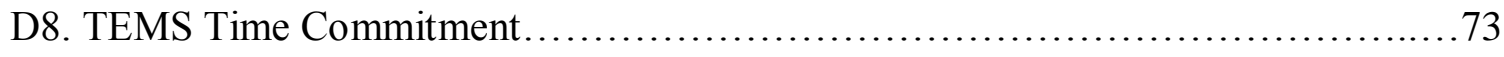

D9. Medical Coverage Personnel............................................73

D10. Medical Coverage Time Commitment..................................... 74

D11. Per-Employment Injuries........................................... 74

D12. Work Related Injuries............................................. 75

D13. Outside of Work Injuries............................................ 75

D14. Ligament Sprains by Body Part....................................... 76

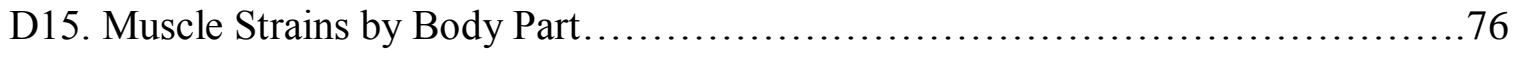

D16. Fractures by Body Part............................................. 77

D17. Dislocations by Body Part........................................... 77

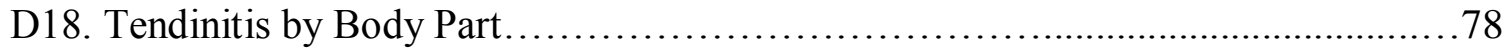

D19. Tear/Rupture by Body Part.......................................... 78

D20. Vertebral Disc Involvement by Body Part................................. 79

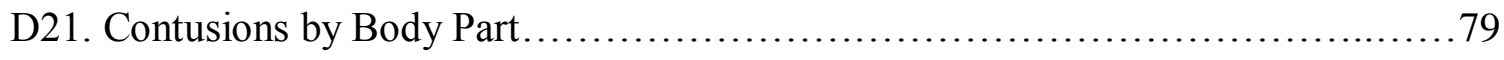

D22. Lacerations by Body Part........................................... 80 
D23. General Pain/Discomfort by Body Part................................. 80

D24. Pre-Employment Injury Medical Care....................................... 81

D25. Time Lost Due to Pre- Employment Injuries.............................. 81

D26. Weeks of Work Missed Due to Pre-Employment Injuries.....................82

D27. Work Related Injury Medical Care ....................................... 82

D28. Time Lost Due to Work Related Injuries................................83

D29. Weeks of Work Missed Due to Work Related Injuries.......................83

D30. Outside of Work Injury Medical Care..................................... 84

D31. Time Lost Due to Outside of Work Injuries............................... 84

D32. Weeks of Work Missed Due to Outside of Work Related Injuries.................85 


\section{INTRODUCTION}

Due to the nature of their profession tactical officers seem to be at high risk of musculoskeletal injuries. Tactical officers, as defined for the purpose of this study, are individuals who are trained in tactical operations as well as athletic maneuvers. ${ }^{1}$ Injuries to Special Weapons And Tactics (SWAT) team members occur at a rate of 33 injuries per 1,000

officer missions. ${ }^{6}$ The incidence of sport related injuries is estimated to be between 10 and 35 per 1,000 playing hours in the adult male professional athlete. ${ }^{7,8}$ Musculoskeletal injuries in the military are even more prevalent. The exact location of musculoskeletal disorders (MSD) among soldiers varies, but the most commonly reported are the knee, lumbar spine, ankle, and glenohumeral joint (GHJ). ${ }^{9,10,11,12,13,14}$ Military personnel are exposed to a range of physical training, sporting, work, and recreational activities that may result in musculoskeletal disorders. ${ }^{9}$ This type of exposure is also seen among tactical officers and athletes. Musculoskeletal disorders are a common occurrence for soldiers and represent substantial losses of time from work and training for the military as a whole. ${ }^{9}$ This resulting morbidity represents a substantial cost to the community. ${ }^{9}$

Tactical officers are individuals with specialized training who put themselves at risk everyday for the safety of their community. When they are not on duty, they can often be found working out, shooting target practice, or running drills in preparation of a call out. Their objective is to prepare for jumping fences while wearing 80 pounds of gear, kicking down doors, securing a suspect, or keeping their trigger finger steady in a hostage situation. Some of the challenges tactical officers are trained to face are weapons transitions, extreme physical exertion, and tactical reloading in addition to performing athletic type movements. ${ }^{1,2}$ SWAT officers 
require optimal speed, power, agility, strength and endurance, and training is an important aspect in maintaining this. ${ }^{1}$

A 2008 Gildea et al $^{3}$ study determined the physician involvement and injury patterns among tactical teams. Only about $6 \%$ of tactical teams had a full time commitment from a physician, while $94 \%$ of tactical officers reported that full time team coverage would be beneficial. $^{3}$ Physicians who volunteer with tactical teams are one of many ways for tactical teams to obtain medical coverage. Tactical emergency medical services (TEMS) are a way tactical teams can obtain medical coverage, as these individuals undergo specific medical training in order to provide proper care to officers and suspects in tactical situations. There are several ways to utilize TEMS personnel, however each has its shortcomings. ${ }^{4,5}$ Many units designate a member of the team to obtain the TEMS certification. This has many advantages because an officer trained in tactical operations can provide his/her own security, and has the custodial authority to make arrests. ${ }^{4,5}$ There are disadvantages to this approach, however. The dual role taken on by this officer can lead to role confusion. ${ }^{5}$ In a highly stressful situation it can be difficult for the officer to determine if he or she should act as a medic first or an officer. This situation can also lead to medical care becoming a secondary priority, instead of the officer's top priority, possibly resulting in a decreased standard of medical care for the tactical team. $^{4,5}$ A second alternative is to designate an outside medical professional to be the TEMS provider for the tactical team. The advantage to this option is that the sole responsibility of the TEMS provider is the health and safety of the tactical unit. ${ }^{5}$ There are still some disadvantages to this option. In this situation the TEMS may not be able to provide his or her own personal security during the mission, and he or she may not have the custodial athority to make arrests. ${ }^{5}$ This would require an officer to be assigned to the medic for protection and to secure any 
suspects in custody requiring medical attention. This option results in one less operator carrying out the mission. The third, final, and least desirable option for tactical teams is "as needed" medical coverage. ${ }^{5}$ This would be provided by fire/rescue or standard Emergency Medical Services (EMS) on site during a call out. A fourth option exists, but has not been adopted by many tactical teams to date. This would include the hiring of a certified athletic trainer (ATC) as the TEMS provider. This individual is trained in the prevention, recognition, and rehabilitation of injuries as an ATC. If one was to combine that with training in tactical emergency medicine, they could prove to be a valuable asset to a tactical team. If one were to go as far as to receive additional tactical training a tactical team would be provided with a professional skilled in injury prevention, recognition, and rehabilitation, in addition to tactical medicine and tactical operations and be able to obtain custodial authority to make an arrest on their own. This individual would help optimize all aspects of the tactical officer's profession.

Research on the frequency and types of injuries sustained among tactical teams is only in the initial stages. There is little known about the musculoskeletal injuries incurred during training exercises and call outs, and how they are managed. However, it might be assumed that the types of musculoskeletal injuries among the military and elite level athletes may be similar. This information may be related to tactical teams because of the special way in which tactical law enforcement combines athletic maneuvers and tactical operations, in both training and during missions. Without injury information available, a study is necessary to determine injury rates for tactical officers. Therefore, the primary purpose of this study is to determine how often tactical officers experience musculoskeletal injuries, what types are most common, and when they occurr. The secondary purpose of this study is to determine how often tactical officers have access to medical professionals and who is managing/treating their musculoskeletal injuries. 


\section{METHODS}

Design

The design of this study was a prospective descriptive study using questionnaire analysis. The area to be explored was the musculoskeletal injuries sustained by tactical officers. Injuries included muscle strains, ligament sprains, bone fractures, dislocations, contusions, tears/ruptures, and overuse type injuries sustained during their employment as tactical officers as well as recreationally sustained injuries during employment and any pre-tactical officer employment injuries.

Participants

The initial participants of this study were the National Tactical Officers Association (NTOA) and 25 other state and regional tactical associations. Membership records are considered confidential and exact member numbers are not disseminated to the public. However, it is estimated by the NTOA that there are almost 30,000 members of the National Tactical Officers Association. These 30,000 members are estimated to contain almost 1600 tactical units with 15-20 officers making up a unit.

The members participated by completing a Tactical Officer Questionnaire. There were fifty two participants in this study, all of whom were members of the previously mentioned organizations. Although answering every question was not mandatory, 40 out of the 52 (76.9\%) completed the entire questionnaire. Members with internet access had the opportunity to complete the questionnaire. This study was approved by the Office of Research Compliance at West Virginia University. 


\section{Instruments}

The Tactical Officer Questionnaire (TOQ) was utilized as the data collection tool during this study. The questions for the TOQ were developed using techniques utilized by other successful epidemiological studies. ${ }^{3,8}$ In order to achieve established content and face validity a draft of the instruments was distributed to two Federal Bureau of Investigation (FBI) agents involved in tactical operations for review. Before the final cover letters and questionnaire were determined, the two law enforcement professionals evaluated the instrument for clarity, and readability. Once their professional approval was obtained the final TOQ was determined.

The TOQ contained demographic questions, specific questions about the current management and treatment of musculoskeletal injuries, and questions related to the types of musculoskeletal injuries incurred and their frequencies related to pre- tactical law enforcement employment, tactical law enforcement employment, and injuries sustained during employment but outside of the work setting.

The TOQ was divided into five sections; background information, medical coverage information, injury information, injury description, and the results of injury. The background information section began with the participant denoting his or her role within the tactical team and identifying whether employment as a tactical officer is full time or part time. The number of years employed as a tactical officer was also included. Hours spent on call outs and during training are also specified during this section. The medical coverage section inquired about the current medical coverage among the team. The following questions were used to gain a description of the team's current medical coverage, and the time commitment put forth by the covering medical professional. Write in options were made available to allow participants to express their specific situations based on the various options tactical units have available for 
medical coverage. Section three "Injury Information" asked the participant to identify if they had any injuries before being employed as a tactical officer that were exacerbated by their current work activities. They were also asked to denote whether or not they have experienced any type of musculoskeletal injury as a result of being employed as a tactical officer; and if they sustained any musculoskeletal injuries outside of work during employment as a tactical officer. Section four was a series of scroll down boxes in which the type of injury was listed to the side and the participant was instructed to choose the body part pertaining to their injury, when that body part was injured, how often and whether or not rehabilitation or surgery was required. There was also a fill in area that allowed for any additional information the participant would be willing to share. Section five was the final section, and required the participant to answer questions related to the results of the injuries that they have sustained. They were asked to specify who managed their injuries previous to tactical law enforcement employment and whether or not it has caused them to miss work and for how long. Management of injuries sustained during employment as a tactical officer and if it caused them to miss work and for how long was also included. Finally they were asked to comment on who managed their recreational injuries, if they missed work as a result of it and for how long.

Procedures

Three cover letters and a questionnaire were utilized during this study. An initial letter was sent to the National Tactical Officers Association (NTOA) and 25 other state and regional tactical officer associations seeking agreement to either post a link to another cover letter on their websites or distribute the cover letter to members directly. The second cover letter was a letter that requested the tactical officers complete the questionnaire. After gaining permission, an 
internet website, embedded as a link within, and included in the cover letter was used for participants to access the questionnaire. Point and click boxes as well as areas to fill in text were utilized for answering the questions. The third and final cover letter sent to the associations was a letter notifying members of the time in which they have left to complete the Tactical Officer Questionnaire. After three weeks of data collection, the follow up letter was distributed to the same organizations to notify them that the time to complete the study would end in one week. This allowed for a total of four weeks of data collection.

Survey Monkey was the website which contained the Tactical Officer Questionnaire. The configuration of this website was such that the anonymity and confidentiality of all responses would be upheld. Individual responses were transferred to the website after clicking "submit." Strict anonymity of answers was upheld and the investigators were blinded to the origin of the submissions. Survey Monkey stated that it would not use the information collected from surveys in any way, shape, or form. In addition, any other material provided to them (including images, email addresses, etc.) was held in the strictest confidence. Survey Monkey does not collect personally identifiable information except when specifically provided this information on a voluntary basis. Survey Monkey states that every effort would be made to ensure that whatever information was provided to them would be maintained in a secure environment.

\section{Statistical Analysis}

The statistical analysis of this study consisted of frequencies and percentages of responses and means when necessary. The frequencies related to the number of musculoskeletal injuries incurred by tactical officers. The percentages reflected the epidemiological information 
related to the type of musculoskeletal injuries. Percentages and numbers of multiple injuries were also analyzed on the additional questions within the tactical officer questionnaire.

\section{RESULTS}

A link to the Tactical Officer Questionnaire was offered to the members of the National Tactical Officers Association (NTOA) and 25 other state and regional tactical associations. The NTOA and the state tactical associations for Ohio, Tennessee, and Indiana were the only tactical associations that expressed agreement to provide their members with the cover letter containing the TOQ link. A total of 52 responses were collected over a four week data collection period. A return rate could not be determined as the exact membership numbers for these organizations are not available to the public. Not all participants answered all of the questions; therefore, results were based on responses to individual questions. The results were divided into five sections: background information, medical coverage information, injury information, injury description, and results of injury. These five sections were designed to address the three primary goals: to determine how often tactical officers experienced musculoskeletal injuries, what type are most common, and when they are occurring; and the two secondary goals: how often tactical officers have access to medical professionals and who is managing/treating their injuries.

\section{Background Information}

The background information identified who was participating in the study and some general information about activity level as a tactical officer. The mean age of participants was 39.6 \pm 6.5 . The majority of participants $(94.2 \%, \mathrm{n}=49)$ identified their role for the study as tactical operators $(49 \%, \mathrm{n}=24)$, team leaders $(40.8 \%, \mathrm{n}=20)$, and medical support $(10.2 \%, \mathrm{n}=5)$. (Figure 
D1) A large majority (96\%) identified their employment status for the study as full time (22\%, $\mathrm{n}=11)$ and part time $(78 \%, \mathrm{n}=39)$ tactical officers. (Figure D2) The majority of tactical officers claimed to be employed for more than 10 years $(38.5 \%, \mathrm{n}=20)$, while the next largest group claimed employment from 3-5 years $(32.7 \%, \mathrm{n}=17)$. (Figure D3) The number of hours spent on call outs was commonly less than 5 hours per week $(76.9 \%, n=40)$. (Figure D4) The number of hours spent training for tactical operations was also less than 5 hours per week $(45.1 \%, \mathrm{n}=23)$, with 6-10 hours being the second most common (39.2\%, $\mathrm{n}=20)$. (Figure D5)

\section{Medical Coverage Information}

The second section of the TOQ is the medical coverage section. This section was designed to gain an understanding of which of the three medical coverage options are being used most frequently by tactical units. Tactical units employed the Tactical Emergency Medical Support (TEMS) system $(78.8 \%, \mathrm{n}=41)$. (Figure D6) Of the $78.8 \%$ that identified having a TEMS system, 70.0\% ( $\mathrm{n}=28$ ) use an outside medical professional with tactical training and TEMS certification as the TEMS provider (Figure D7). Their time commitment was largly reported as part time $(41.9 \%, \mathrm{n}=18)$. (Figure D8). Of those that indicated not having a TEMS provider, $61.1 \%$ (n=11) use an EMT in emergency situations only, which was considered the least desirable option reported in the literature, and $38.9 \%(\mathrm{n}=7)$ used a physician for medical coverage during call outs. (Figure D9) Most of the time the medical professional's time commitment was considered part time $(30.0 \%, \mathrm{n}=9)$, while $23.3 \%(\mathrm{n}=7)$ described this person's commitment as an as needed situation during call outs only. (Figure D10) Only a small portion reported having a full time medical professional $(13.3 \%, \mathrm{n}=4)$. (Figure D10) 
Injury Information

The third section of the TOQ consisted of injury information. This section was designed to determine if tactical officers had musculoskeletal injuries prior to being employed as tactical officers that were exacerbated by law enforcement duties, during employment as tactical officers as a direct result of work related activities, and if they had experienced any musculoskeletal injuries outside of work related activities during their employment as a tactical officer. The majority of tactical officers claimed to not have any previous injuries that were exacerbated by their tactical officer duties $(71.2 \%, n=37)$, while $28.8 \%(n=15)$ answered that they had musculoskeletal injuries prior to tactical officer employment that were exacerbated by work related activities. (Figure D11) Work related injuries were quite the opposite, as $80.8 \%(\mathrm{n}=42)$ admitted to experiencing some kind of musculoskeletal injury as a direct result of being employed as a tactical officer. (Figure D12) The majority of tactical officers $(67.3 \%, \mathrm{n}=35)$ also admitted that they had sustained a significant number of injuries as a result of non-work related activities while employed as a tactical officer. (Figure D13)

\section{Injury Description}

The fourth section of the TOQ was a series of drop down menus designed to determine the types of musculoskeletal injuries that were most common for each injury. This section was also able to account for multiple injuries of the same nature. Not all participants responded to this section. The first part determined the body parts most commonly injured by tactical officers. Ankle sprains $(63.2 \%, \mathrm{n}=12)$, and knee sprains $(26.3 \%, \mathrm{n}=5)$ were the most common ligament sprains. (Figure D14) The back (42.1\%, n=8), thigh (upper leg) $(21.1 \%, \mathrm{n}=4)$, and lower leg $(15.8 \%, \mathrm{n}=3)$ were the most common sights for muscle strains. (Figure D15) Fractures were less 
common over all with the face, forearm, finger, and back each accounting for $14.3 \%(n=2)$. (Figure D16) Shoulder dislocations $(60.0 \%, \mathrm{n}=6)$, and finger dislocations $(20.0 \%, \mathrm{n}=2)$ were the most common type of dislocations reported. (Figure D17) Tendinitis was reported most commonly in the elbow $(62.5 \%, \mathrm{n}=5)$. (Figure D18) The knee accounted for $68.8 \%(\mathrm{n}=11)$ of tears/ruptures. (Figure D19) Vertebral disc involvement was reported in the neck (22.2\%, n=2) and back $(77.8 \%, \mathrm{n}=7)$. (Figure D20) Contusions were more commonly reported to be of the forearm $(30.0 \%, \mathrm{n}=3)$ and the thigh $(20.0 \%, \mathrm{n}=2)$. (Figure D21) Impingement was rare (one case reported). Lacerations were most common in the hand (38.5\%, $\mathrm{n}=5)$. (Figure D22) Burns were not common. General pain and discomfort was most commonly reported in the knee (41.7\%, $\mathrm{n}=5)$, the back $(25 \%, \mathrm{n}=3)$, and the shoulder $(25 \%, \mathrm{n}=3)$. (Figure D23).

The second part determined the number of injuries that officers sustained prior to their employment as tactical officers (Table D1). Percentages have not been reported for parts two, three, and four due to the number of participants that omitted this part of the questionnaire. Participants were asked to denote multiple injuries in these sections. The numbers reported reveal the number of people who sustained one or more of the same type of injury in the respective categories. Thirteen (13) tactical officers reported experiencing one or more ligament sprains. Nine (9) reported experiencing one or more muscle strains. Eight (8) tactical officers reported experiencing one or more instances of general pain or discomfort.

Four (4) had sustained one or more contusions. Two (2) officers reported one or more burns, and one (1) reported impingement prior to tactical officer employment. Table D1 can be referred to for the entire number of responses for this section.

The third part of the injury description section determined the number of musculoskeletal injuries sustained by tactical officers during work related activities (training or call outs). (Table 
D2) Seventeen (17) tactical officers reported experiencing one or more muscle strains. Fourteen (14) tactical officers reported experiencing one or more ligament sprain, and eleven (11) sustained one or more lacerations. Five (5) officers reported one or more dislocations. Two (2) officers reported single cases of burns. Only one (1) case of impingement had been reported. The entire table of results for this section is displayed in Table D2.

The fourth part of the injury description section determined the number of injuries tactical officers sustained while employed as tactical officer as a result of outside of work activities (recreational). (Table D3) Fourteen (14) tactical officers reported experiencing one or more muscle strains. Ten (10) tactical officers reported experiencing one or more ligament sprains and seven (7) sustained one or more tears/ruptures. Four (4) officers had experienced one or more cases of tendinitis. Three (3) officers had sustained one or more cases of vertebral disc involvement and one (1) reported four cases of burns. The entire results of this section can be seen in Table D3.

The final two parts of section four determined whether or not injuries required rehabilitation or surgery. Rehabilitation was needed for 12 tears/ruptures, 8 ligament sprains, 8 muscle strains, 8 fractures, 8 vertebral disc injuries, 7 dislocations, 6 general pain and discomfort cases, 3 tendinitis injuries, 1 contusion, 1 impingement, and 1 laceration. Surgery was required for 11 tear/ruptures, 6 fractures, 1 ligament sprain, 1 dislocation, 1 tendinitis condition, 1 vertebral disc involvement, and 1 impingement case.

\section{Results of Injury}

The final section of the TOQ examined the results of these injuries based on who treated the injury and time lost from work due to the injuries. Related to the injuries sustained prior to 
tactical officer employment, $74.2 \%(n=23)$ were treated by physicians and $22.6 \%(n=7)$ were not treated by anyone. (Figure D24) A majority $82.4 \%(\mathrm{n}=28)$ claimed that injuries sustained pretactical officer employment did not cause any time lost from work (Figure D25). Figure D26 reported the number of weeks missed due to injury, with $70.0 \%,(n=21)$ reported no weeks missed.

Most musculoskeletal injuries sustained during work related activities were treated by a physician $(82.9 \%, n=29), 42.9 \%(n=15)$ were treated by a physical therapist, and $37.1 \%(n=13)$ were treated by the TEMS provider. (Figure 27) The majority reported missing time from work due to injuries sustained on the job $(63.2 \%, n=24)$. (Figure D28), and 34.3\% $(n=12)$ reported missing 2-6 weeks of work as a result of work related musculoskeletal injuries. (Figure D29).

Musculoskeletal injuries sustained as a result of outside of work related activities were predominantly treated by a physician $(78.1 \%, \mathrm{n}=25)$ and $25 \%(\mathrm{n}=8)$ were reported to be treated by a physical therapist. (Figure D30) The majority reported no time lost due to injuries sustained outside of work related activities $(65.7 \%, \mathrm{n}=23)$. (Figure D31) The number of weeks of work missed due to injury were reported, with $44.8 \%$, (n=13) missing no weeks. (Figure D32).

\section{DISCUSSION}

The primary purpose of this study was to determine how often tactical officers experience musculoskeletal injuries, what types are most common, and when they are occurring. The secondary purpose of this study was to determine how often tactical officers have access to medical professionals, who is managing/treating their musculoskeletal injuries, and if there are similar injuries incurred between tactical officers, and military personnel as presented in the literature. The intent was to use the information obtained by the Tactical Officer Questionnaire to shed light on the fact that tactical officers, like military personnel are experiencing similar musculoskeletal injuries 
while on the job. The participating tactical officers shared valuable information regarding the musculoskeletal injuries that they have sustained throughout their careers.

This study found that most tactical officers operate on a part time level putting in less than five hours per week on call outs and less than 5 hours training per week. The population of tactical officers was also older than what was originally assumed, making the experience of the participants greater also. The most common body parts sustaining ligament sprains were the ankle and knee. The most common body parts sustaining muscle strains were the back and thigh. The most commonly fractured body parts were the face, forearm, finger, and back. The shoulder was most commonly dislocated. Tendinitis was most found in the elbow. Tear/ruptures occurred mostly in the knee. The back was commonly affected by vertebral disc involvement. Contusions were sustained commonly in the forearm, thigh, and hand. The hand, face, and forearms were the most lacerated, and pain/discomfort was common in the knee, shoulder, and back.

It was also found that most tactical teams are equipped with an outside TEMS provider with tactical training on, at least, a part time basis. The tactical teams who did not indicate having a TEMS provider seemed to use Emergency Medical Services (EMS) on an as needed, part time basis for medical coverage during call outs. The majority of tactical officers are not affected by injuries sustained pre-tactical officer employment, indicating that overuse injuries are not a common problem in tactical officers. The majority of injuries seem to be acute in nature as a result of work related activities. Unfortunately, this study was unable to decipher if more injuries occurred as a result of call outs or training exercises. The highest frequency of musculoskeletal injuries occurred from work related activities with 100 total responses that multiple injuries were sustained. The most frequent musculoskeletal injuries sustained as a result of work related activities were sprains, strains, tears/ruptures, lacerations, and vertebral disc involvement. The second highest frequency of musculoskeletal injuries occurred as a result of pre-employment activities, with 71 total responses that multiple injuries were sustained. The most frequent were sprains, strains, general 
pain/discomfort, and fractures. The lowest frequency of musculoskeletal injuries occurred as a result of recreational activities, with 66 total responses that multiple injuries were sustained. The most frequent musculoskeletal injuries sustained as a result of recreational activity were sprains, strains, and tear/ruptures. The most time lost from work was as a result of work related activities, with the majority of tactical officers being out of duty for 2-6 weeks. Musculoskeletal injuries across the board were predominantly treated by physicians.

A review of the literature was first obtained in order to develop appropriate questions to include in the Tactical Officer Questionnaire. The TOQ allowed ample opportunity for participants to include their own opinions when appropriate, and were taken into consideration during data collection. The data collected identified that musculoskeletal injuries are occurring in tactical law enforcement. Injury prevention, recognition, and rehabilitation can be beneficial to the operational training of tactical officers, in addition to tactical emergency medical care for call outs. Most tactical teams that did not have a TEMS provider within the team utilized EMT services on an as needed basis during call outs. Some had no coverage at all. These tactical officers deserve the most comprehensive clinical care that can be provided to them.

It was hypothesized based on responses that the body parts injured by tactical officers will be most commonly to the lower extremity similar to those incurred by military personnel based on the literature. Ankle, knee, shoulder, back, and thigh were among the most commonly reported among tactical officers in our study. Therefore, this hypothesis was accepted. It was also hypothesized that there will be more overuse musculoskeletal injuries experienced by tactical officers as a result of more intense training exercises. The study was unable to determine which injuries were caused by training or call outs, but the tendinitis and vertebral disc involvement injury types were not as common responses as sprains, strains, and fractures. The tendinitis and vertebral disc injuries were present to gauge overuse injuries. It was also hypothesized that there 
would be more acute musculoskeletal injuries experienced by tactical officers as a result of call outs. As with the above hypothesis the TOQ was unable to specify between training injuries and call out injuries, but the majority of injuries sustained by tactical officers were a result of work related activities (100) and recreational activities (66). These two parts accounted for a total of 166 injuries reported. The pre-tactical officer employment category of the questionnaire was to determine overuse conditions exacerbated by tactical work requirements, and accounted for a total of 71 injuries. The most common pre-employment injuries were sprains, strains, general pain/discomfort and fractures. These seem to be more acute types of injuries, and therefore tactical officers are not suffering from an excessive amount of overuse injuries. The most common work related injuries were sprains, strains, tears/ruptures, lacerations, and vertebral disc involvement. These appear to be similar to the military data reported in the literature. The most common recreational injuries were also sprains, strains, and tear/ruptures. Responses from the TOQ did not indicate which body parts were injured in each of the three injury categories.

The numbers of injuries sustained in each of the three employment categories collected were weak in this study. Based on results, the specific type of injuries that occurred most often in each employment category could not be determined. Therefore, the body parts most commonly injured during work related activities, pre-employment, or recreationally could not be ascertained. However, the most commonly occurring types of injuries in each of the three injury categories were sprains, strains, dislocations, tears/ruptures, and vertebral disc involvement and general pain/discomfort. This revealed that injuries are more commonly sustained as a result of work related activities. It was also noted that very few injuries required rehabilitation and/or surgery. Based on results, it could not be specified if more rehabilitation and/or surgery were required for work related injuries, pre-existing injuries, or outside of work injuries. 
The majority of injuries across all three categories were treated by a physician with chiropractors and physiotherapists also a common response for the treatment of work related injuries. The most time lost from work was due to work related injuries. Pre-existing injuries and outside of work injuries were not commonly reported to cause tactical officers to miss time from work. This information surrounding work related injuries in tactical officers is of concern. The fact that the most musculoskeletal injuries are occurring due to work related activities and that the most time lost from work is due to work related injuries makes this data valuable. Even though only 40 of 52 participants completed section \#4 (Injury Description), musculoskeletal injuries are present and persistent on the job in tactical law enforcement.

Musculoskeletal injuries were the most commonly occurring injuries among military personnel, with the lower extremity being the most prevalent. ${ }^{6,9,10,11,12,13,14}$ Musculoskeletal disorders (MSD) often result in significant time off from duty. ${ }^{10,11,12,13,14}$ The exact location of MSD among soldiers varies, but the most commonly reported are the knee, lumbar spine, ankle, and glenohumeral joint $(\mathrm{GHJ}) .^{9,10,11,12,13,14}$ Leggat described $20 \%-40 \%$ of military training injuries involved the knee, lumbar spine, and ankle. ${ }^{9}$ The Finish Defense Forces (FDF) reported a $46 \%$ injury rate with low back pain, lower extremity, and sprains and strains being most common. $^{11}$ Jennings $^{12}$ found that the back and knees accounted for $26 \%$ of all MSDs in the U.S. Army personnel. Most were work related and interfered with military duty. ${ }^{12}$ Darakjy $^{13}$ found that musculoskeletal injuries were one of the most common conditions at Fort Erwin, with sprains, strains, fractures, and contusions being the most common. ${ }^{13}$ The New Zealand Defense Force $(\mathrm{NZDF})^{15}$ experienced lower extremity injuries that accounted for almost half of their compensation claims. In this study among tactical officers the most common types of injuries were also sprains, strains, dislocations, tendinitis, tears/ruptures, vertebral disc involvement, 
lacerations, and general pain. The military literature describes the same types of injuries occurring within their populations. Collected information from this study described the same trends as the military research with the most commonly reported injured body parts being the

knee, lumbar spine, ankle, and GHJ as well..$^{9,10,11,12,13,14}$ Gildea et al ${ }^{3}$ determined that most physicians involved with tactical teams only dedicate to a part time commitment. Tactical officers participating in the Gildea study also felt that having a greater time commitment from a medical professional would be beneficial. Tactical officers in this study claimed that the majority of their musculoskeletal injuries were treated/managed by a physician with a part time commitment to the tactical team. Ankle sprains, knee sprains, back strains, shoulder dislocations, elbow tendinitis, knee tears/ruptures, vertebral disc involvement of the back, hand lacerations, and general knee pain were the most commonly injured body parts in tactical officers. They are occurring most commonly as a result of work related activities, but are only being treated by a physician with only a part time commitment to the tactical team.

\section{Clinical Implications}

This information will benefit tactical officers in several different ways. It provides evidence that musculoskeletal injuries are a common occurrence in tactical law enforcement. This could lead to police departments focusing more on preventing these types of injuries from occurring. Injury prevention programs could decrease the amount of general pain/discomfort, tears/ruptures, and sprains and strains. This study also shed light on the medical coverage encountered in the tactical law enforcement profession. This information should be seen as an indicator that too many tactical teams are still operating without a TEMS provider. Tactical officers will benefit from proper medical coverage in all aspects of their job. This could 
ultimately lead to less duty time lost due to musculoskeletal injuries, helping to keep the tactical unit ready at a moment's notice to ensure the safety of our communities around the country.

\section{Limitations of the Study}

The TOQ was unable to decipher between the work related injuries occurring during training and call outs. It was also unable to determine which body parts were most commonly injured pre-employment, work related, and recreationally. This was due to the pull down menu format of question number 15 and the way in which the information provided was analyzed by Survey Monkey. The question allowed for the participants to indicate multiple injuries, which took away from the more pertinent focus of the question. Due to these limitations cross correlations of data were unable to be made.

Another limitation was that the TOQ was accessible by internet only; meaning only tactical officers with internet access could participate in this study. Exact membership numbers are not public information; therefore, an exact response rate is unable to be determined for this study. Although the sample size collected was small, the information provided was in agreement with the military literature.

\section{CONCLUSION}

Musculoskeletal injuries in tactical officers occurred most often in the lower extremity with ankle sprains, knee sprains, back strains, knee tears/ruptures, vertebral disc involvement of the back, and general knee pain being the most common. Shoulder dislocations, elbow tendinitis, hand lacerations were the most common upper extremity injuries experienced. These were occurring most commonly as a result of work related activities, and occurring at a rather common rate. Overuse injuries did not appear to be occurring regularly in tactical law 
enforcement. Acute injuries were common in all three injury categories, but most were a result of work related activities (training or call outs). Most tactical officers spent less than 20 hours per week between training and call outs, but are still experiencing multiple musculoskeletal injuries during their careers. There are a significant number of tactical officers entering the profession with pre-existing acute musculoskeletal injuries. Work related injuries seemed to be the most prevalent. Tactical officers experience more injuries as a result of work related activities as opposed to injuries sustained previous to tactical officer employment and outside of work injuries. Work related musculoskeletal injuries also accounted for the most time lost from work. The data collected identified that musculoskeletal injuries were occurring in tactical law enforcement. Injury prevention, recognition, and rehabilitation could be beneficial to the operational training of tactical officers, in addition to tactical emergency medical care for call outs. Most tactical teams that did not have a TEMS provider within the team utilized EMT services on an as needed basis during call outs. Some had no coverage at all. These tactical officers deserve the most comprehensive clinical care that can be provided to them. The information gained through this study is a picture of a small number of tactical officers' experiences during their careers in regard to the types of injuries that are most common and when they are occurring. A more focused study with more participants and fewer variables is needed to improve the validity and power of this information. 


\section{REFERENCES}

1. Wuebben J. Training tactics. Joe Weider's Muscle Fitness. 2009;70(8):176-178.

2. Dallau AM. Sultans of SWAT. Tactical Weapons. 2008;11.

3. Gildea JR, Janssen AR. Tactical emergency medical support: physician involvement and injury patterns in tactical teams. J Emerg Med. 2008;35(4):411-414

4. Lavery RF, Addis MD, Doran JV, Corrice MA, Tortella BJ, Livingston DH. Taking care of the "good guys:" a trauma center-based model of medical support for tactical law enforcement. J Trauma. 2000;48(1):125-129.

5. Vayer JS, Schwartz RB. Developing a tactical emergency medical support program. Top Emerg Med. 2003;25(4):282-298.

6. Ciccone TJ, Anderson PD, Gann CAD, Riley JM, Maxwell M, Hopkins R, Ciottone G. Successful development and implementation of a tactical emergency medical technician training program for United States federal agents. Prehosp Disaster Med. 2005;20(1):3640.

7. Fuller C, Walker J. Quantifying the functional rehabilitation of injured football players. Br J Sports Med. 2006; 40:151-157.

8. Agel J, Evans TA, Dick R, Putukian M, Marshall SW. Descriptive epidemiology of collegiate men's soccer injuries: National Collegiate Athletic Association Injury Surveillance System, 1988-1989 through 2002-2003. J Athl Train. 2007;42(2):270-7.

9. Leggat PA, Smith DR. Military training and musculoskeletal disorders. J Musculoskelet Pain. 2007;15(2):25-32.

10. Gates C, Huard J. Management of skeletal muscle injuries in military personnel. Oper Tech Sports Med. 2005;13:247-256.

11. Taanila H, Suni J, Pihlajamaki H, Mattila VM, Ohrankammen O, Vuorinen P, Parkkari J. Musculoskeletal disorders in physically active conscripts: a one-year follow-up study in the Finnish Defence Forces. BMC Musculoskel Dis. 2009; 89(10).

12. Jennings BM, Yoder LH, Heiner SL, Loan LA, Bingham MO. Soldiers with musculoskeletal injuries. J Nurs Scholarship. 2008;40(3):268-274.

13. Darakjy S, Marin RE, Knapik JJ, Jones BH. Injuries and illnesses among armor brigade soldiers during operational training. Mil Med. 2006;171(11):1051-1056.

14. Evans R, Reynolds K, Creedon J, Murphy M. Incidence of acute injury related to fitness testing of U.S. Army personnel. Mil Med. 2005;170(12):1005-1011.

15. Davidson PL, Chalmers DJ, Wilson BD, McBride D. Lower limb injuries in New Zealand Defence Force personnel: descriptive epidemiology. Aust Nz J Publ Heal. 2008;32(2):167-173. 
APPENDICIES 


\section{APPENDIX A}

\section{THE PROBLEM}

\section{Research Question}

Tactical police officers are a vital part of law enforcement. They are the individuals who dedicate their lives to protect the lives of others. Many of them possess special skills, and training, making their role among the team unique. In order to be able to perform at their highest ability, these groups of individuals undergo very intense training regimens. They train to improve speed, agility, strength, power, and endurance, in addition to their law enforcement tactical skills.

There are many branches of the military that take advantage of the services that athletic trainers can provide. The Federal Bureau of Investigation (FBI), Navy, Army, U.S. Coast Guard, and the U.S. Marshalls utilize athletic training services for their personnel. These organizations have found that athletic trainers can be effective and valuable in this setting; therefore, it seems apparent that tactical teams would experience the same type of injuries. Most tactical teams contain a tactical medic, who provides care for wounds and other serious injuries while on call. However, they are not trained in the prevention, evaluation, treatment, and rehabilitation of musculoskeletal injuries.

Gildea et $\mathrm{al}^{3}$ found that only $6 \%$ of tactical teams are provided with a full time commitment from physicians. Thus, there is a need for extensive physician involvement in all aspects of team health. Research on musculoskeletal injuries is available among almost every branch of the military and even among the Federal Bureau of Investigation. However, there is very limited research on the epidemiology and number of musculoskeletal injuries among tactical teams. If epidemiology studies present the number of musculoskeletal injuries among 
tactical teams, it may be possible to increase medical coverage for these individuals. Research questions are:

1. How often do tactical officers experience musculoskeletal injuries?

2. In what setting are most musculoskeletal injuries occurring?

3. What types of musculoskeletal injuries are the most common among tactical officers?

4. Do tactical officers experience musculoskeletal injuries similar to those experienced by military personnel and elite level athletes as stated in the research?

5. Who is managing/treating musculoskeletal injuries sustained by tactical officers during training exercises and call outs?

6. How often do the tactical officers have access to medical professionals?

Experimental Hypotheses

1. Musculoskeletal injuries in tactical officers will occur most often in the lower extremity similar to military personnel as presented in the literature.

2. There will be more overuse injuries experienced by tactical officers as a result of intense training sessions based on responses.

3. There will be more acute musculoskeletal injuries experienced by tactical officers as a result of call out situations based on responses.

Assumptions

1. All data collected will be truthful and accurate.

2. All data will be collected and distributed properly.

3. Everyone will answer the same set of questions.

4. The questionnaire will be accessible to all tactical law enforcement personnel.

5. The questionnaire will be representative of musculoskeletal injuries incurred by tactical officers.

Delimitations

1. Data was collected as a self report of injury by the tactical officer. 
2. The only injuries reported were musculoskeletal injuries sustained during call outs or training exercises.

3. The data may not be generalized to other branches of law enforcement.

\section{Operational Definitions}

1. Acute injury- Any trauma to the body incurred during the time of activity.

2. Athletic trainer- An allied health professional trained in the prevention, recognition, and rehabilitation of acute and chronic injuries.

3. Call out- A real time situation requiring the immediate services of a tactical unit.

4. Chronic injury- Any injury resulting in a gradual onset of symptoms over time.

5. Contusion- A bruise as a result of trauma to soft tissue.

6. Dislocation- The complete separation of two articulating bone surfaces. ${ }^{16}$

7. Fracture- A complete non-union of any bony structure's body as a result of direct trauma.

8. Musculoskeletal injury- Any trauma that occurs to a skeletal muscle, tendon, ligament, joint or any related tissue. ${ }^{16}$

9. Sprain- A traumatic joint twist that results in stretching or tearing of stabilizing connective tissue when a joint is forced beyond its normal anatomical limits. ${ }^{16}$

10. Strain- The extent of muscle tissue deformation under loading. ${ }^{16}$

11. Tactical Emergency Medical Support (TEMS) - A term referring to nonmilitary emergency medical services that have been modified for the realities of the tactical environment. $^{17}$

12. Tactical officer - A police officer who has tactical operation training, training in athletic maneuvers, and holds a specific role within a tactical unit.

13. Tactical physician- A medical doctor with specific tactical operation training in addition to medical training.

14. Tactical Team- A team of specialized individuals equipped and trained to function as a tactical unit under extremely stressful circumstances.

15. Tactical Training exercises- Any drill that practices real life scenarios for a tactical officer.

16. Tendinitis- Inflammation of a tendon. ${ }^{16}$ 


\section{Limitations}

1. Not all musculoskeletal injuries were reported.

2. Not all tactical officers participated.

3. Not every tactical officer had access to the survey.

4. Not every question was answered

Significance of the Study

A study of this nature will provide the number and type of musculoskeletal injuries sustained by tactical officers, and the level of care received following an injury. This information can be used to lobby for better care for tactical officers. It can also be used to reduce the number of worker's compensation cases, and reduce time missed from training and call outs. Both of which can help save police department's resources. It is anticipated that with the proper care, tactical teams will be able to train harder for longer periods of time, and stay together longer.

It is vital that the tactical officer be provided with daily medical coverage and care. The job description is very unique, and dangerous situations are inevitable. Activities such as a foot chase or breaking down doors can occur all in the same day. At times serious medical injuries and health problems can occur; but, usually the training process and everyday responsibilities result in musculoskeletal injuries. Determining the type of musculoskeletal injuries, and the number of these injuries sustained in this line of work can have many benefits for tactical officers, athletic trainers, and police departments in many ways.

This data can be important to both athletic training and the law enforcement communities. Therefore, it is crucial to disseminate this information to those that can benefit the most from it. This data can be distributed in a number of ways. Presentations to tactical officers at state and national tactical officers' association meetings and to corresponding web pages are 
one way. Presentations to athletic trainers can be through state, district, and national athletic training conventions, along with corresponding web pages. Publications can be submitted to various peer reviewed medical, athletic training, and law enforcement journals. The importance of this study is the potential for athletic trainers, other allied health professionals, medical personnel, and tactical law enforcement professionals to become aware of the need for improvements in musculoskeletal injury care. 


\section{APPENDIX B}

\section{LITERATURE REVEIW}

Introduction

When athletes sustain injuries they may require time off from play and cause a team to be a man down. When tactical officers sustain injuries and require time off it could mean the difference in safety for the community and the tactical unit. A musculoskeletal injury is any type of trauma sustained to the bone, ligament, or muscle of the body, and accounts for the greatest number of injuries in sporting events. ${ }^{16}$ As in athletics, musculoskeletal disorders (MSDs) are

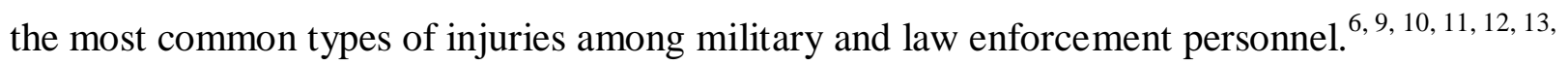
14 There seems to be a lack of research among tactical law enforcement officers and the injuries that they incur during all aspects of their profession. Due to the connection tactical units have with athletic teams and military personnel, it is possible to correlate the information from those groups to tactical officers. Military personnel are exposed to a range of physical training, sporting, work, and recreational activities that may result in musculoskeletal disorders. ${ }^{9}$ This type of exposure is also seen among tactical officers and athletes. Musculoskeletal disorders are a common occurrence for soldiers and represent substantial losses of time from work and training for the military as a whole. ${ }^{9}$ This resulting morbidity represents a substantial cost to the community. ${ }^{9}$

The most commonly injured areas of the body consist of the upper and lower extremity, with the lower extremity being more prevalent. ${ }^{6,9,10,11,12,13,14}$ It is important to understand the bones, ligaments, and muscles of the body in order to understand the injuries to the body. The trunk consists of the spine, ligaments associated with it, and muscles associated with everyday movements. ${ }^{16,18,19}$ The upper extremity consists of the wrist, hand, elbow, and shoulder. The 
bones, muscles, and ligaments of the upper extremity are often put at risk through athletic movements. Injuries to this region of the body occur frequently, but still less than injuries to the lower extremity. ${ }^{6,9,10,11,12,13,14}$ The lower extremity; pelvis, hip, knee, ankle, and foot account for the highest number of injuries among military and tactical personnel. ${ }^{6,9,10,11,12,13,14}$ Being lower extremity dependent, increasing activity through intense training exercises places added stress on this area of the body.

Upper and lower extremity injuries account for the majority of musculoskeletal disorders in military personnel. There have been numerous studies conducted around the globe to determine time lost from work (duty), and frequency of musculoskeletal disorders in military populations. Most have determined that knee and ankle injuries are the most common, with the low back next. The amount of running and load carrying that is experienced in military training is likely a cause for these injuries.

The type of training incurred in the military around the world could be considered intense. The loads required to carry coupled with running, marching, and operational exercises place military and tactical personnel among the most elite and conditioned individuals. ${ }^{1}$ Injuries can occur in two ways; acute and chronic. Acute injuries are those that are associated with rapid trauma to the body. These can be contusions, lacerations, sprains, strains, or fractures. These injuries usually require medical care immediately. Chronic injuries can be considered as injuries that are caused by overuse of a particular body part. These injuries include things such as tendinitis, stress fractures, and impingement conditions.

Tactical law enforcement officers have several options for medical care within their unit. Often times these options are only available during call outs, in case of an emergency. Only $6 \%$ of tactical teams are provided with a full time physician commitment for treatment of injuries 
outside of an emergency situation. ${ }^{3}$ There are many factors to take into account when it comes to providing medical coverage to tactical teams. Many times, it is difficult for a team member to take on a dual role as tactical officer first and medical personnel second. This can lead to role confusion and a reduction in the quality of medical care provided to the tactical unit.

Tactical officers are commonly referred to as tactical athletes. They are the athletes of the police department. Tactical officers undergo specialty training in tactical operations, and are required to maintain peak physical performance at all times. ${ }^{1}$ These individuals are placed in extreme high risk situation on almost every call out. When these individuals sustain a time loss injury they are not merely replaced with the next person on the depth chart. Each member has a specific role within the team, which helps the team operate as a single unit. Missing one part of that unit can result in a decrease in preparedness of the team. Information included in the literature review are musculoskeletal anatomy, tactical officers, current medical coverage, epidemiology, and etiology

\section{Musculoskeletal Anatomy}

Trunk: Bones, ligaments, and musculature of the trunk are discussed in this section.

Bones: The spinal column is composed of 33 bones and houses the spinal cord. The spinal column is divided into five vertebral regions of vertebrae known as the cervical, thoracic, lumbar, sacrum, and coccyx. The cervical region has seven vertebrae and has a lordotic curvature. $^{20,21}$ The top two vertebral segments are different from the other five cervical vertebrae. The first vertebral body is known as the atlas which articulates with the occipital bone and supports the head. ${ }^{16,18,21}$ The atlas does not have a vertebral body because it must allow for articulation with the dens of the axis, or $\mathrm{C} 2$ vertebrae. The cervical spine as a whole allows for 
good mobility in flexion, extension, rotation, and lateral flexion. ${ }^{16,21}$ However, the two specialized joints of the atlantooccipital and atlanto-axial joints only allow for certain motions. The atlanto-occipital joint only permits flexion and extension while rotation occurs in the atlanto-axial joint. ${ }^{16,22,21}$ The overall good mobility of the cervical spine is attributed to the flattened, oblique alignment of the articular facets..$^{16,18,21,22}$

The thoracic spine consists of 12 vertebrae that articulate with the 12 coinciding ribs. ${ }^{16 \text {, }}$ ${ }^{21,23}$ The thoracic spine has a kyphotic curvature and does not allow for good mobility secondary to the articulation of the ribs and the vertical alignment of the articulating facets. ${ }^{16,21}$ The twelve ribs are divided into three categories which are the true ribs, false ribs, and the floating ribs. ${ }^{21,24}$ The seven superior ribs are known as the true ribs and each have a separate connection to the sternum via costal cartilage. ${ }^{16,18,21,22}$ The next three ribs are known as the false ribs which attach to the sternum through a common cartilaginous structure. ${ }^{16,18,21}$ The floating ribs do not have an attachment to the sternum. However, these two ribs do not float freely because they have muscular attachments.

The lumbar spine has a lordotic curvature with five large vertebrae that are the base of support for the upper body. ${ }^{16,21,23}$ The medial alignment of the superior articular facets and the lateral alignment of the inferior articular facets allow for lateral flexion, minimal amounts of flexion and extension, and limits rotation. ${ }^{16,21,23}$

The sacrum is comprised of five vertebral segments that become fused within adults. ${ }^{21,23}$ The sacrum attaches to the two innominate bones to create the sacroiliac (SI) joint. The SI joint is stable in nature and only allows for very minimal amounts of motion. ${ }^{16,21}$ The coccyx is commonly termed the "tailbone" and is the most distal segment of the vertebral column. It consists of four bony segments that are free-moving at birth and become fused in adulthood. 
Ligaments: The spine has six ligaments that provide stability and limit motion. The ligaments of the spine include the anterior/posterior longitudinal, supraspinous, interspinous, ligamentum nuchae, and ligamentum flavum. ${ }^{16,18,21,23}$ The anterior longitudinal ligament runs from the occiput to the sacrum and limits extension while the posterior longitudinal ligament runs the same distance and limits flexion. The supraspinous ligament and ligamentum nuchae attach spinous process to spinous process and limits spinal flexion. ${ }^{16,21}$ The ligamentum nuchae also attaches laminae to laminae and runs from the occiput to the inferior cervical spine while the supraspinous ligament runs from C7 to the mid-sacrum. ${ }^{16,19,21}$ The ligamentum flavum attach the lamina of one vertebrae to the one above it and help to bring the spine back to neutral from a flexed position. ${ }^{21,23}$ The interspinous ligaments fill the space between each spinous process and limit spinal flexion and rotation. ${ }^{16,18,19,21}$ The sacroiliac joint has five major ligaments which are the interosseous sacroiliac, dorsal and ventral sacroiliac, sacrotuberous, and the sacrospinous ligaments. These ligaments help to stabilize the sacroiliac joint and limit excessive motion at this joint. $^{16,18,21,22}$

Musculature: The musculature of the trunk is most easily identified according to location. The two groups that will be explained in this section are the vertebral column and abdomen/thorax musculature. The muscles of the vertebral column include the erector spinae, multifidus, quadratus lumborum, semispinalis, and the splenius capitis/cervicis. ${ }^{21,22,23,24}$ The combined responsibility of these muscles is stabilization, extension, rotation, and lateral flexion of the vertebral column. The muscles acting on the abdomen and thorax include the four abdominal muscles, the diaphragm, and the intercostals. The four abdominal muscles are transverse abdominis, rectus abdominis, and the internal and external obliques. ${ }^{21,22,24}$ Each individual muscle provides trunk movement, but together they work to compress and support the 
abdominal viscera. $^{21,22,24}$ The diaphragm and intercostals contract to increase the size of the

thorax and elevate the ribs to allow for inhalation. Table B1 includes origin, insertion, and action

of the vertebral column musculature, and table B2 does the same with the muscles of the

abdomen.

Table B1.Vertebral Column Musculature ${ }^{16}$

\begin{tabular}{|c|c|c|c|}
\hline Muscle & Origin & Insertion & Action \\
\hline Multifidus & $\begin{array}{l}\text { Posterior surface of the sacrum and ilium, } \\
\text { transverse processes of the lumbar, thoracic, and } \\
\text { lower cervical vertebrae }\end{array}$ & $\begin{array}{l}\text { Spinous processes of the lumbar, } \\
\text { thoracic, and cervical vertebrae }\end{array}$ & $\begin{array}{l}\text { Extends the vertebral column; rotates } \\
\text { it toward the opposite side }\end{array}$ \\
\hline Quadratus Lumborum & $\begin{array}{l}\text { Medial half of inferior } \\
\text { border of } 12^{\text {th }} \text { ribs and } \\
\text { lumbar transverse processes }\end{array}$ & $\begin{array}{l}\text { Iliolumbar ligament and iliac } \\
\text { crest }\end{array}$ & $\begin{array}{l}\text { Extension, Lateral flexion of vertebral } \\
\text { column }\end{array}$ \\
\hline Splenius Capitis & $\begin{array}{l}\text { Ligamentum nuchae, } \\
\text { spinous processes of } \mathrm{C} 7, \mathrm{~T} 1-3\end{array}$ & $\begin{array}{l}\text { Mastoid process of temporal } \\
\text { bone and occipital bone }\end{array}$ & $\begin{array}{l}\text { Extension of neck, unilateral flexion } \\
\text { and rotation to same side }\end{array}$ \\
\hline
\end{tabular}

Table B2.Abdomen/Thorax Musculature ${ }^{16}$

\begin{tabular}{llll}
\hline \multicolumn{1}{c}{ Muscle } & \multicolumn{1}{c}{ Origin } & \multicolumn{1}{c}{ Insertion } & \multicolumn{1}{c}{ Action } \\
\hline Rectus Abdominus & Pubic crest & $\begin{array}{l}\text { Xiphoid process, costal cartilages } \\
\text { of the } 5^{\text {th }}-7^{\text {th }} \text { ribs }\end{array}$ & $\begin{array}{l}\text { Compress the abdominopelvic cavity; } \\
\text { flexes the vertebral column }\end{array}$ \\
Transverse Abdominus & $\begin{array}{l}\text { Inguinal ligament, iliac crest, lumbodorsal } \\
\text { fascia, costal cartilages of the last } 6 \text { ribs }\end{array}$ & Linea alba and pubic crest & Compress the abdominopelvic cavity \\
Internal Oblique & $\begin{array}{l}\text { Inguinal ligament, iliac crest, lumbodorsal } \\
\text { fascia }\end{array}$ & $\begin{array}{l}\text { Linea alba, pubic crest, lower } 4 \\
\text { ribs }\end{array}$ & $\begin{array}{l}\text { Compress the abdominopelvic cavity; } \\
\text { assists in flexing and rotating the } \\
\text { vertebral column }\end{array}$ \\
External Oblique & External surface of the lower 8 ribs & $\begin{array}{l}\text { Linea alba and the anterior half of } \\
\text { the iliac crest }\end{array}$ & $\begin{array}{l}\text { Compress the abdominopelvic cavity; } \\
\text { assists in flexing and rotating the } \\
\text { vertebral column }\end{array}$ \\
Diaphragm & $\begin{array}{l}\text { Inferior border of the rib cage; Xiphoid } \\
\text { process; costal cartilages; and the lumbar } \\
\text { vertebrae }\end{array}$ & Central tendon of the diaphragm & $\begin{array}{l}\text { Pulls central tendon downward, } \\
\text { increasing size of thoraciz cavity, } \\
\text { causing inspiration }\end{array}$ \\
Bntercostals & Between ribs & Between ribs & Elevates ribs for inspiration \\
\hline
\end{tabular}

Wrist and Hand: Bones, ligaments, and musculature of the wrist and hand are discussed

in this section. 
Bones: The wrist is composed of eight carpal bones arranged in proximal and distal rows

of four. ${ }^{16,18,19,22,25,26,27}$

Table B3. Carpal Bones ${ }^{21,22}$

Proximal row: Scaphoid Lunate Triquetrum Pisiform

Distal row: Trapezium Trapezoid Capitate Hamate

Key: listed from left to right in a lateral to medial orientation in anatomical neutral position.

The proximal carpal bones articulate with the two bones in the forearm, the radius and ulna,

connecting the distal forearm to the hand. ${ }^{16,22,26}$ The ten bones of the wrist utilize three joints for movement. The three joints of the wrist include the distal radio-ulnar joint, radio-carpal joint, and the intercarpal joints. ${ }^{16,18,19,22,25,26,27}$ The distal radio-ulnar joint allows pronation and supination of the hand. The radio-carpal joint is a condyloid joint and permits flexion, extension, abduction, and circumduction. ${ }^{16,22,25}$ The carpal bones articulate with one another and combine movements with those of the radio-carpal joints and carpo-metacarpal joints of the hand.

The bones of the hand include those that form the metacarpal joints and the phalangeal joints. The metacarpal bones are five bones that join the distal row of carpal bones above and the phalangeal bones below. These form the metacarpo-phalangeal (MCP) articulations with movements of flexion, extension, abduction, adduction, and circumduction. ${ }^{16,19,22}$ Each digit is referred to as the phalanges, and contain the proximal, middle, and distal portions of the digit. These three bones in each digit form the proximal inter-phalangeal joint (PIP) between the proximal and middle phalangeal bones, and the distal inter-phalangeal joint (DIP) between the middle and distal phalangeal bones. ${ }^{18,22,26,27}$

Ligaments: The wrist consists of many ligaments that bind the carpal bones to one another, to the ulna and radius, and to the proximal carpal bones. ${ }^{16,18,26,27}$ The main ligaments of the wrist and hand are the collateral ligaments of the wrist, thumb, and fingers. These ligaments provide stability and limit excessive varus and valgus stress at the wrist, MCP, PIP, 
and DIP joints. ${ }^{18,21,26,27}$ Another ligament of the wrist is the transverse carpal ligament which

attaches to the hamate and pisiform medially, and the scaphoid and trapezium laterally. The

transverse carpal ligament serves as the "roof" of the carpal tunnel which houses nine structures

(eight tendons of flexor digitorum profundus and superficialis and median nerve). ${ }^{16,19,25}$

Musculature: The hand and wrist are acted upon by extrinsic muscles in the forearm and

intrinsic muscles in the hand. ${ }^{16,18,22,25,26,27}$

Table B4. Forearm Musculature ${ }^{16}$

\begin{tabular}{|c|c|c|c|}
\hline Muscle & Origin & Insertion & Action \\
\hline Flexor Carpi Radialis & Medial epicondyle of the humerus & $\begin{array}{l}\text { Ventral surface of the } 2^{\text {nd }} \text { and } 3^{\text {rd }} \\
\text { metacarpals }\end{array}$ & $\begin{array}{l}\text { Flexes the wrist and abducts the hand; aids in } \\
\text { flexion of the elbow and pronation }\end{array}$ \\
\hline Palmaris Longus & Medial epicondyle of the humerus & Palmar aponeurosis & Flexes the wrist \\
\hline Flexor Carpi Ulnaris & $\begin{array}{l}\text { Medial epicondyle of the humerus, } \\
\text { olecranon process, and the proximal } \\
\text { two thirds of the posterior surface of the } \\
\text { ulna }\end{array}$ & Pisiform, hamate, and $5^{\text {th }}$ metacarpal & Flexes the wrist and adducts the hand \\
\hline Flexor Digitorum Superficialis & $\begin{array}{l}\text { Medial epicondyle of the humerus, } \\
\text { coronoid process of the ulna, and } \\
\text { anterior radius }\end{array}$ & $\begin{array}{l}\text { Ventral surface of the middle phalanges } \\
\text { of } 2^{\text {nd }}-5^{\text {th }} \text { fingers }\end{array}$ & Flexes the wrist and phalanges \\
\hline Flexor Digitorum Profundus & $\begin{array}{l}\text { Medial epicondyle and coronoid of the } \\
\text { humerus, interosseus membrane, } \\
\text { ventral surface of ulna }\end{array}$ & $\begin{array}{l}\text { Ventral surface of the base of the distal } \\
\text { phalanges of the } 2^{\text {nd }}-5^{\text {th }} \text { fingers }\end{array}$ & Flexes the wrist and phalanges \\
\hline Flexor Pollicis Longus & $\begin{array}{l}\text { Ventral surface of the radius and the } \\
\text { interosseus membrane }\end{array}$ & $\begin{array}{l}\text { Ventral surface of the base of the distal } \\
\text { phalanx of the thumb }\end{array}$ & Flexes the thumb; aids in flexing the wrist \\
\hline Pronator Quadratus & Distal ventral surface of the ulna & Distal ventral surface of the radius & Pronates the hand \\
\hline Extensor Carpi Radialis Longus & $\begin{array}{l}\text { Lateral subcondylar ridge of the } \\
\text { humerus }\end{array}$ & $\begin{array}{l}\text { Dorsal surface of the base of the } 2^{\text {nd }} \\
\text { metacarpal }\end{array}$ & Extends the wrist and abducts the hand \\
\hline Extensor Carpi Radialis Brevis & Lateral epicondyle of the humerus & $\begin{array}{l}\text { Dorsal surface of the base of the } 3^{\text {rd }} \\
\text { metacarpal }\end{array}$ & Extends the wrist and abducts the hand \\
\hline Extensor Digitorum Communis & Lateral epicondyle of the humerus & $\begin{array}{l}\text { Dorsal surface of the phalanges of the } \\
2^{\text {nd }}-5^{\text {th }} \text { fingers }\end{array}$ & Extends the fingers and wrist \\
\hline Extensor Digiti Minimi & $\begin{array}{l}\text { Tendon of the extensor digitorum } \\
\text { communis }\end{array}$ & $\begin{array}{l}\text { Tendon of the extensor digitorum } \\
\text { communis on the dorsum of the } 5^{\text {th }} \\
\text { finger }\end{array}$ & Extends the $5^{\text {th }}$ finger \\
\hline Extensor Carpi Ulnaris & Lateral epicondyle of the humerus & Base of $5^{\text {th }}$ metacarpal & Extends the wrist and adducts the hand \\
\hline Abductor Pollicis Longus & $\begin{array}{l}\text { Posterior surface of the middle of the } \\
\text { radius and ulna, interosseus membrane }\end{array}$ & Base of $1^{\text {st }}$ metacarpal & Abducts the thumb and hand \\
\hline Extensor Pollicis Brevis & $\begin{array}{l}\text { Posterior surface of the middle of the } \\
\text { radius, interosseus membrane }\end{array}$ & Base of $1^{\text {st }}$ phalanx of the thumb & Extends the thumb and abducts the hand \\
\hline Extensor Pollicis Longus & $\begin{array}{l}\text { Posterior surface of the middle of the } \\
\text { ulna, interosseus membrane }\end{array}$ & Base of the last phalanx of the thumb & Extends the thumb and abducts the hand \\
\hline Extensor Indicis & $\begin{array}{l}\text { Posterior surface of the distal end of the } \\
\text { ulna, interosseus membrane }\end{array}$ & $\begin{array}{l}\text { Tendon of the extensor digitorum } \\
\text { communis to the index finger }\end{array}$ & Extends the index finger \\
\hline
\end{tabular}


Several muscles of the forearm have long tendons that cross the MCP joints and move the fingers. The muscles of the forearm are divided into anterior and posterior compartments; each compartment is also divided into superficial and deep layers. ${ }^{16,18,22,25,26,27}$ Most muscles of the anterior compartment are flexors of the wrist and hand. Muscles of the posterior compartment are mostly wrist and hand extensors. $16,18,22,25,26,27$ There are also a number of muscles that are intrinsic to the hand. The dorsal and palmar interossei muscles are lateral to the MCP joints and are responsible for abduction and adduction of the MCP joints. The lumbrical muscles are volar to the axis of rotation of the MCP joint, but insert into the lateral bands and are dorsal to the PIP and DIP joints. $^{18,22,26,27}$ Their function is MCP joint flexion and IP joint extension. There are also muscles that provide movement to the thumb and $5^{\text {th }}$ finger. Three thenar muscles move the thumb and three hypothenar muscles move the $5^{\text {th }}$ finger. ${ }^{16,18,22,26,27}$ Table B4 includes the origin, insertion, and action of the forearm and Table B5 does the same for the hand musculature.

\begin{tabular}{|c|c|c|c|}
\hline Muscle & Origin & Insertion & Action \\
\hline Lumbricales & $\begin{array}{l}\text { Tendons of the flexor digitorum } \\
\text { profundus }\end{array}$ & $\begin{array}{l}\text { Tendons of the extensor digitorum } \\
\text { communis }\end{array}$ & Flex the MCP joints and extend the IP joints \\
\hline Dorsal Interossei & Adjacent sides of all of the metacarpals & Proximal phalanx of $2^{\text {nd }}, 3^{\text {rd }}, 4^{\text {th }}$ fingers & Abduct the fingers from the middle finger \\
\hline Palmar Interossei & $\begin{array}{l}\text { Medial side of the } 2^{\text {nd }} \text { metacarpal and } \\
\text { lateral side of the } 4^{\text {th }} \text { and } 5^{\text {th }} \\
\text { metacarpals }\end{array}$ & Proximal phalanx of the same finger & Adduct the fingers toward the middle finger \\
\hline Abductor Pollicis Brevis & $\begin{array}{l}\text { Flexor retinaculum, scaphoid, } \\
\text { trapezium }\end{array}$ & Proximal phalanx of the thumb & Abducts the thumb \\
\hline Opponens Pollicis & Flexor retinaculum and trapezium & $\begin{array}{l}\text { Lateral border of the metacarpal of the } \\
\text { thumb }\end{array}$ & $\begin{array}{l}\text { Pulls the thumb in front of the palm to meet } \\
\text { the } 5^{\text {th }} \text { finger }\end{array}$ \\
\hline Flexor Pollicis Brevis & $\begin{array}{l}\text { Flexor retinaculum, trapezium, } 1^{\text {st }} \\
\text { metacarpal }\end{array}$ & $\begin{array}{l}\text { Base of the proximal phalanx of the } \\
\text { thumb }\end{array}$ & Flexes and adducts the thumb \\
\hline Adductor Pollicis & Capitates, $2^{\text {nd }}, 3^{\text {rd }}$ metacarpals & Proximal phalanx of the thumb & Adducts the thumb \\
\hline Palmaris Brevis & Flexor retinaculum & Skin on the ulnar border of the hand & Pulls the skin toward the middle of the palm \\
\hline Abductor Digiti Minimi & $\begin{array}{l}\text { Pisiform, the tendon of the flexor carpi } \\
\text { ulnaris }\end{array}$ & $\begin{array}{l}\text { Base of the proximal phalanx of the } 5^{\text {th }} \\
\text { finger }\end{array}$ & Abducts the $5^{\text {th }}$ finger \\
\hline Flexor Digiti Minimi Brevis & Flexor retinaculum and hamate & $\begin{array}{l}\text { Base of the proximal phalanx of the } 5^{\text {th }} \\
\text { finger }\end{array}$ & Flexes the little finger \\
\hline Opponens Digiti Minimi & Flexor retinaculum and hamate & Metacarpal of the $5^{\text {th }}$ finger & Brings the $5^{\text {th }}$ finger out to meet the thumb \\
\hline
\end{tabular}


Elbow: Bones, ligaments, and musculature of the elbow are discussed in this section.

Bones: The elbow joint is comprised of three bones; the distal humerus, and the proximal radius and ulna. $16,19,22,24,28,29,30,31$ The distal end of the humerus forms two articulating condyles. The lateral condyle is called the capitulum, and the medial condyle is the trochlea. The capitulum articulates with the head of the radius. The head of the radius rotates freely around the capitulum allowing for pronation and supination movements. ${ }^{22,24,28,29,30,31}$ The throchlea fits into the trochlear notch of the ulna. This allows for strictly flexion and extension of the elbow. ${ }^{16,}$ 22, 24, 28, 29, 30, 31 The three bones of the elbow provide three articulations; these are the humeroulnar joint, the humero-radial joint, and the proximal radio-ulnar joint.

Ligaments: The joint capsule at the elbow is reinforced by the radial collateral or lateral collateral ligament (RCL/LCL) and the ulnar collateral or medial collateral ligament (UCL/MCL). The UCL is composed of a strong anterior band with a weaker transverse and middle band. The RCL does not attach to the radius; instead the annular ligament attaches to the anterior and posterior radial notch and encircles the neck and head of the radius. ${ }^{16,24,28,29,30,31}$ Valgus stability depends mainly on the UCL, while lateral elbow stability depends on the RCL and annular ligaments. ${ }^{16,24,28,29,30,31}$

Musculature: There are three muscles that flex the elbow; they are the biceps brachii, brachialis, and brachioradialis. $22,24,28,29,30,31$ The biceps brachii not only flexes the elbow but is also the main supinator of the forearm, along with the supinator muscle. ${ }^{16,22,24,28,29,30,31}$ The brachioradialis, in addition to flexing the elbow, also functions as a forearm pronator and semisupinator. $^{16,22,24,28,29,30,31}$ The pronator teres is the main muscle for pronation. The triceps brachii and the anconeus are the main elbow extensor muscles. ${ }^{16,22,24,27,29,30,31}$ Table B6 includes the origin, insertion, and action of the elbow musculature. 
Shoulder Girdle/Complex: Bones, ligaments, and musculature of the shoulder discussed in this section.

Bones: The Clavicle, scapula, and humerus make up the bones of the glenohumeral complex. These bones form the four joints of the shoulder girdle, the sternoclavicular joint (SC), acromioclavicular joint (AC), the glenohumeral joint (GHJ), and the scapulothoracic joint. ${ }^{16,19,}$ 22, 24, 31, 32, 33 The SC joint is where the clavicle articulates with the manubrium of the sternum. Table B6. Elbow Musculature ${ }^{16}$

\begin{tabular}{|c|c|c|c|}
\hline Muscle & Origin & Insertion & Action \\
\hline Biceps Brachii & $\begin{array}{l}\text { Long head: Supraglenoid tuberosity. } \\
\text { Short head: Coracoid process }\end{array}$ & Radial tuberosity & $\begin{array}{l}\text { Flexes the elbow, the arm, and supinates the } \\
\text { forearm }\end{array}$ \\
\hline Brachialis & $\begin{array}{l}\text { Anterior surface of the distal half of the } \\
\text { humerus }\end{array}$ & Coronoid process of the ulna & Flexes the elbow \\
\hline Brachioradialis & $\begin{array}{l}\text { Lateral supracondylar ridge of the } \\
\text { humerus }\end{array}$ & Styloid process of the radius & Flexes the elbow \\
\hline Triceps Brachii & $\begin{array}{l}\text { Long head: Infraglenoid tuberosity } \\
\text { Lateral head: posterior surface of the } \\
\text { humerus above the radial groove } \\
\text { Medial head: posterior surface of the } \\
\text { humerus below the radial groove }\end{array}$ & Olecranon process of the ulna & Extends the elbow and the forearm \\
\hline Supinator & Lateral epicondyle of the humerus & $\begin{array}{l}\text { Proximal end of the lateral surface } \\
\text { of the shaft of the radius }\end{array}$ & Supinates the elbow \\
\hline Pronator Teres & $\begin{array}{l}\text { Medial epicondyle of the humerus and the } \\
\text { coronoid process of the ulna }\end{array}$ & $\begin{array}{l}\text { Middle of the lateral surface of the } \\
\text { radial shaft }\end{array}$ & Pronates the elbow \\
\hline Anconeus & Lateral epicondyle of the humerus & $\begin{array}{l}\text { Lateral surface of the olecranon } \\
\text { process }\end{array}$ & Extends the elbow \\
\hline
\end{tabular}

This is the only direct connection between the upper extremity and the trunk. ${ }^{16,19,24,31,32,33}$ The function of this joint is to act as a shock absorber to medial forces, in addition to allowing clavicle movement up, down, forward, backward, rotation, and any combination of the previously mentioned. ${ }^{16,19,22}$

The AC joint is the joint formed by the lateral end of the clavicle and the acromion process. This tends to be a weak junction with a thin fibrous capsule surrounding the joint. ${ }^{16,24,}$ 31, 32, 33 The GHJ, considered the true shoulder joint, is a modified ball and socket joint. A good way to think of this joint is as a golf ball sitting on a golf tee. This is where the humerus 
articulates with the scapula, either actively or passively. ${ }^{16,19,24,25,31,32,33}$ The scapulothoracic joint is actually not a joint at all, this is because it does not join two bony surfaces, rather; the scapulothoracic joint allows for articulation of the scapula along the wall of the thoracic rib cage. This joint is important in providing a base for the highly mobile GH joint. ${ }^{16,19,22,24,31,32,33}$

Ligaments: The main ligaments of the SC articulation include the anterior sternoclavicular ligament, the posterior sternoclavicular ligament, the interclavicular ligament, and the costoclavicular ligament. These prevent upward displacement, lateral displacement, and upward displacement of the clavicle, respectively. ${ }^{16,21,24,31,32,33}$ These ligaments are particularly strong to compensate for the lack of a stable articular surface. ${ }^{16,19,24,31,32,33}$

The AC joint ligaments include the acromioclavicular, coracoclavicular, and the coracoacromial ligaments. The acromioclavicular ligament includes anterior, posterior, superior, and inferior portions, which attach the clavicle to the acromion process and limit superior translation of the distal clavicle. ${ }^{16,19,21,24,31,32,33}$ The coracoclavicular ligament is divided into the conoid and trapezoid ligaments, and attaches the clavicle to the coracoid process. The coracoacromial ligament connects the coracoid to the acromion. This ligament and the acromion form the coracoacromial arch. ${ }^{16,19,21,24,25,31,32,33}$

The GHJ ligaments consist of the glenohumeral ligaments, coracohumeral ligament, and transverse humeral ligament. The glenohumeral ligament has superior, middle, and inferior bands. The superior band limits posterior-inferior translation of the humeral head. The middle band limits external rotation and inferior translation of the humeral head. The inferior band limits anterior inferior translation of the humeral head. ${ }^{16,21,24,31,32,33}$ The coracohumeral ligament attaches the coracoid process to the greater tuberosity of the humerus, and performs the same tasks as the inferior band of the glenohumeral ligament. ${ }^{16,24,31,32,33}$ The transverse ligament 
holds the long head of the biceps brachii in the bicipital groove, and does not actually act on the GHJ. ${ }^{16,19,21,25}$

Musculature: The shoulder girdle allows for movement in many different planes (35). Movements at the GHJ include flexion, extension, abduction, adduction, horizontal adduction/abduction, internal/external rotation, and circumduction. ${ }^{16}$ The muscles that cross the GHJ produce dynamic motions and establish stability to compensate for bony and ligamentous insufficiencies. ${ }^{16,22,24,31,32,33}$ The muscles acting on the GHJ can be divided into two groups. One group consists of muscles that originate on the axial skeleton and attach to the humerus and includes the latissimus dorsi and the pectoralis major. ${ }^{16,22,24,31,32,33}$ The other group originates on the scapula and attaches to the humerus and includes the deltoid, teres major, and coracobrachialis. ${ }^{16,22,24,31,32,33}$ Additionally the subscapularis, supraspinatus, infraspinatus, and teres minor muscles form the rotator muscles referred to as the rotator cuff. The tendons of these SITS muscles adhere to the articular capsule and serve as reinforcing structures. ${ }^{16,22,24,31,32,33}$ Table B7 contains the origin, insertion, and action of the shoulder girdle/complex musculature. Pelvic Girdle/Hip: Bones, ligaments, and musculature of the pelvic girdle and hip are discussed in this section.

Bones: The pelvic girdle is a boney ring formed by two innominate bones, the sacrum and the coccyx. ${ }^{16,22,24,34}$ Each innominant bone is composed of an ilium, ischium, and pubis. ${ }^{16}$ The femur attaches to the pelvis in the acetabulum providing the link from the trunk to the lower extremity.

There are three articulations formed at the pelvic girdle. The sacroiliac joint and the coccyx form two and the femur and the innominant form the ball and socket hip joint. ${ }^{16,22,34}$ 
Table B7. Shoulder Girdle/Complex Musculature ${ }^{16}$

\begin{tabular}{|c|c|c|c|}
\hline Muscle & Origin & Insertion & Action \\
\hline Pectoralis Major & $\begin{array}{l}\text { Medial half of the clavicle, sternum, costal } \\
\text { cartilages of the upper } 6 \text { ribs, aponeurosis of the } \\
\text { external oblique }\end{array}$ & Greater tubercle of the humerus & Flexes, adducts, medially rotates the arm \\
\hline Latissimus Dorsi & $\begin{array}{l}\text { Spinous processes of the lower } 6 \text { thoracic and } \\
\text { lumbar vertebrae, sacrum, posterior iliac crest }\end{array}$ & $\begin{array}{l}\text { Medial margin of the intertubercular } \\
\text { groove of the humerus }\end{array}$ & $\begin{array}{l}\text { Extends, adducts, and medially rotates } \\
\text { the arm, pulls shoulder downward }\end{array}$ \\
\hline Deltoid & $\begin{array}{l}\text { Lateral third of the clavicle, acromion process, } \\
\text { spine of the scapula }\end{array}$ & Deltoid tuberosity & Abducts the arm \\
\hline Supraspinatus & Supraspinatus fossa & Greater tubercle of the humerus & $\begin{array}{l}\text { Abducts the arm with slight lateral } \\
\text { rotation }\end{array}$ \\
\hline Infraspinatus & Infraspinatus fossa & Greater tubercle of humerus & $\begin{array}{l}\text { Rotates the arm laterally, slight } \\
\text { adduction }\end{array}$ \\
\hline Subscapularis & Subscapular fossa & Lesser tubercle of humerus & Rotates the arm medially \\
\hline Teres Major & $\begin{array}{l}\text { Dorsal surface of the interior angle of the } \\
\text { scapula }\end{array}$ & Lesser tubercle of humerus & $\begin{array}{l}\text { Adducts, extends, medially rotates the } \\
\text { arm }\end{array}$ \\
\hline Teres Minor & Axillary border of scapula & Greater tubercle of humerus & Rotates the arm laterally \\
\hline Coracobrachialis & Coracoids process & Middle of the humerus, medial surface & Flexes and adducts the arm \\
\hline Trapezius & $\begin{array}{l}\text { Occipital bone, ligamentum nuchae, spinous } \\
\text { processes of } \mathrm{C} 7 \text { and all thoracic vertebrae }\end{array}$ & $\begin{array}{l}\text { Lateral third of the clavicle, acromion } \\
\text { process, and spine of the scapula }\end{array}$ & $\begin{array}{l}\text { Elevates, depresses, rotates, adducts, and } \\
\text { stabilizes the scapula }\end{array}$ \\
\hline Rhomboid Major & Spinous processes of $\mathrm{T} 2-\mathrm{T} 5$ & $\begin{array}{l}\text { Vertebral border of scapula below the } \\
\text { spine of scapula }\end{array}$ & $\begin{array}{l}\text { Adduct, stabilize, and rotate the scapula, } \\
\text { lowering its lateral angle }\end{array}$ \\
\hline Rhomboid Minor & Spinous process of $\mathrm{C} 7-\mathrm{T} 1$ & $\begin{array}{l}\text { Vertebral border of the scapula at the } \\
\text { base of the spine of scapula }\end{array}$ & $\begin{array}{l}\text { Adduct, stabilize, and rotate the scapula, } \\
\text { lowering its lateral angle }\end{array}$ \\
\hline Levator Scapulae & $\begin{array}{l}\text { Transverse processes of the upper } 4 \text { cervical } \\
\text { vertebrae }\end{array}$ & $\begin{array}{l}\text { Vertebral border of the scapula, above } \\
\text { the spine of scapula }\end{array}$ & Elevates scapula bends the neck laterally \\
\hline Pectoralis Minor & Anterior surface of the $3^{\text {rd }}-5^{\text {th }}$ ribs & Coracoids process & $\begin{array}{l}\text { Draws the scapula anteriorly and } \\
\text { downward }\end{array}$ \\
\hline Serratus Anterior & Outer surface of the first 9 ribs & $\begin{array}{l}\text { Entire length of the ventral surface of } \\
\text { the vertebral border of the scapula }\end{array}$ & $\begin{array}{l}\text { Stabilizes, abducts, and rotates the } \\
\text { scapula }\end{array}$ \\
\hline
\end{tabular}

The sacrum is joined to the ilium by strong ligaments on each side, forming the sacroiliac joint. ${ }^{16}$, 22, 24, 34 Only a small amount of forward and backward movement is present at this articulation.

The coccyx is made up of four or five small fused vertebral bodies that articulate with the sacrum. ${ }^{16,24,22,34}$ The ball and socket hip joint is formed by the articulation of the femur with the innominate. ${ }^{16,22,24,34}$ The head of the femur fits deep into the acetabulum of the innominate, making it a very stable bony articulation.

Ligaments: The hip joint is a ball and socket joint that utilizes four ligaments

(iliofemoral, pubofemoral, ischiofemoral, ligamentum teres) to create a stable joint. ${ }^{16,22,24,34}$ 
The iliofemoral ligament has two bands. When the bands of this ligament are working together, hyperextension is prevented. ${ }^{16}$ Separately, the lateral band limits adduction while the medial band limits external rotation. ${ }^{16}$ The pubofemoral ligament limits abduction while the ischiofemoral ligament limits internal rotation. ${ }^{16,24,34}$ Ligamentum teres runs from the fovea capitis of the femoral head to the acetabulum and limits distraction of the femoral head from the acetabulum. $^{19,34}$ More importantly, this ligament houses branches of the obturator artery that supply blood to the head of the femur. ${ }^{34}$

Musculature: The muscles of the hip can be divided into two groups, anterior and posterior. The anterior group includes the iliacus and psoas muscles. The posterior group includes the tensor fasciae latae, gluteus maximus, gluteus medius, gluteus minimus, and the six deep outward rotators including: piriformis, superior gemellus, inferior gemellus, obturator internus, obturator externus, and quadratus femoris. ${ }^{16,22,24}$

The hip joint relies on multiple planes of motion to allow for abduction, adduction, flexion, extension, internal rotation, and external rotation. ${ }^{16,21}$ The gluteus medius and minimus along with the tensor fascia latae provide abduction and medial rotation while the adductors (longus, brevis, magnus), pectineus, and gracilis move the hip medially into adduction. ${ }^{16,22,24,35}$ Lateral rotation is provided by the six, small, deep muscles. These muscles can be easily memorized by the acronym "P GO GO Q" which stands for piriformis, gemellus superior, obturator internus, gemellus inferior, obturator externus, and quadratus femoris. ${ }^{21,24}$ This acronym also denotes the superior to inferior order of these muscles within the pelvis. Flexion of the hip is primarily provided by the iliopsoas (combination of psoas and iliacus) and is assisted by the pectineus, sartorius, and the rectus femoris. ${ }^{16,22,24,35}$ The gluteus maximus is the prime 
mover of hip extension while the hamstrings group and adductor magnus help to provide added strength to the range of motion. ${ }^{16,21,35}$ Table B8 lists the pelvic girdle/hip musculature.

\begin{tabular}{|c|c|c|c|}
\hline Muscle & Origin & Insertion & Action \\
\hline Sartorius & ASIS & $\begin{array}{l}\text { Proximal medial surface of the tibia, } \\
\text { below the tuberosity }\end{array}$ & $\begin{array}{l}\text { Flexes the thigh and leg, laterally } \\
\text { rotates the thigh }\end{array}$ \\
\hline Rectus Femoris & $\begin{array}{l}\text { AIIS and above the acetabulum of the os } \\
\text { coxae }\end{array}$ & $\begin{array}{l}\text { Tibial tuberosity, via patella and } \\
\text { patellar ligament }\end{array}$ & Extend the leg and flexes the thigh \\
\hline Biceps Femoris & $\begin{array}{l}\text { Long head: ischial tuberosity } \\
\text { Short head: lateral lip of the linea aspera }\end{array}$ & $\begin{array}{l}\text { Lateral surface of the head of the fibula, } \\
\text { and the lateral condyle of the tibia }\end{array}$ & $\begin{array}{l}\text { Flexes the leg; long head extends the } \\
\text { thigh }\end{array}$ \\
\hline Semitendinosus & Ischial tuberosity & Medial surface of the proximal tibia & Flexes the leg, extends the thigh \\
\hline Semimembranosus & Ischial tuberosity & Medial surface of the proximal tibia & Flexes the leg, extends the thigh \\
\hline Adductor Magnus & Act only on femur & & Adduct and laterally rotate thigh \\
\hline Adductor Longus & Act only on femur & & Adduct and laterally rotate thigh \\
\hline Adductor Brevis & Act only on femur & & Adduct and laterally rotate thigh \\
\hline Pectineus & Act only on femur & & Adduct and laterally rotate thigh \\
\hline Gracilis & Symphasis pubis and pubic arch & $\begin{array}{l}\text { Medial surface of the tibia below } \\
\text { condyle }\end{array}$ & Adducts the thigh, flexes the leg \\
\hline Psoas & $\begin{array}{l}\text { Transverse processes and bodies of the } \\
\text { last thoracic and all lumbar vertebrae }\end{array}$ & Lesser trochanter of the femur & Flex the thigh, flex the trunk \\
\hline Iliacus & Iliac crest and fossa & & \\
\hline Tensor Fasciae Latae & $\begin{array}{l}\text { Anterior portion of the iliac crest, and } \\
\text { the ASIS }\end{array}$ & Iliotibial band of the fascia latae & $\begin{array}{l}\text { Tenses the fascia latae, assists flexion, } \\
\text { abduction, medial thigh rotation }\end{array}$ \\
\hline Gluteus Maximus & $\begin{array}{l}\text { Posterior gluteal line of the ilium, and } \\
\text { the posterior surface of the sacrum and } \\
\text { the coccyx }\end{array}$ & Gluteal tuberosity of the femur ITB & Extends and laterally rotates the thigh \\
\hline Gluteus Medius & $\begin{array}{l}\text { Outer surface of the ilium, between the } \\
\text { posterior and anterior gluteal lines }\end{array}$ & Lateral surface of the greater trochanter & Abducts and medially rotates the thigh \\
\hline Gluteus Minimus & $\begin{array}{l}\text { Outer surface of the ilium, between the } \\
\text { anterior and inferior gluteal lines }\end{array}$ & $\begin{array}{l}\text { Anterior surface of the greater } \\
\text { trochanter }\end{array}$ & Abducts and medially rotates the thigh \\
\hline Piriformis & Anterior surface of the sacrum & $\begin{array}{l}\text { Superior border of the greater } \\
\text { trochanter }\end{array}$ & $\begin{array}{l}\text { Rotates the thigh laterally, assists in } \\
\text { extending and abducting the thigh }\end{array}$ \\
\hline Superior Gemellus & Ischial spine & Greater trochanter & Laterally rotates thigh \\
\hline Inferior Gemellus & Ischial tuberosity & Greater trochanter & Laterally rotates thigh \\
\hline Obturator Internus & $\begin{array}{l}\text { Inner surface of the obturator membrane } \\
\text { and margins of obturator foramen }\end{array}$ & Greater trochanter & Laterally rotates thigh \\
\hline Obturator Externus & $\begin{array}{l}\text { Outer surface of the obturator } \\
\text { membrane, margins of obturator foramen }\end{array}$ & Trochanteric fossa & Laterally rotates thigh \\
\hline Quadratus Femoris & Ischial tuberosity & $\begin{array}{l}\text { Shaft of femur below the greater } \\
\text { trochanter }\end{array}$ & Laterally rotates the thigh \\
\hline
\end{tabular}


Knee: Bones, ligaments, and musculature of the knee are discussed in this section.

Bones: The knee consists of the femur, tibia, fibula, and the patella. These four bones create four articulations at the knee. The first two articulations of the knee are the medial and lateral tibio-femoral joints. The tibio-femoral joint is the articulation of the tibial plateau and the medial and lateral femoral condyles. ${ }^{16,18,21}$ This joint is a hinge joint that allows for flexion and extension but also for a small rotary component. The patello-femoral joint is another articulation of the knee where the patella articulates with the femur. ${ }^{16,18,21,33}$ The patella lies within the quadriceps tendon and tracks between the femoral condyles acting as a pulley during extension of the knee. ${ }^{16,19,21}$ The proximal tibiofibular joint is the articulation of the tibia and fibula. It is not the true joint of the knee but can have an effect on stability when damaged due to its proximity, muscular, and ligamentous attachments. ${ }^{16,18,19,21}$

Ligaments: The knee joint is a hinge joint that relies on muscular attachments and ligaments for stability. Six ligaments of the knee help provide stability include: the anterior cruciate ligament (ACL), posterior cruciate ligament (PCL), medial collateral ligament (MCL), lateral collateral ligament (LCL), arcuate ligament, and the posterior oblique ligament. 16, 21, 33, 36, 37,38 The ACL limits anterior translation and internal rotation of the tibia in relation to the femur while the PCL limits posterior translation. ${ }^{16,18,21,37}$ The MCL and LCL limit excessive motion from side to side. The posterior oblique ligament assists the MCL in limiting valgus stress that is applied to the knee. ${ }^{16,18,21,38}$ The arcuate ligament limits posterior lateral rotation of the tibia. ${ }^{21,}$ 38

Musculature: For the knee to function properly, a number of muscles must work together in a very complex fashion. ${ }^{16}$ Knee flexion is executed by the biceps femoris, semitendinosus, semimembranosus, gracilis, sartorius, gastrocnemius, popliteus, and plantaris muscles. ${ }^{16,19,22}$ 
Knee extension is executed by the quadriceps group: vastus medialis, vastus lateralis, vastus intermedius, and the rectus femoris. ${ }^{16,19,22}$ External rotation at the knee is occurs using the popliteal, semitendinosus, semimembranosus, sartorius, and gracilis muscles. Rotation of the tibia is limited and can only occur when the knee is flexed. ${ }^{16,19,22}$ The iliotibial band on the lateral side functions as a dynamic lateral stabilizer at the knee. ${ }^{16,19,22}$ Table B9 includes the knee musculature with origin, insertion, and action of each muscle.

Table B9. Knee Musculature ${ }^{16}$

\begin{tabular}{|c|c|c|c|}
\hline Muscle & Origin & Insertion & Action \\
\hline Semitendinosus & Ischial tuberosity & Medial surface of proximal tibia & Flexes leg, extends thigh \\
\hline Semimembranosus & Ischial tuberosity & $\begin{array}{l}\text { Medial surface of the proximal } \\
\text { tibia }\end{array}$ & Flexes leg, extends thigh \\
\hline Biceps Femoris & $\begin{array}{l}\text { Long head: ischial tuberosity } \\
\text { Short head: lateral lip of linea aspera }\end{array}$ & $\begin{array}{l}\text { Lateral head of fibula and lateral } \\
\text { condyle of tibia }\end{array}$ & Flexes the leg, long head extends thigh \\
\hline Rectus Femoris & AIIS & Tibial tuberosity & Extend leg, flexes thigh \\
\hline Vastus Medialis & medial lip of linea aspera & Tibial tuberosity & Extends leg \\
\hline Vastus Lateralis & $\begin{array}{l}\text { Greater trochanter, lateral lip of linea } \\
\text { aspera }\end{array}$ & Tibial tuberosity & Extends leg \\
\hline Vastus Intermedius & Anterior surface of femur & Tibial tuberosity & Extends leg \\
\hline Gastrocnemius & Medial and lateral condyles of femur & Calcaneus & Flexes leg, plantar flexes foot \\
\hline Popliteus & Laeral condyle of the femur & Proximal portion of tibia & Flexes and rotates leg medially \\
\hline
\end{tabular}

Ankle/Foot: Bones, ligaments, and musculature of the ankle and foot are discussed in this section.

Bones: The bones of the ankle are the tibia, fibula, and talus. The ankle is comprised of three joints which are the distal tibiofibular joint, talocrural joint, and the subtalar joint. The tibiofibular joint is an articulation of the distal tibia and the lateral malleolus of the fibula. ${ }^{16,18,21}$ 36 The talocrural joint is also known as the ankle joint or ankle mortise. ${ }^{16,21}$ The joint is comprised of the tibia, fibula, and the talus. The primary articulation of this joint is the trochlea of the talus meeting the distal articulating facet of the tibia but also has articulations on the medial and lateral aspects of the talus. ${ }^{16,21,36}$ The ankle mortise is a hinge joint and provides planterflexion and dorsiflexion of the ankle. The subtalar joint is the articulation of the talus and 
calcaneus. This joint allows for four motions at the ankle including inversion, eversion, pronation, and supination. ${ }^{16,18,21,36}$

The foot consists of 26 bones; 14 phalanges, 5 metatarsals, and 7 tarsals. ${ }^{16}$ The first toe has two phalanges the rest have three, a proximal, middle, and distal. The metatarsals are the five bones that lie between and articulate with the tarsals and the phalanges. They create a semimovable tarso-metatarsal and metatarso-phalangeal joints. ${ }^{16}$ The tarsal bones are the calcaneus, talus, navicular, cuboid, and the three cuneiforms.

Ligaments: With the many bony structures and joints of the ankle and foot, multiple ligaments are present to provide stability to these areas. The ankle has six ligamentous structures to provide stability. The ligaments of the ankle include the anterior talofibular (ATF), calcaneofibular $(\mathrm{CF})$, posterior talofibular (PTF), deltoid, and the anterior and posterior tibiofibular (AITF and PITF) ligaments. ${ }^{16,21,36,39,40,41}$ The lateral ankle structures include the ATF, CF, and PTF and limit inversion, while the medial ankle mortise is supported by the deltoid ligament which limits eversion. ${ }^{16,21,36,39,41}$ The deltoid ligament has four portions called the anterior and posterior tibiotalar, tibionavicular, and tibiocalcaneal ligaments. ${ }^{16,21,41,36}$ The distal tibiofibular joint is supported by the anterior and posterior tibiofibular ligaments which limit excessive tibiofibular separation. ${ }^{16,21,39,41}$

Five ligamentous tissues within the foot support the structure of the arches of the foot and limit excessive motion of downward forces. The ligaments that support the foot include the short plantar, long plantar, bifurcate, and spring ligament. ${ }^{16,18,21,42}$ Another structure that supports this area is the plantar fascia which is not a true ligament but provides vital support to the arches of the foot against downward forces. ${ }^{16,18,21}$ 


\section{Musculature: The muscles of the foot and ankle are responsible for motion in the planes}

\section{of eversion, inversion, plantarflexion, dorsiflexion, and motion of the toes.}

\begin{tabular}{|c|c|c|c|}
\hline Muscle & Origin & Insertion & Action \\
\hline Gastrocnemius & Medial and lateral condyles of femur & Calcaneus & Flexes leg, plantar flexes foot \\
\hline Soleus & $\begin{array}{l}\text { Posterior surface of the proximal third of the } \\
\text { fibula and middle third of tibia }\end{array}$ & Calcaneus & Plantar flexes foot \\
\hline Plantaris & $\begin{array}{l}\text { Posterior surface of the femur above lateral } \\
\text { condyle }\end{array}$ & Calcaneus & Flexes the leg, plantar flexes foot \\
\hline Tibialis Posterior & $\begin{array}{l}\text { Posterior surface of the interosseus } \\
\text { membrane, tibia, and fibula }\end{array}$ & $\begin{array}{l}\text { Navicular, cuneiforms, cuboid, } \\
2^{\text {nd }}-4^{\text {th }} \text { metatarsals }\end{array}$ & Plantar flexes and inverts foot \\
\hline Flexor Digitorum Longus & Posterior surface of the tibia & Distal phalanx of $2^{\text {nd }}-5^{\text {th }}$ toes & $\begin{array}{l}\text { Plantar flexes, inverts foot, flexes } \\
\text { toes }\end{array}$ \\
\hline Flexor Hallicis Longus & Lower two thirds of fibula & Distal phalanx of great toe & $\begin{array}{l}\text { Plantar flexes, inverts foot, flexes } \\
\text { great toe }\end{array}$ \\
\hline Tibialis Anterior & $\begin{array}{l}\text { Lateral condyle and proximal two thirds of } \\
\text { the tibia, and interosseus membrane }\end{array}$ & $\begin{array}{l}\text { Medial surface of the } 1^{\text {st }} \\
\text { cuneiform and } 1^{\text {st }} \text { metatarsal }\end{array}$ & Dorsiflexes and inverts foot \\
\hline Extensor Hallucis Longus & $\begin{array}{l}\text { Anterior surface of fibula, and interosseus } \\
\text { membrane }\end{array}$ & $\begin{array}{l}\text { Dorsal surface of the distal } \\
\text { phalanx of the great toe }\end{array}$ & $\begin{array}{l}\text { Dorsiflexes, inverts foot, extends } \\
\text { great toe }\end{array}$ \\
\hline Extensor Digitorum Longus & $\begin{array}{l}\text { Lateral condyle of the tibia, anterior surface } \\
\text { of fibula, and interosseus membrane }\end{array}$ & $\begin{array}{l}\text { Dorsal surface of the } 5^{\text {th }} \\
\text { metatarsal }\end{array}$ & Dorsiflexes, everts foot \\
\hline Peroneus Longus & Lateral surface of fibula & $\begin{array}{l}\text { Ventral surface of } 1^{\text {st }} \text { metatarsal } \\
\text { and medial cuneiform }\end{array}$ & Plantar flexes and everts foot \\
\hline Peroneus Brevis & Distal fibula & Lateral side of the $5^{\text {th }}$ metatarsal & Plantar flexes and everts the foot \\
\hline Peroneus Tertius & $\begin{array}{l}\text { Anterior surface of fibula and interosseus } \\
\text { membrane }\end{array}$ & $\begin{array}{l}\text { Dorsal surface of the } 5^{\text {th }} \\
\text { metatarsal }\end{array}$ & Dorsiflexes and everts foot \\
\hline Abductor Hallucis & Calcaneus & Proximal phalanx of the great toe & Abducts great toe \\
\hline Flexor Digitorum Brevis & Calcaneus and plantar aponeurosis & $\begin{array}{l}\text { Middle phalanx of the } 2^{\text {nd }}-5^{\text {th }} \\
\text { toes }\end{array}$ & Flexes $2^{\text {nd }}-5^{\text {th }}$ toes \\
\hline Abductor Digiti Minimi & Calcaneus and plantar aponeurosis & $5^{\text {th }}$ toe & Abducts $5^{\text {th }}$ toe \\
\hline Quadratus Plantae & Calcaneus & $\begin{array}{l}\text { Into tendons of the flexor } \\
\text { digitorum longus }\end{array}$ & Aids in flexing the $2^{\text {nd }}-5^{\text {th }}$ toes \\
\hline Lumbricales & From tendons of the flexor digitorum longus & $\begin{array}{l}\text { Into tendons of the extensor } \\
\text { digitorum longus }\end{array}$ & Flexes $2^{\text {nd }}-5^{\text {th }}$ toes \\
\hline Flexor Hallucis Brevis & Cuboid and lateral cuneiform & Proximal phalanx of the great toe & Flexes great toe \\
\hline Adductor Hallucis & $\begin{array}{l}\text { Oblique: } 2^{\text {nd }}, 3^{\text {rd }}, 4^{\text {th }} \text { metatarsals } \\
\text { Transverse: ligaments of the MTP joints }\end{array}$ & Proximal phalanx of the $5^{\text {th }}$ toe & Adducts great toe \\
\hline Flexor Digiti Minimi Brevis & $5^{\text {th }}$ metatarsal & Proximal phalanx of the $5^{\text {th }}$ toe & Flexes $5^{\text {th }}$ toe \\
\hline Plantar Interossei & $3^{\text {rd }}, 4^{\text {th }}, 5^{\text {th }}$ metatarsals & Proximal phalanx of the same toe & Adduct toes toward $2^{\text {nd }}$ toe \\
\hline Dorsal Interossei & Bases of the adjacent matatarsals & $\begin{array}{l}\text { Proximal phalanges, both sides of } \\
2^{\text {nd }} \text { toe, lateral side of } 3^{\text {rd }} \text { and } 4^{\text {th }} \\
\text { toes }\end{array}$ & $\begin{array}{l}\text { Abduct the toes from the } 2^{\text {nd }} \text { toe, } \\
\text { move the } 2^{\text {nd }} \text { toe medially and } \\
\text { laterally }\end{array}$ \\
\hline Popliteus & Lateral condyle of the femur & Proximal tibia & $\begin{array}{l}\text { Flexes and rotates the leg } \\
\text { medially }\end{array}$ \\
\hline
\end{tabular}


The primary muscles of plantarflexion are the gastrocnemius, soleus, and the plantaris and are assisted by tibialis posterior, flexor digitorum, hallicus longus, and the peroneus longus and brevis. ${ }^{16,21,24,35}$ Tibialis anterior is the prime mover in the direction of dorsiflexion and is assisted by the toe extensor muscles and the peroneus tertius. ${ }^{16,21,24,36}$ Both the tibialis anterior and posterior provide inversion at the ankle while the peroneals move the ankle into eversion. ${ }^{16,}$ 21, 24 The toes are moved by many muscles but the majority of the movement is provided by the flexor digitorum and hallicus longus and the extensor digitorum and hallicus longus. ${ }^{16,21,24}$ Table B10 includes the origin, insertion, and action of the ankle/foot musculature.

\section{Tactical Officers}

The use of teams comprised of specially selected, trained and equipped personnel to resolve high-risk incidents, such as barricaded suspect/hostage situations, was born out of necessity. One of the most influential causes for the origination of these teams was the so-called “Texas Tower" shootings at the University of Texas at Austin, where Charles Whitman killed fifteen people and wounded thirty-one others on August 1, 1966. Also influential were the violent riots and disorders of the decade of the sixties, many of which involved sniper fire directed at police and civilians. ${ }^{48}$ The first agencies to organize SWAT teams were the Los Angeles Police Department and the Los Angeles County Sheriff's Department, both having established their fledgling teams during the latter part of 1966. The acronym SWAT (Special Weapons and Tactics) was originated by the Los Angeles Police Department. ${ }^{48}$ The passage of time has proven that the use of SWAT teams is the safest and most effective means of resolving high-risk incidents. ${ }^{48}$ The ultimate mission of SWAT is to improve public safety and domestic security through training, education and tactical excellence. ${ }^{48}$ 
Tactical officers in Colorado train at the National Strength and Conditioning Association's headquarters in Colorado Springs, and are often seen performing weighted pull ups, barbell squats, and running drills. These are all activities often seen in traditional athletic facilities. However, the objective for these individuals is not to translate hard work outside of game time into goals, touchdowns, or homeruns. Their sights are set on preparing for jumping fences while wearing 80 pounds of gear or keeping their trigger finger steady in a hostage situation. ${ }^{1}$ SWAT officers in Colorado Springs are called out to potentially fatal operations 130 150 times in an average year. This can be at any time of the day or night on any day of the year. ${ }^{1}$ Some of the challenges tactical officers face on call outs, and what they train for during practice exercises are weapons transitions, extreme physical exertion, and tactical reloading in addition to performing athletic type movements. ${ }^{1,2}$ SWAT officers need speed, power, agility, strength and endurance. ${ }^{1}$ After hours of observation it was concluded that SWAT officers are tactical athletes and should train as such. ${ }^{1}$

\section{Current Medical Coverage}

Currently most tactical teams are not without medical coverage during call outs. However, there are different options for obtaining medical coverage. A majority of teams are furnished with tactical emergency medical services (TEMS) or EMS is on the scene. ${ }^{6,16,17}$ However, there are very few tactical medicine curricula training traditional emergency medical services (EMS) providers to operate in the high risk missions often encountered by tactical teams. ${ }^{6}$ Tactical teams may have several members who have received TEMS training. For example federal agents of the Drug Enforcement Agency (DEA) can enroll in a special agent emergency medical technician (SAEMT) curriculum. This is available for agents with experience 
in tactical operations, but without previous medical training. ${ }^{6}$ These individuals will then be qualified to apply their EMT skills in the field.

Some teams require all of their TEMS providers to be fully sworn officers who are qualified first as tactical team members and secondarily as medics. This approach has several benefits. First, the tactical team is an elite unit and is often slow to accept "outsiders." Having a team member as the TEMS provider instills confidence in other team members and meets operational security requirements. Second, the medic can provide his/her own security when not caring for a patient. Third, the medic has arrest and custodial authority, which can be useful when caring for a prisoner. ${ }^{4,5}$ On the other hand, medical support of the team becomes a collateral duty, continuing education and skills maintenance in both the tactical and medical arenas may become burdensome, and the available manpower for this type of assignments is usually very limited. ${ }^{4,5}$ It is easy to understand how role confusion can occur for a dual trained member in this situation.

Many teams elect to use fire/rescue/EMS personnel as TEMS providers. This has the advantage that medical support of the team is their primary function and they are not distracted by other duties. Generally tactical team members will have greater confidence in their medical skills compared to a classroom trained EMT who is a police officer first and has little practical experience. Continuing education and skills maintenance are easier to achieve and role confusion is less likely to occur. It also seems that the man power for this kind of assignment is more readily available. However, these providers have no arrest powers and will require an officer in attendance if they are treating a prisoner. They also require the team to provide for their security at all times and represent an operational security risk. Their relative lack of tactical skills can be remedied with rigorous training and most team commanders consider it easier to train a medic in 
tactical operations than for a tactical officer to learn medical operations. ${ }^{4,5}$ A few tactical teams continue to rely on standby coverage of their operations by conventional fire/rescue/EMS. While this is the easiest type of coverage to accomplish, it delays the delivery of care to the patient and is a grossly inadequate model for addressing tactical operational medical support. ${ }^{4,5}$ An allied health professional, such as an athletic trainer with TEMS education, may solve many of the inadequacies described in the above models. This medical professional would spend time with the team during training exercises, just as covering an athletic practice, which would build confidence within the team. Medical coverage is the priority of this individual already, and most athletic trainers have a willingness to learn the general operations of their team. Athletic trainers are very versatile individuals, and work in a variety of traditional and nontraditional settings ranging from the athletic arena to the military and the industrial setting.

\section{Epidemiology}

Injuries to SWAT team members occur at a rate of 33 injuries per 1,000 officer missions. ${ }^{6}$ There seems to be a lack of epidemiological research among tactical teams. This is more than likely due to the small numbers of tactical officers that function within these elite groups. However, significant studies have been conducted among military personnel around the globe. This information can be easily compared to tactical teams due to the nature of their training being very military like.

Musculoskeletal disorders (MSDs) are the most common injuries among military personnel. $^{9,10,11,12,13,14}$ A systematic review found that MSD rates during military training range from 6-12 per 100 male recruits per month, and up to 30 per 100 per month in Naval Special Warfare training. 9 Some studies have suggested that as many as $50 \%$ of recruits can be 
expected to suffer an injury during their military training. ${ }^{9}$ Musculoskeletal disorders often result in significant loss of strength and flexibility, a propensity for recurrence of injury, and time off from duty. ${ }^{10,11,12,13,14}$ The frequency of MSDs and the outcomes result in a decrease in military readiness and an increase in monetary costs. ${ }^{10}$ Musculoskeletal disorders often result in disabilities with long term rehabilitation and functional impairment leading to premature military discharge. ${ }^{11}$ Data from the Armed Forces Epidemiological Board (AFEB) indicate that during peacetime or conflict, injuries have a greater effect on the health and readiness of United States military personnel than any other medical complaint. ${ }^{12}$ More specifically, musculoskeletal injuries are the major problem among military personnel because they are the leading cause of disability among all military service. ${ }^{12}$ Musculoskeletal injuries rank as the $5^{\text {th }}$ most common reason for hospitalization among all military services. ${ }^{10,12}$ Despite the health benefits of physical activity, when training intensifies, injury risks also increase. Combat readiness requires a strong emphasis on physical fitness, which predisposes soldiers and tactical officers to musculoskeletal injury. ${ }^{43}$

The exact location of MSD among soldiers varies, but the most commonly reported are the knee, lumbar spine, ankle, and GHJ. ${ }^{9,10,11,12,13,14}$ Leggat describes 20\%-40\% of military training injuries involved the knee, and most knee injuries were reported to have occurred during military training activities, which also accounted for the greatest number of lumbar spine problems and ankle problems. ${ }^{9} \quad$ The GHJ was the site more often affected by other causes. ${ }^{9}$ In a study of over 15,000 hospitalized military personnel, the most common location for MSD was the $^{\text {back. }}{ }^{9}$

During a 12 month study among the Finnish Defense Forces (FDF), which are a smaller more specialized force similar to U.S. tactical teams, there were 437 outpatient clinic visits in 
955 people studied, a $46 \%$ injury rate. The most common types of MSD were low back pain (20\%), lower limb overuse injuries (16\%), and sprains and strains accounted for $13 \%{ }^{11}$ Forty percent of these occurred while in combat gear, while $28 \%$ were related to overuse pathologies. ${ }^{11}$ Musculoskeletal disorders represent the second biggest reason for ultimately being discharged from the $\operatorname{FDF}(62 \%){ }^{11}$

Jennings ${ }^{12}$ found that the back and knees accounted for $26 \%$ of all MSDs among U.S. Army personnel. At least $47 \%$ of the injuries were work related, and they interfered with the soldier's ability to complete military tasks such as marching and physical training. In another study of 218 male light infantry soldiers who completed a 100 mile tactical road march carrying 103.4 pounds of gear, 78 of the soldiers experienced 98 injuries for an incidence rate of $36 \% .^{12}$ Almost $95 \%$ of the injuries were lower extremity related and resulted in 69 days of limited duty. $^{12}$ In another study fractures, sprains/strains, and dislocations accounted for $82 \%$ of all injuries. Knees were the most common of these. An average of 29,435 days/year were lost from work over this 6 year study. ${ }^{12}$ Over a one year study of 1,965 soldiers from an airborne unit, 508 overuse injuries were experienced. Injury rates were 2.4 per soldier per month; this resulted in 22,041 work days lost. ${ }^{12}$

Darakjy $^{13}$ found that musculoskeletal injuries, environmental conditions, and dermatological conditions accounted for most visits to medical services over a five week training period at the National Training Center in Fort Erwin, CA. Rates of injury were $1.2 \%$ and $2.3 \%$ per week for men and women, respectively. Just over $11 \%$ of the total brigade at the training center sought medical care. Injuries were defined as anatomical pain, sprains, strains, fractures, contusions, and blisters. Environmental conditions, such as dehydration, heat exhaustion, and heat stroke were also prominent. ${ }^{13}$ 
Evans ${ }^{14}$ reported acute injury related to fitness testing among U.S. Army personnel. All injuries, performance limiting injuries, and time loss injuries were reported. A total of 117 soldiers $(7.6 \%)$ reported sustaining an injury with $11 \%$ attributed to the push up event, $56 \%$ to the sit up event, and $32 \%$ to the run event. Forty six of these injuries limited performance and 11 soldiers $(.7 \%)$ received a duty limiting profile. ${ }^{14}$

In a study conducted among an Australian Defense Force (ADF), sport and physical training accounted for more than $50 \%$ of injuries. ${ }^{44}$ Reported incident rates range from 3.3 to 34.4 injuries per 100 person-months, depending on level of service. ${ }^{43}$ In 2002 and 2003 the New Zealand Defense Force (NZDF) experienced lower limb injuries that accounted for almost half of all NZDF injuries that resulted in compensation claims. ${ }^{44}$ The most common musculoskeletal injury among this small specialized force were ankle sprains and strains (35\%). The next most occurring MSD was found at the knee (16\%). ${ }^{44}$

An occupational health department in the United Kingdom expressed concern about their police officers missing substantial amounts of work due to musculoskeletal problems. They found that exposure to driving a car or helicopter had significant effects on self reported low back pain. ${ }^{45}$ This information can be correlated to the U.S. tactical teams because there is normally a fair amount of driving involved and each unit is usually accompanied by air support. Police motorcyclists also had a higher prevalence of GHJ pathology. ${ }^{45}$ The effects were normally seen among drivers who were tall, drove fleet cars, and spent most of their eight hour shift in a car. ${ }^{45}$ This amount of sitting for prolonged periods of time can lead to adaptive muscle shortening. It is no surprise that injuries occur when someone is in a seated position for a long period of time and then attempts to sprint after a suspect. 
A study conducted among public safety personnel, including police officers, stated that injuries lead to seeking medical care, in turn resulting in time off from work. ${ }^{46}$ Eight hundred fifty police officers accounted for 608 worker's compensation cases. ${ }^{46}$ Almost $72 \%$ filed a claim within a two year span. Minor traumatic musculoskeletal injuries such as strains and sprains accounted for the majority of missed days of work. ${ }^{46}$

It is apparent from this reported military and police force data that there is significant cause for concern regarding MSD among individuals in this line of duty. Time lost from duty or work is costly to everyone involved. Similar injuries seen among police departments could result in many dollars in worker's compensation cases, which could potentially burden the whole department.

\section{Etiology}

Many forces can contribute to the onset of musculoskeletal injuries. The types of stresses that could cause musculoskeletal injury include tension, stretching, compression, shearing, and bending. ${ }^{16}$ Tension and stretching are similar in that they both include the mechanism to straining a muscle or rupture a ligament by going beyond the normal yield of that structure. ${ }^{16,33}$ Compression is usually caused by direct contact and causes injury by crushing the tissue that has been contacted. Tissues that are generally damaged by these forces include skin, muscle, and bones. A direct blow to the abdomen or thorax could also cause compression of the internal organs causing a fracture or rupture of that organ. Compression of the cervical spine can also cause a burst type fracture that would ultimately cause spinal cord damage. ${ }^{20}$ Shearing forces affect the structure being acted upon in a parallel plane. This type of force can result in fractures, ligament sprains/tears, and damage to the skin. ${ }^{16}$ Excessive shearing forces of the cervical spine 
can also cause damage to the spinal cord and/or vertebral discs. Bending is the final force that can be applied to a structure. It occurs in the horizontal plane. Generally, bending is specific to bone and causes fractures when enough force is applied. The type of fracture that results is due to the combination of the bending force applied to the bone and the rotational or compression force that may or may not be present. ${ }^{15,21}$

As one can imagine, law enforcement officers can encounter a number of different scenarios on any given day. They may be running up/down stairs, repelling from a helicopter to a roof top, or sprinting over uneven terrain in order to apprehend a suspect. ${ }^{47}$ In addition to these athletic movements, SWAT officers carry an additional 60-80 pounds of gear during missions. ${ }^{1}$ This added weight and highly athletic movements can put tactical officers at a higher risk for musculoskeletal injuries.

Tactical officers can incur musculoskeletal injuries in two ways. One way is in an acute fashion, in which the majority of contusions, fractures, and strains and sprains occur. The other is in a chronic fashion, in which the majority of overuse injuries occur. These injuries often include tendinitis, impingement, and stress related injuries. Acute injuries often require more immediate treatment and are more apparent, while chronic injuries occur over an extended period of time and may be described as a gradual onset of symptoms. ${ }^{16}$ Both types of injuries are common among military and tactical personnel. Acute injuries can occur at any time during training exercises or missions. Chronic injuries will more than likely be a result of extensive over use training over a prolonged period of time. Research studies reference that many military soldiers around the world are susceptible to a large number of acute musculoskeletal injuries. This research also tells us that a significant amount of musculoskeletal injuries are chronic in nature. Military physical training requires excessive running and marching while carrying about 
100 pounds of gear ${ }^{12}$, making military physical training a breeding ground for overuse type injuries. Military training and tactical law enforcement training is very similar in nature, making tactical law enforcement a high risk environment for overuse type injuries as well as acute injuries.

Summary

It is important to have a strong knowledge of the musculoskeletal anatomy in order to have a better understanding of injured body parts. The musculoskeletal anatomy presented in this study is a comprehensive overview of the upper extremity, lower extremity, and trunk. Many different forces act on the body when performing tactical and athletic maneuvers. The forces that can be encountered are compression, shearing, and tensile. These can have many different effects on how a body part is injured. Tactical officers are undoubtedly heroes to many people in their communities. They possess unique skills and train hard in preparation for life threatening situations. Over the course of time tactical officers have proven their worth by saving countless lives. However, saving lives on a daily basis does not come without a price. Tactical officers are often injured on the job and during training exercises. Aside from the life threatening injuries that can occur as a result of this job, many officers sustain musculoskeletal injuries that can jeopardize their careers as well. The medical coverage available to tactical officers today focuses on life threatening injuries in emergency situations. Out of the three main options for medical coverage, Tactical Emergency Medical Support during call outs is the most common type of medical coverage during call outs. An optimal fourth option can be made available through the hiring of an athletic trainer with TEMS certification and tactical training. This individual would be available to the tactical unit on a daily basis and be able to prevent, rehabilitate, and recognize 
any injuries that could occur both during training and call outs. This option is validated by the research presented among military personnel, who most closely resemble tactical officers. Their training is similar and their job requirements are also very similar. The military encompasses a balance of athletic maneuvers with tactical operations. In fact, many individuals enlisted in the military often find themselves in law enforcement after their military careers. Tactical law enforcement has not been a popular topic for research in the past; however, the military has been studied extensively.

Musculoskeletal injuries are very common in the military. Research suggests that more than half of the injuries in the military are musculoskeletal in nature, and account for substantial time lost from duty. Injuries to SWAT team members occur at a rate of 33 injuries per 1,000 officer missions. The incidence of sport related injuries is estimated to be between 10 and 35 per 1,000 playing hours in the adult male professional athlete. Musculoskeletal injuries in the military are even more prevalent than this. Although, the exact location of musculoskeletal disorders (MSD) among soldiers varies, the most commonly reported are the knee, lumbar spine, ankle, and glenohumeral joint (GHJ). 


\section{APPENDIX C}

\section{ADDITIONAL METHODS}

Table C1. Association Letter of Interest

Your assistance is requested

My name is Nathan Roberts and I am a Graduate Athletic Training Student at West Virginia University. I will be conducting a study with the primary investigator Michelle A. Sandrey PhD, ATC to fulfill my requirements for a Master of Science degree in Athletic Training affiliated with West Virginia University. The purpose of this study will be to determine the number and type of musculoskeletal injuries incurred by tactical officers throughout their careers.

I am writing to gain your support in data collection for the thesis titled Musculoskeletal Injuries in Tactical Law Enforcement. I would like to either post a link on your website or ask your organization to distribute a link via individual email to your entire membership base. If you have another method for distributing information electronically to your members, I would be willing to accommodate that as well. It is extremely important for the study that I gain the highest response rate possible. If you are willing to help in any way it would be greatly appreciated.

The goal of this study is to use the information collected to determine if there is a need to increase the medical coverage among tactical units. In order to accomplish this, I am asking for your assistance in distributing a letter to tactical officers explaining the study. The letter will contain the link to the actual questionnaire. This is an excellent opportunity for your organization to take part in research that will help improve the continuity in which medical professionals nationwide provide medical care to tactical teams. The entire process will only take a few minutes to complete and will have contributed very important information about your profession. All that is asked is that you agree to assist in electronic distribution of a letter which members could easily access, and encourage them to participate.

If your organization is interested in assisting in this study please respond to this email indicating so, and how you would prefer to distribute the information. Also, include any instructions or questions you may have for me. Upon receipt of said email a cover letter containing a link to the questionnaire will be provided in an electronic format of your preference, along with a short email thanking you for your participation. If you do not wish to participate, an email stating such is greatly appreciated.

The participation in this study will not affect employment status, and the responses will be completely confidential. If you are willing to participate please indicate so by responding to this e-mail.

I would like to thank you and your association for taking the time to consider this request.

Kind Regards,

Nathan T Roberts LAT, ATC

nrobert5@mix.wvu.edu

610-533-0074

* West Virginia University Institutional Review Board acknowledgment of this study is on file 
Your assistance and experience is needed

My name is Nathan Roberts and I am a Graduate Athletic Training Student at West Virginia University. I will be conducting a study with the primary investigator Michelle A. Sandrey PhD, ATC to fulfill my requirements for a Master of Science degree in Athletic Training affiliated with West Virginia University. The purpose of this study will be to determine the number and type of musculoskeletal injuries incurred by tactical team members throughout their careers.

Ultimately, the goal of this study is to use the information collected to determine if there is a need to increase the medical coverage provided to tactical units. In order to accomplish this, I am asking for you to tell me about your injury experiences. You are members of an elite group of extremely dedicated individuals, and have a very special role in your community's safety. Therefore, it is important that the medical community become aware of the injuries experienced by tactical officers.

This is an excellent opportunity for you to take part in research that will help improve the continuity in which medical professionals nationwide provide medical care to tactical teams. The entire process will only take a few minutes of your time and you will have contributed important information that will help the medical profession provide better care for you as a tactical officer.

This is a completely voluntary activity and all responses are guaranteed to be anonymous and confidential. You are not required to answer every question, and you have the right to withdraw any data you submit at any time. Your participation in this study will not affect your employment status in any way. If you are willing to participate please continue to the questionnaire link below.

By clicking the link below you have expressed your interest in improving the injury information available about tactical teams. Your participation in this research is extremely important and will provide you with the opportunity to help develop better medical coverage for tactical teams across the country.

Hold the Ctrl key and click the link below to access the Tactical Officer Questionnaire. http://www.surveymonkey.com/s/F36CB5B

I would like to thank you in advance for your willingness to participate in this study and for your continued dedication to the safety of our communities.

Thank you,

Nathan T. Roberts LAT, ATC

nrobert5@mix.wvu.edu

610-533-0074

* West Virginia University Institutional Review Board acknowledgment of this study is on file 
Greetings,

This is a reminder that the questionnaire for the study of "Musculoskeletal Injuries in Tactical Law Enforcement" can be completed by April 16, 2010. For those of you who have already submitted your responses or are in the process, I apologize for this interruption and thank you for your participation. For those of you who have not yet provided your input, please hold the Ctrl key and click the link below to view the introduction letter and complete the questionnaire.

Remember that this is an excellent opportunity for you to take part in research that will enhance the knowledge base of injuries experienced by tactical officers. I will be conducting this research study with the primary investigator Michelle A. Sandrey $\mathrm{PhD}$, ATC to fulfill requirements for a Master's thesis and to complete an MS degree in Athletic Training at West Virginia University.

\section{http://www.surveymonkey.com/s/F36CB5B}

I encourage all of you to take a few minutes to fill out the questionnaire. Your experiences are very important in providing better medical coverage for our tactical units!

This is a completely voluntary activity and all responses are guaranteed to be anonymous and confidential. You are not required to answer every question, and you have the right to withdraw any data you submit at any time. Your job status will not be affected by a failure to participate.

If you have any questions or concerns please contact Nathan Roberts by phone at (610) 533-0074 or by email at nrobert5@mix.wvu.edu.

Thank you again,

Nathan T Roberts, LAT, ATC

* West Virginia University Institutional Review Board acknowledgment of this study is on file 
I. BACKGROUND INFORMATION

Tactical Officer Questionnaire

1. What is your role within the team?

$\square \quad$ Team Leader

$\square$ Operator

$\square$ Medical Support

$\square$ Other:

2. How old are you? years old

3. Please indicate your employment status as a tactical officer.

口 I am a full time tactical officer

$\square \quad$ I am a part time tactical officer

$\square$ Other

4. How many years have you been employed as a tactical officer?

$\square \quad$ Less than 2 years

$\square \quad 3-5$ years

ㄴ 6-10 years

$\square \quad$ More than 10 years

5. On average, how many hours per week do you spend on call outs?

$\square \quad$ Less than 5 hours

6-10 hours

$\square \quad 11-15$ hours

$\square \quad$ 16-20 hours

$\square \quad$ More than 20 hours

6. How many hours per week do you spend training for tactical operations?

$\square \quad$ Less than 5 hours

$\square \quad$ 6-10 hours

11-15 hours

$\square$ 16-20 hours

$\square \quad$ More than 20 hours

\section{MEDICAL COVERAGE INFORMATION}

7. Does your tactical unit employ a Tactical Emergency Medical Support (TEMS) system?

$\square$ Yes

$\square \quad$ No

$\square \quad$ Not sure 
8. If yes to \#7, who possesses the TEMS certification within the tactical team?

$\square \quad$ Another officer within the team is our TEMS provider

$\square \quad$ An outside medical professional with tactical training and the TEMS certification is our TEMS provider

$\square \quad$ An outside medical professional without tactical training is our TEMS provider

$\square$ Other

9. If your team employs an outside medical professional with TEMS certification, how would you describe this person's time commitment to the tactical team?

$\square \quad$ Full time

$\square \quad$ Part time

$\square \quad$ As needed (During call outs only)

My team does not employ an outside medical professional

10. If you answered no to \#7, who, if anyone, provides the medical coverage to your tactical unit? Check as many as apply.

$\square$ Physician

$\square \quad$ Physician assistant

$\square \quad$ Nurse

․ An EMT in emergency situations only

$\square$ Other

$\square \quad$ No one

11. Based on your response to question \#10, how would you describe that medical professional's time commitment to the tactical team?

$\square \quad$ Full time

$\square \quad$ Part time

$\square \quad$ As needed

$\square \quad$ Question does not apply

\section{INJURY INFORMATION}

12. Do you have any pre-employment (before being employed as a tactical officer) musculoskeletal injuries (any trauma resulting in pain/injury to the bone, ligament, or muscle) that you feel are exacerbated by work related activities?

$\square$ Yes

$\square$ No

13. Have you ever experienced a musculoskeletal injury (any trauma resulting in pain/injury to the bone, ligament, or muscle) as a result of being employed as a tactical officer?

$\square$ Yes

口 No 
14. Have you ever experienced a musculoskeletal injury (any trauma resulting in pain/injury to the bone, ligament, or muscle) outside of the workplace during the time you have been employed as a tactical officer?

$\square$ Yes

$\square$ No

\section{INJURY DESCRIPTION}

Example \#1:

"I sprained my ankle once playing college football, once while running an obstacle course during a training exercise, twice while on call outs, and once during a pick-up basketball game after work."

You would choose the ligament sprain row, choose ankle as your injured body part, choose 1 under \# of injuries pre-tactical officer employment, choose 3 under \# of injuries work related, choose 1 under \# of injuries outside of work (recreational), and yes/no if you performed rehabilitation exercises, and yes/no if you required surgery.

Example \#2

"I dislocated my finger once while arresting a suspect."

Choose the dislocation row, choose finger as your injured body part, choose 0 for \# of injuries pre-tactical officer employment, choose 1 for \# of injuries work related, choose 0 for \# of injuries outside of work (recreational), and yes/no in the last two columns.

Example \#3

"I tore my ACL playing baseball in high school."

Choose the tear/rupture row, choose knee as the injured body part, choose 1 for \# of injuries pre-tactical officer employment, choose 0 in the other two columns, and choose yes for both rehabilitation required and surgery required. 
15. If you answered yes to any of the questions in the previous section, please fill in the boxes below to the best of your ability. Use the examples above as a template for your responses.

\begin{tabular}{|c|c|c|c|c|c|c|}
\hline Type of injury & $\begin{array}{l}\text { Body part } \\
\text { (Specify) }\end{array}$ & $\begin{array}{l}\text { \# of injuries } \\
\text { Pre-Tactical } \\
\text { Officer } \\
\text { Employment }\end{array}$ & $\begin{array}{l}\text { \# of injuries } \\
\text { Work } \\
\text { Related }\end{array}$ & $\begin{array}{l}\text { \# of injuries } \\
\text { Outside of } \\
\text { work } \\
\text { (recreational) }\end{array}$ & $\begin{array}{l}\text { Rehabilitation } \\
\text { Required? } \\
\text { (Y/N) }\end{array}$ & $\begin{array}{l}\text { Surgery } \\
\text { Required? } \\
(\mathrm{Y} / \mathrm{N})\end{array}$ \\
\hline \multicolumn{7}{|l|}{ Ligament sprain } \\
\hline \multicolumn{7}{|l|}{\begin{tabular}{|l|} 
Muscle strain \\
\end{tabular}} \\
\hline \multirow{2}{*}{\multicolumn{7}{|c|}{ Fracture }} \\
\hline & & & \multicolumn{4}{|c|}{ Dislocation } \\
\hline \multirow{2}{*}{\multicolumn{7}{|c|}{ Tendinitis }} \\
\hline & & & & & & Tear/rupture \\
\hline \multicolumn{7}{|l|}{$\begin{array}{l}\text { Vertebral disc } \\
\text { involvement }\end{array}$} \\
\hline \multicolumn{7}{|l|}{$\begin{array}{l}\text { Contusion } \\
\text { (Bruise) }\end{array}$} \\
\hline \multicolumn{7}{|l|}{ Impingement } \\
\hline \multicolumn{7}{|l|}{ Laceration (cut) } \\
\hline \multicolumn{7}{|l|}{ Burn } \\
\hline \multicolumn{7}{|l|}{$\begin{array}{l}\text { General } \\
\text { pain/discomfort }\end{array}$} \\
\hline Other(Specify) & & & & & & \\
\hline
\end{tabular}

\section{RESULTS OF INJURY}

16. Of the injuries that you incurred prior to tactical officer employment, who was responsible for managing your injuries? Check all that apply
$\square$ Physician
$\square \quad$ Nurse
口 Physician assistant
口 Physical therapist
$\square \quad$ Athletic trainer
$\square$ No one
口 Other

17. Did any of the pre-tactical officer employment injuries cause you to miss work as a tactical officer?
$\square$ Yes
No 
18. If so, approximately how many weeks of work have you missed related to injuries incurred that you sustained before you became a tactical officer?

$\square$ None

$\square$ Less than 1 week

2-6 weeks

$7-12$ weeks

$\square \quad$ More than 12 weeks

19. Of the injuries that you incurred from work related activities, who was responsible for managing your injuries? Check all that apply

$\square$ Physician

$\square \quad$ Nurse

$\square \quad$ Physician assistant

口 Physical therapist

$\square \quad$ Certified Athletic trainer

$\square$ TEMS

$\square \quad$ No one

$\square \quad$ Other

20. Did any of the work related injuries cause you to miss work as a tactical officer?
口 Yes
No

21. If so, approximately how many weeks of work have you missed associated with work related injuries?

$\square$ None

口 Less than 1 week

2-6 weeks

$\square \quad 7-12$ weeks

More than 12 weeks

22. Of the injuries that you incurred from outside of work (recreational) activities during your employment as a tactical officer, who was responsible for managing your injuries? Check all that apply

$\square$ Physician

$\square \quad$ Nurse

$\square \quad$ Physician assistant

$\square$ Physical therapist

$\square$ Certified Athletic trainer

$\square \quad$ No one

$\square$ Other

23. Did any of your outside of work (recreational) activity injuries while a tactical officer cause you to miss work as a tactical officer?

$\square$ Yes

$\square$ No 
24. If so, approximately how many weeks of work have you missed related to injuries that you sustained during outside of work (recreational) activities?

$\square \quad$ None

$\square \quad$ Less than 1 week

2-6 weeks

7-12 weeks

$\square \quad$ More than 12 weeks

Thank you very much for your participation in this study 


\section{APPENDIX D}

\section{ADDITIONAL RESULTS}

Table D1. Pre-Tactical Officer Employment Injuries

\begin{tabular}{llllllllllllllllllllll}
\hline & 1 & 2 & 3 & 4 & 5 & 6 & 7 & 8 & 9 & 10 & 11 & 12 & 13 & 14 & 15 & 16 & 17 & 18 & 19 & 20 & $\mathrm{~T}$ \\
\hline Ligament Sprain & 1 & $\mathbf{6}$ & 1 & 1 & 1 & - & 1 & - & - & - & - & - & - & - & - & - & - & - & - & 2 & $\mathbf{1 3}$ \\
Muscle Strain & $\mathbf{6}$ & 1 & 1 & - & 1 & - & - & - & - & - & - & - & - & - & - & - & - & - & - & - & $\mathbf{9}$ \\
Fracture & $\mathbf{5}$ & 1 & - & 1 & - & - & - & - & - & - & - & - & - & - & - & - & - & - & - & - & $\mathbf{7}$ \\
Dislocation & 3 & - & - & - & 1 & - & - & - & 1 & - & - & - & - & - & - & - & - & - & - & - & 5 \\
Tendinitis & 2 & 2 & 1 & - & - & - & - & - & - & - & - & - & - & - & - & - & - & - & - & - & 5 \\
Tear/Rupture & $\mathbf{4}$ & 2 & 1 & - & - & - & - & - & - & - & - & - & - & - & - & - & - & - & - & - & $\mathbf{7}$ \\
Vertebral Disc & $\mathbf{4}$ & 1 & - & - & - & - & - & - & - & - & - & - & - & - & - & - & - & - & - & - & 5 \\
Contusion & - & - & 2 & 1 & - & - & - & - & - & 1 & - & - & - & - & - & - & - & - & - & - & 4 \\
Impingement & 1 & - & - & - & - & - & - & - & - & - & - & - & - & - & - & - & - & - & - & - & 1 \\
Laceration & 3 & - & 1 & 1 & - & - & - & - & - & - & - & - & - & - & - & - & - & - & - & - & 5 \\
Burn & 1 & 1 & - & - & - & - & - & - & - & - & - & - & - & - & - & - & - & - & - & - & 2 \\
General & 3 & 2 & 3 & - & - & - & - & - & - & - & - & - & - & - & - & - & - & - & - & - & $\mathbf{8}$ \\
Pain/Discomfort & & & & & & & & & & & & & & & & & & & & & \\
\hline
\end{tabular}

*Numbers in bold are the most commonly reported. $\mathrm{T}=$ total number of injuries reported per row

Table D2. Work Related Injuries

\begin{tabular}{lllllllllllllllllllllll}
\hline & 1 & 2 & 3 & 4 & 5 & 6 & 7 & 8 & 9 & 10 & 11 & 12 & 13 & 14 & 15 & 16 & 17 & 18 & 19 & 20 & $\mathrm{~T}$ \\
\hline Ligament Sprain & $\mathbf{8}$ & 2 & 2 & 1 & - & - & - & - & - & - & - & - & - & - & - & - & - & - & - & 1 & $\mathbf{1 4}$ \\
Muscle Strain & $\mathbf{8}$ & 3 & 3 & 2 & 1 & - & - & - & - & - & - & - & - & - & - & - & - & - & - & - & $\mathbf{1 7}$ \\
Fracture & $\mathbf{6}$ & 1 & - & - & - & - & - & - & - & - & - & - & - & - & - & - & - & - & - & - & 7 \\
Dislocation & 3 & 2 & - & - & - & - & - & - & - & - & - & - & - & - & - & - & - & - & - & - & 5 \\
Tendinitis & 2 & 2 & 1 & - & - & - & - & - & - & - & - & - & - & - & - & - & - & - & - & 1 & 6 \\
Tear/Rupture & $\mathbf{7}$ & 3 & - & - & - & - & - & - & - & - & - & - & - & - & - & - & - & - & - & - & $\mathbf{1 0}$ \\
Vertebral Disc & $\mathbf{6}$ & - & 1 & 1 & - & - & - & - & - & - & - & - & - & - & - & - & - & - & - & - & 8 \\
Contusion & 3 & 2 & - & 1 & - & - & - & 1 & - & 2 & - & - & - & - & - & - & - & - & - & - & 9 \\
Impingement & 1 & - & - & - & - & - & - & - & - & - & - & - & - & - & - & - & - & - & - & - & 1 \\
Laceration & $\mathbf{6}$ & 2 & 2 & 1 & - & - & - & - & - & - & - & - & - & - & - & - & - & - & - & - & $\mathbf{1 1}$ \\
Burn & 2 & - & - & - & - & - & - & - & - & - & - & - & - & - & - & - & - & - & - & - & 2 \\
General & 3 & 4 & 1 & - & 1 & - & - & - & - & - & - & - & - & - & - & - & - & - & - & 1 & $\mathbf{1 0}$ \\
Pain/Discomfort & & & & & & & & & & & & & & & & & & & & & \\
\hline
\end{tabular}

*Numbers in bold are the most commonly reported. $\mathrm{T}=$ total number of injuries reported per row 
Table D3. Outside of Work Injuries (Recreational)

\begin{tabular}{lllllllllllllllllllllll}
\hline & 1 & 2 & 3 & 4 & 5 & 6 & 7 & 8 & 9 & 10 & 11 & 12 & 13 & 14 & 15 & 16 & 17 & 18 & 19 & 20 & $\mathrm{~T}$ \\
\hline Ligament Sprain & 3 & 4 & - & - & 1 & - & - & - & - & - & - & - & - & - & - & - & - & - & - & 1 & $\mathbf{9}$ \\
Muscle Strain & $\mathbf{7}$ & $\mathbf{5}$ & 2 & - & - & - & - & - & - & - & - & - & - & - & - & - & - & - & - & - & $\mathbf{1 4}$ \\
Fracture & 3 & 2 & - & - & - & - & - & - & - & - & - & - & - & - & - & - & - & - & - & - & 5 \\
Dislocation & 5 & - & - & - & - & - & - & - & - & - & - & - & - & - & - & - & - & - & - & - & 5 \\
Tendinitis & 3 & 2 & - & - & - & - & - & - & - & - & - & - & - & - & - & - & - & - & - & 1 & $\mathbf{6}$ \\
Tear/Rupture & $\mathbf{5}$ & 2 & - & - & - & - & - & - & - & - & - & - & - & - & - & - & - & - & - & - & $\mathbf{7}$ \\
Vertebral Disc & 2 & - & - & 1 & - & - & - & - & - & - & - & - & - & - & - & - & - & - & - & - & 3 \\
Contusion & 1 & 3 & - & - & - & - & - & - & - & 1 & - & - & - & - & - & - & - & - & - & - & 5 \\
Impingement & - & - & - & - & - & - & - & - & - & - & - & - & - & - & - & - & - & - & - & - & 0 \\
Laceration & 2 & 2 & - & 1 & - & - & - & - & - & - & - & - & - & - & - & - & - & - & - & - & 5 \\
Burn & - & - & - & 1 & - & - & - & - & - & - & - & - & - & - & - & - & - & - & - & - & 1 \\
General & 3 & 2 & - & - & - & - & - & - & - & - & - & - & - & - & - & - & - & - & - & 1 & $\mathbf{6}$ \\
Pain/Discomfort & & & & & & & & & & & & & & & & & & & & & \\
\hline
\end{tabular}

*Numbers in bold are the most commonly reported. $\mathrm{T}=$ total number of injuries reported per row

Figure D1. Role within Tactical Team

What is your role within your tactical team?

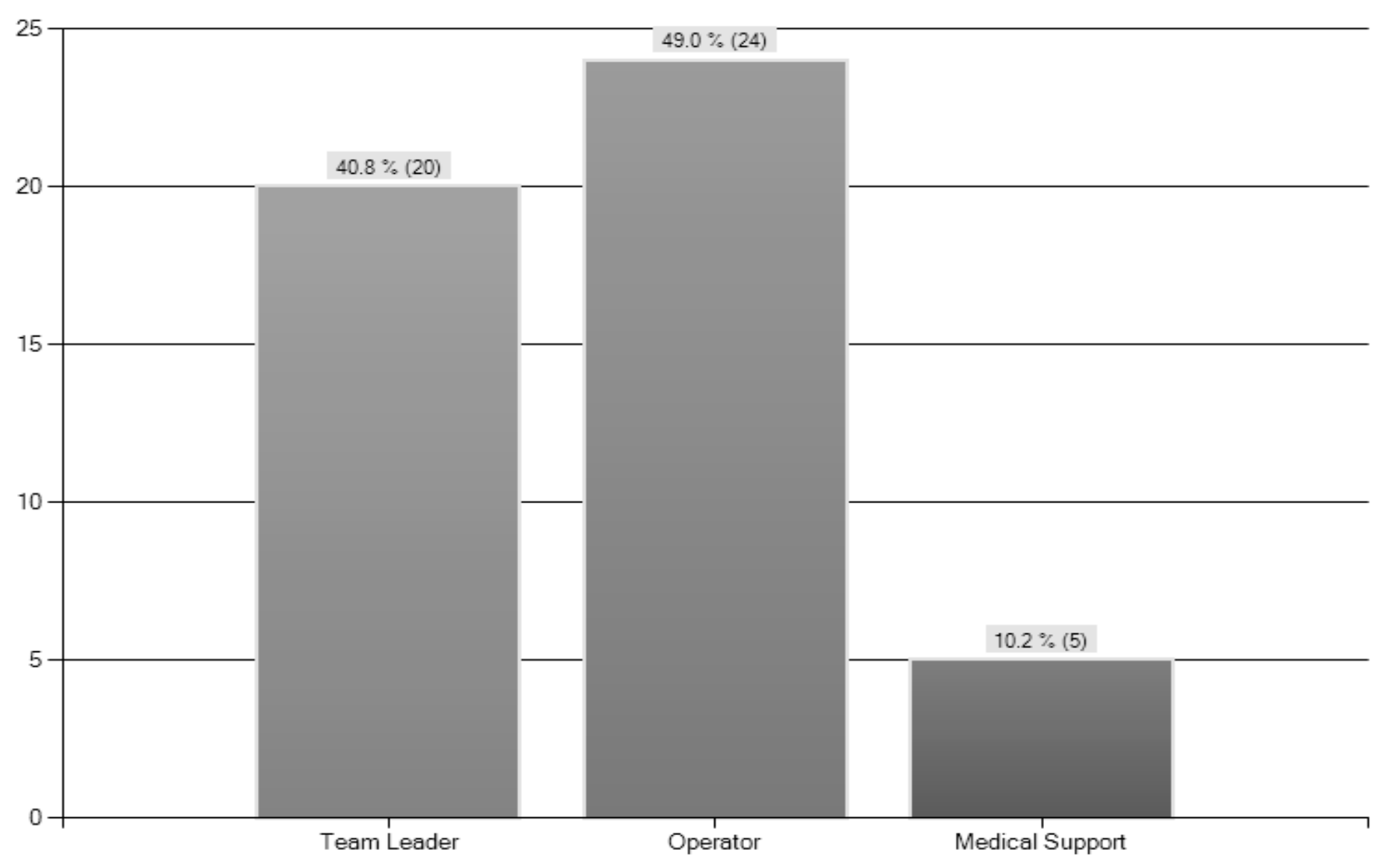


Figure D2. Employment Status

Please indicate your employment status as a tactical officer.

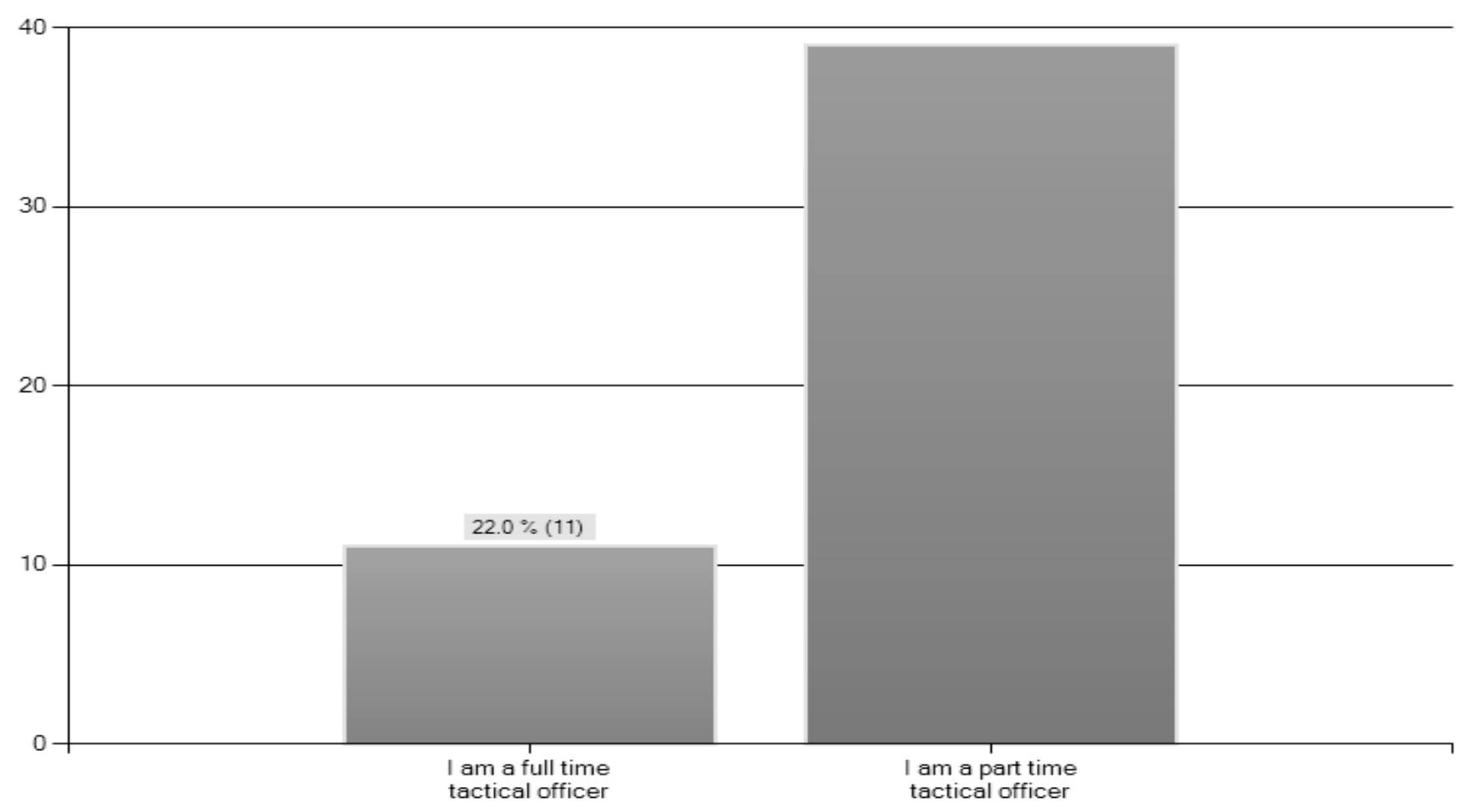

Figure D3. Years of Employment

How many years have you been employed as a tactical officer?

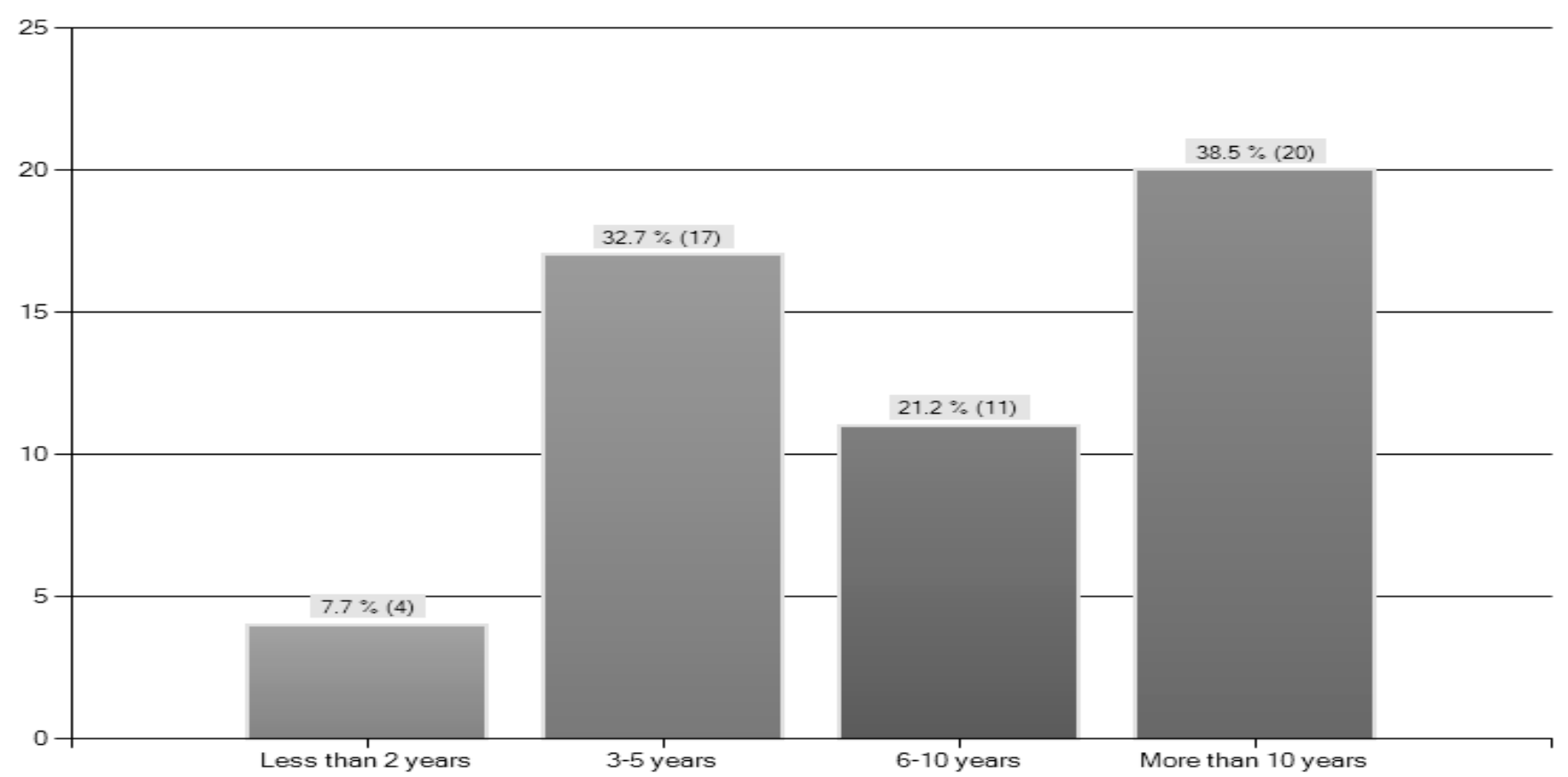


Figure D4. Hours Spent on Call Outs per Week

On average, how many hours per week do you spend on call outs?

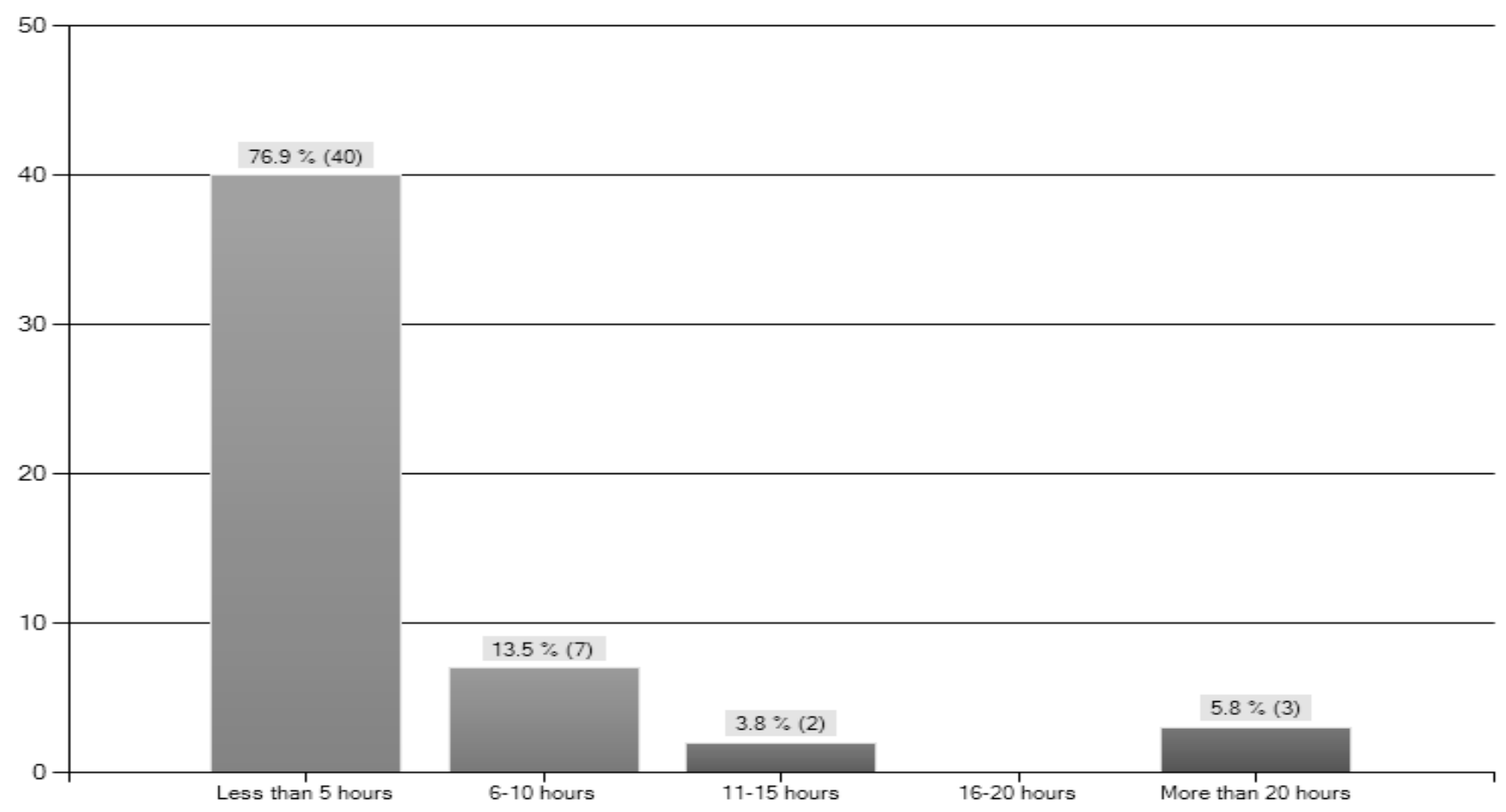

Figure D5. Hours Spent Training per Week

How many hours per week do you spend training for tactical operations?

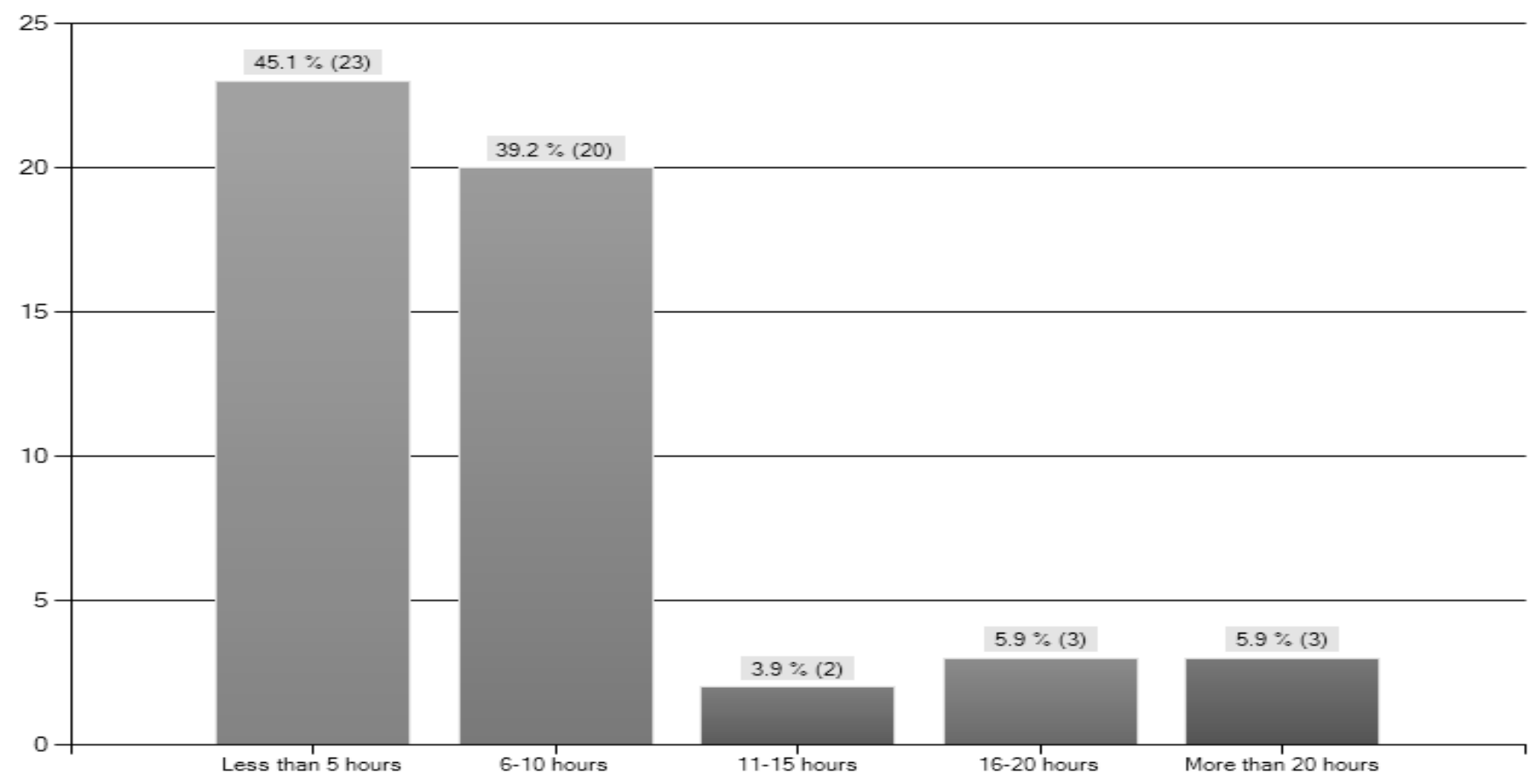


Figure D6. Tactical Emergency Medical Support (TEMS)

Does your tactical unit employ a Tactical Emergency Medical Support (TEMS) system?

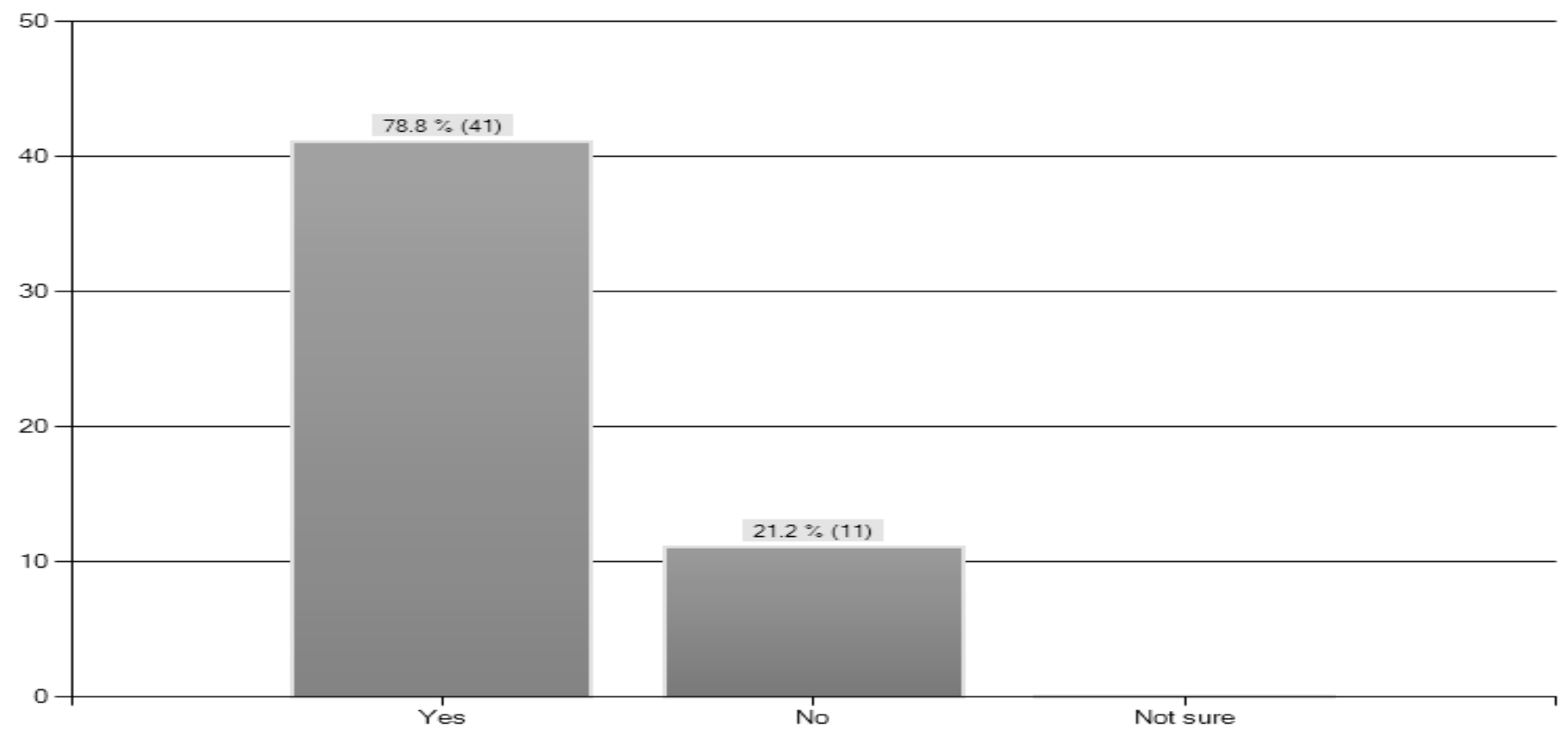

Figure D7. TEMS Personnel

If you answered yes to the previous question, who possesses the TEMS certification within your tactical team?

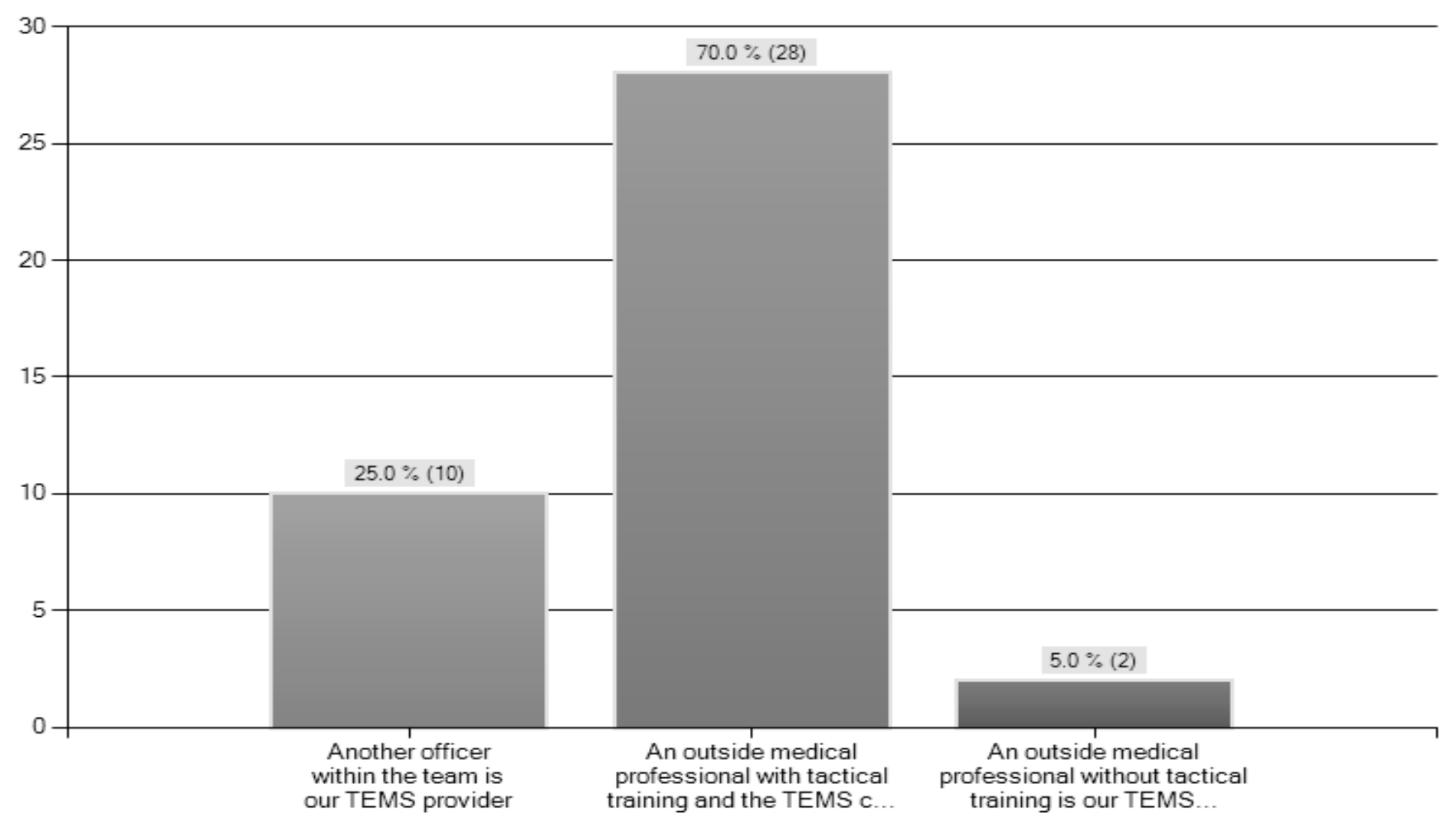


Figure D8. TEMS Time Commitment

If your team employs an outside medical professional with TEMS certification, how would you describe this person's time commitment to the tactical team?

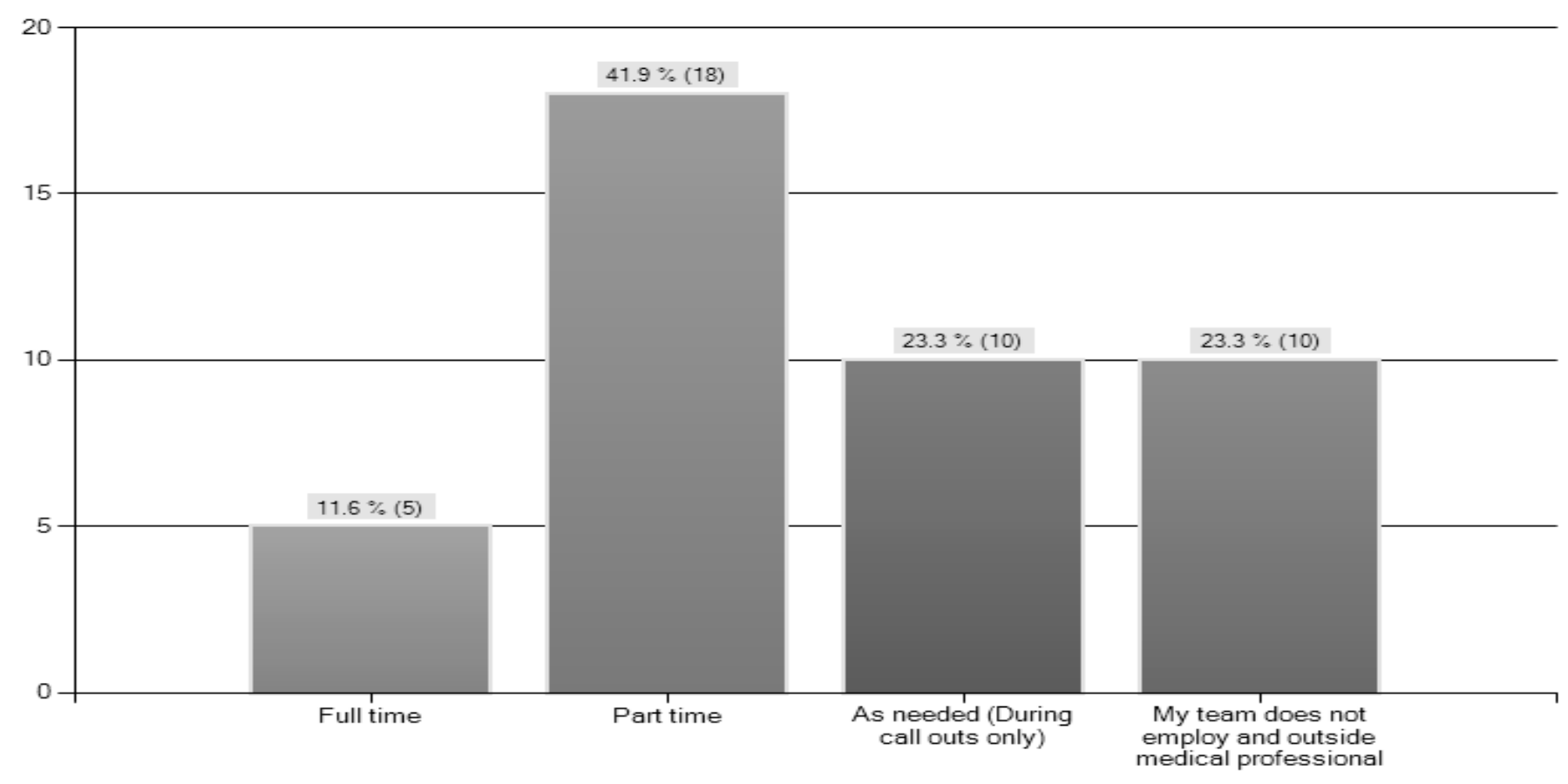

Figure D9. Medical Coverage Personnel

If you answered no to question \#7, who, if anyone, provides the medical coverage to your tactical unit? Check as many as apply.

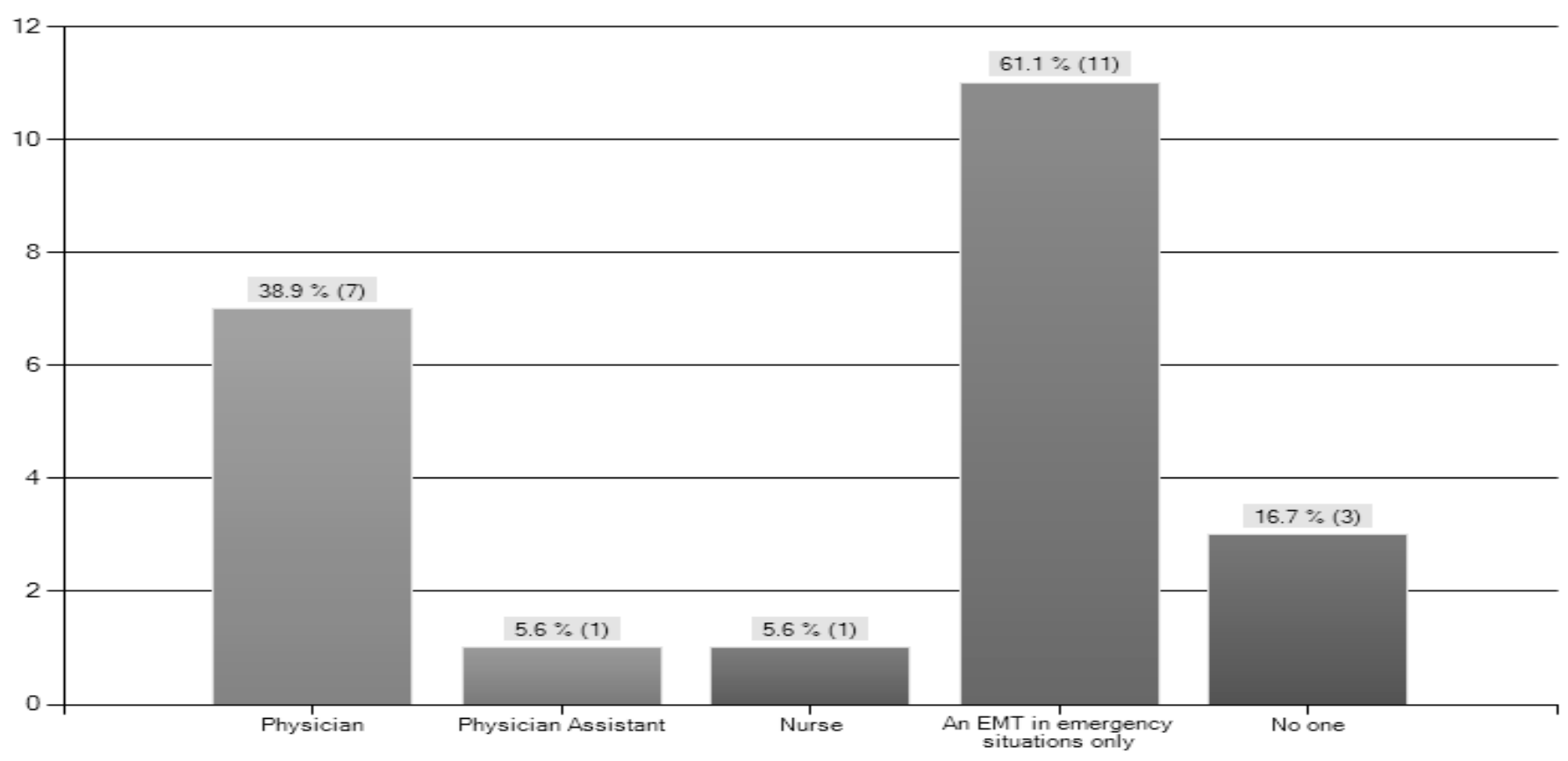


Figure D10. Medical Coverage Time Commitment

Based on your response to question \#10, how would you describe that medical professional's time commitment to the tactical team?

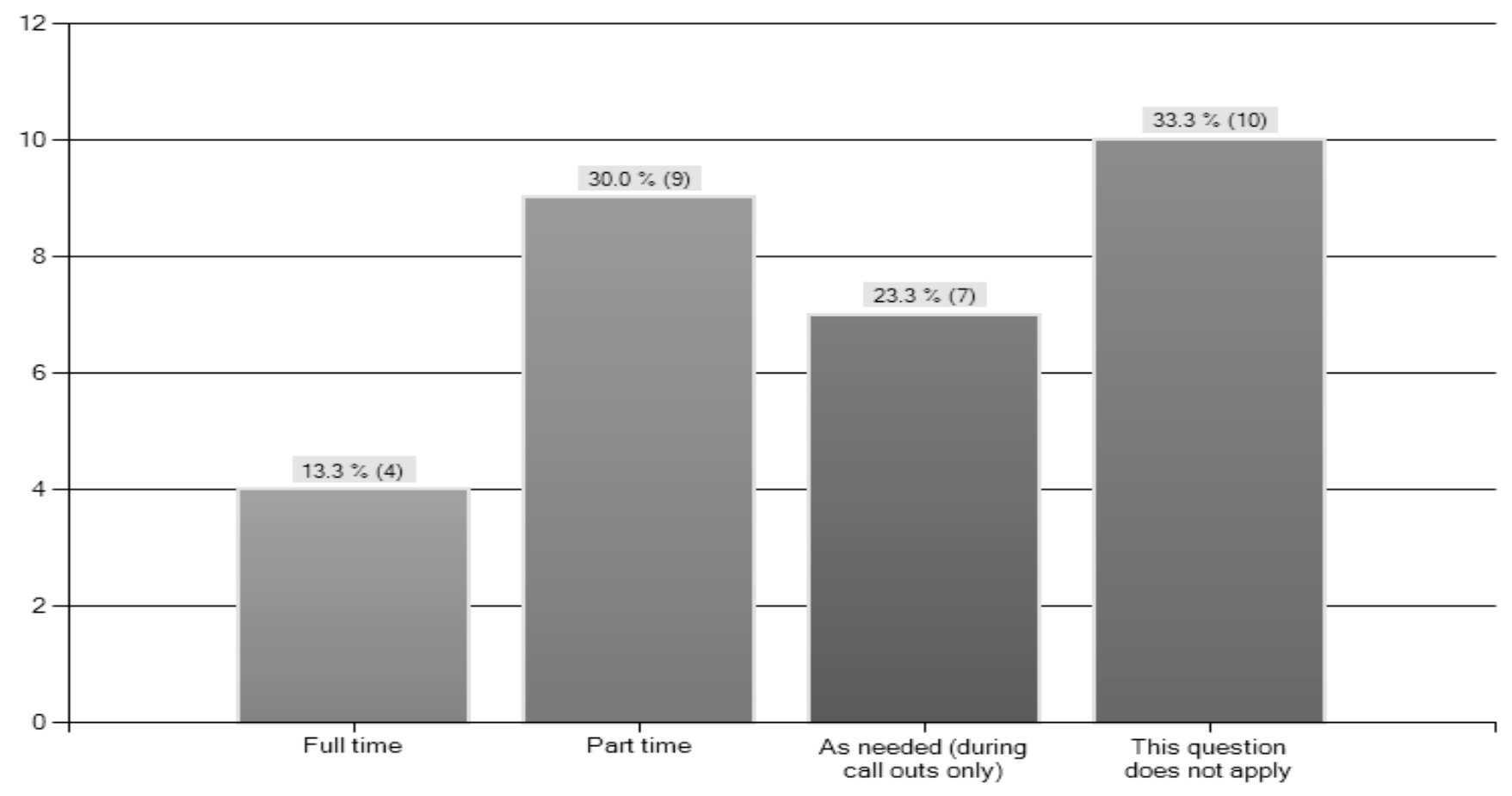

Figure D11. Pre-Employment Injuries

Do you have any pre-employment (before being employed as a tactical officer) musculoskeletal injuries (any trauma resulting in pain/injury to the bone, ligament, or muscle) that you feel are exacerbated by your work related activites?

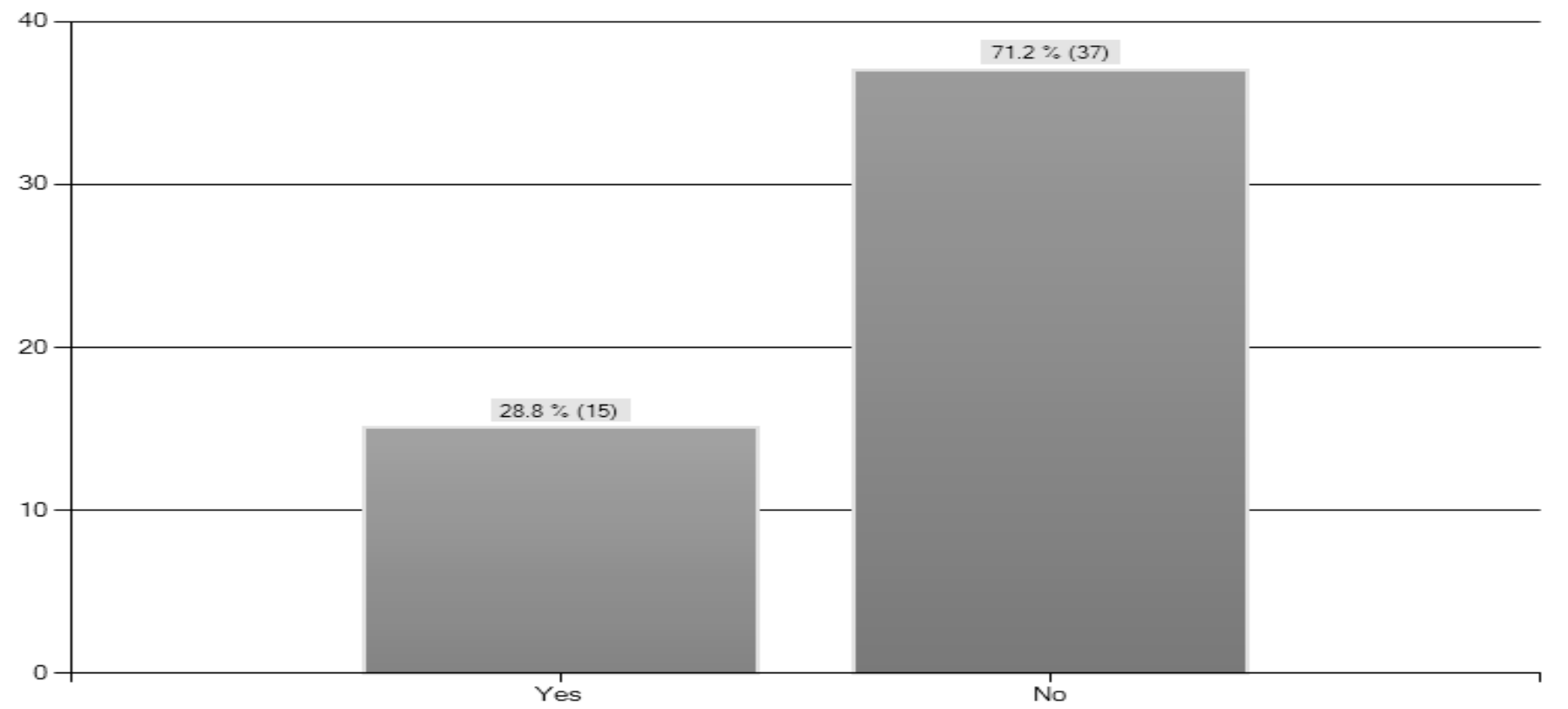


Figure D12. Work Related Injuries

Have you ever experienced a musculoskeletal injury (any trauma resulting in pain/injury to the bone, ligament, or muscle) as a result of being employed as a tactical officer?

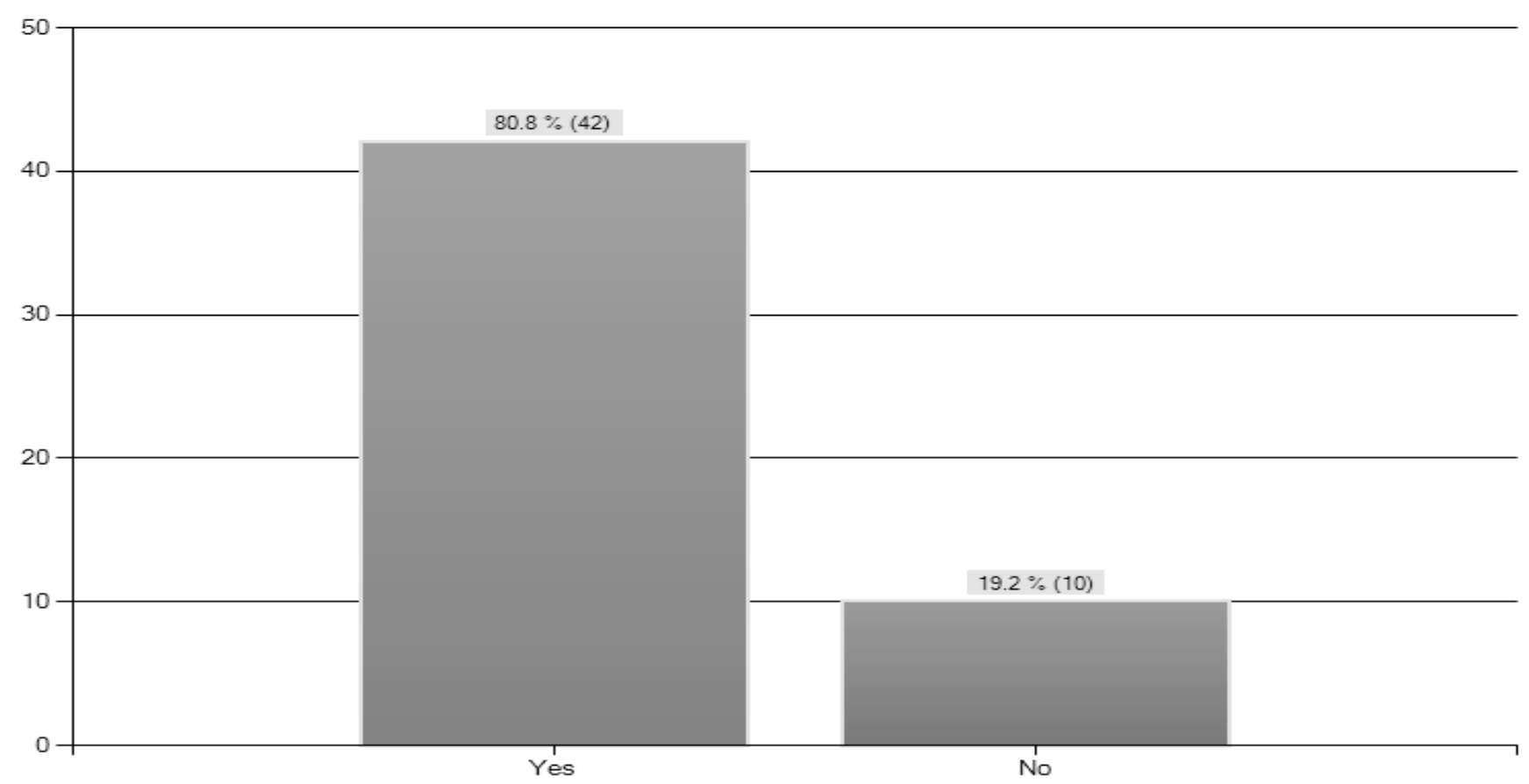

Figure D13. Outside of Work Injuries

Have you ever experienced a musculoskeletal injury (any trauma resulting in pain/injury to the bone, ligament, or muscle) outside of the workplace during the time you have been employed as a tactical officer? i.e. recreational activities on your own time.

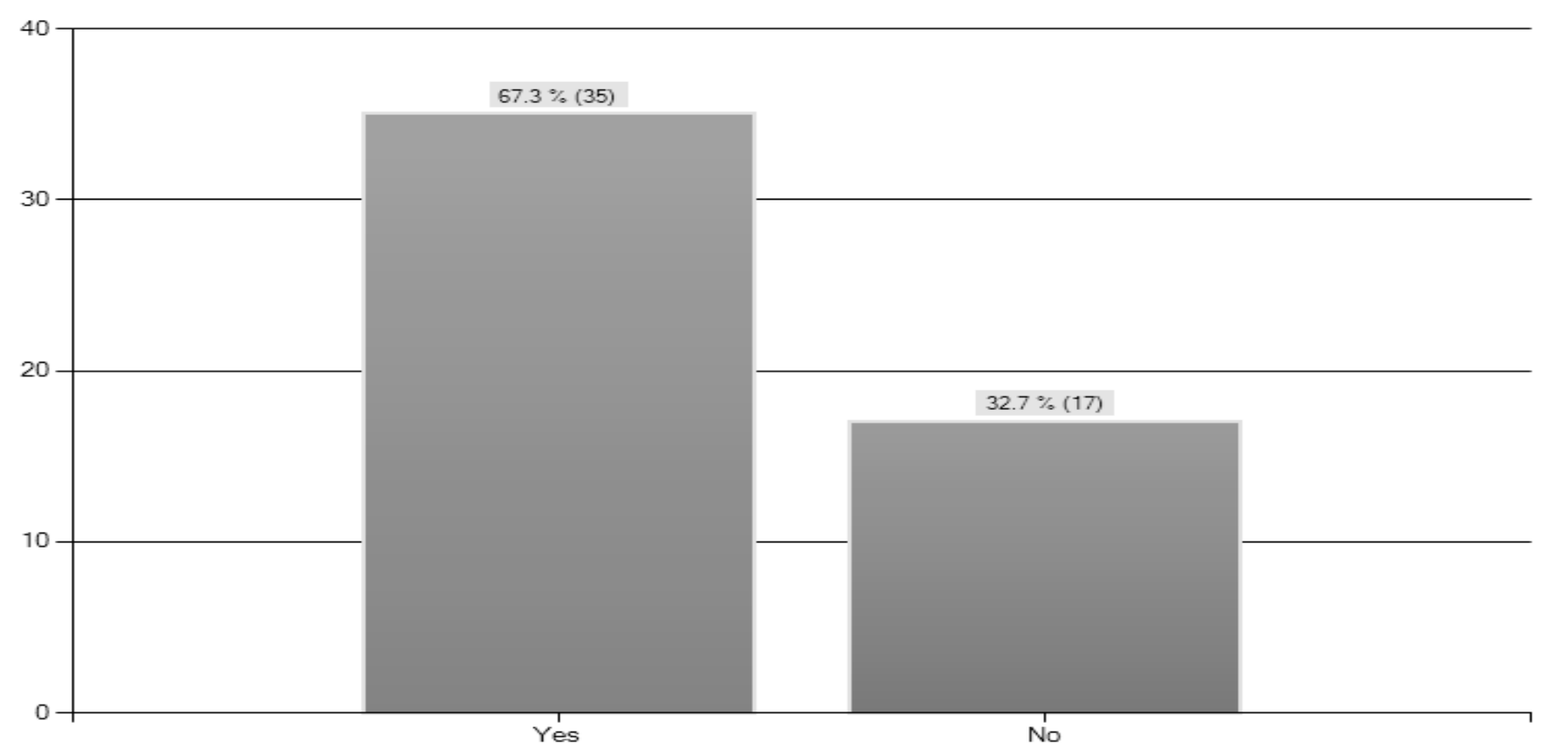


Figure D14. Ligament Sprain by Body Part

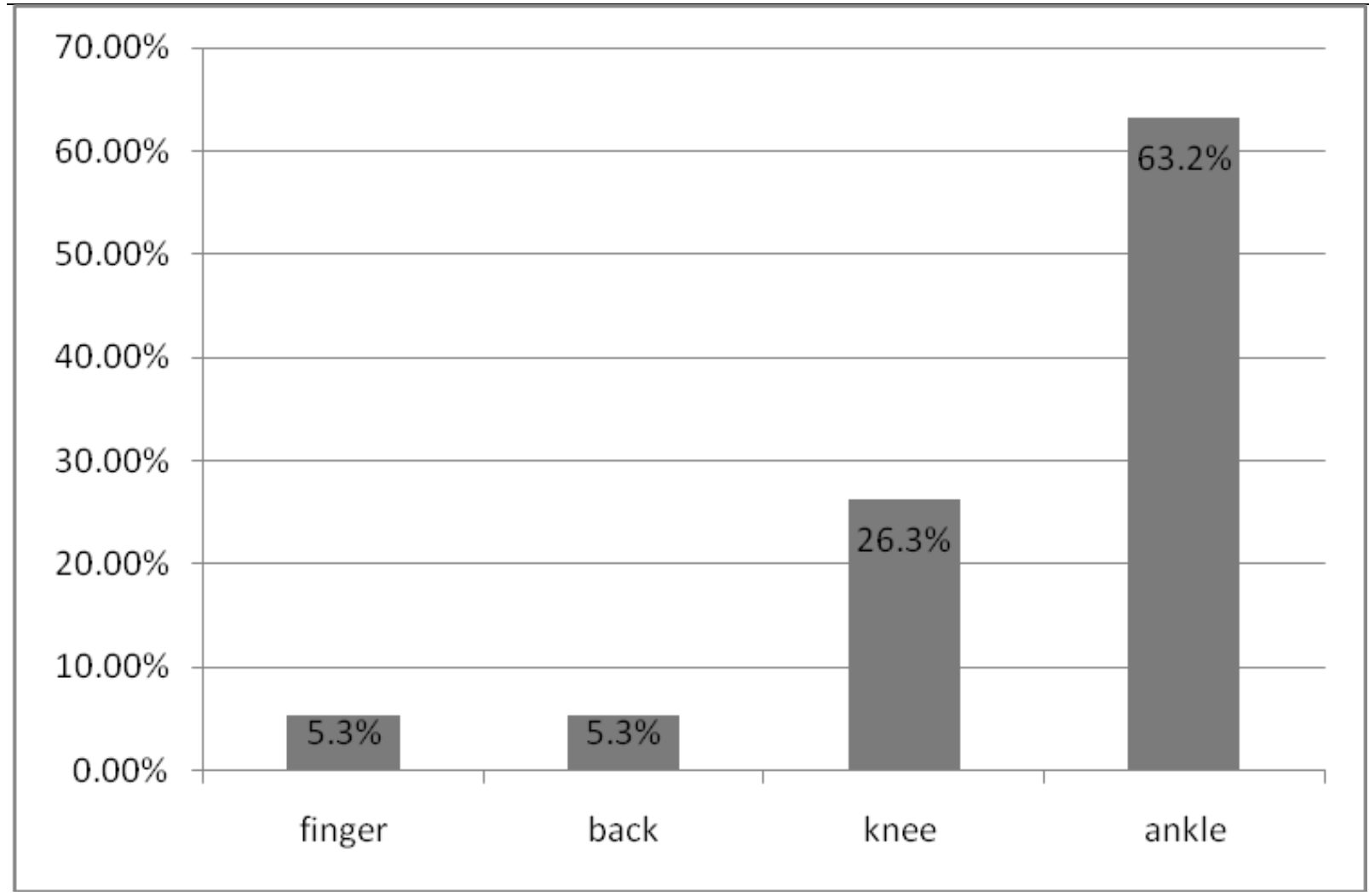

Figure D15. Muscle Strain by Body Part

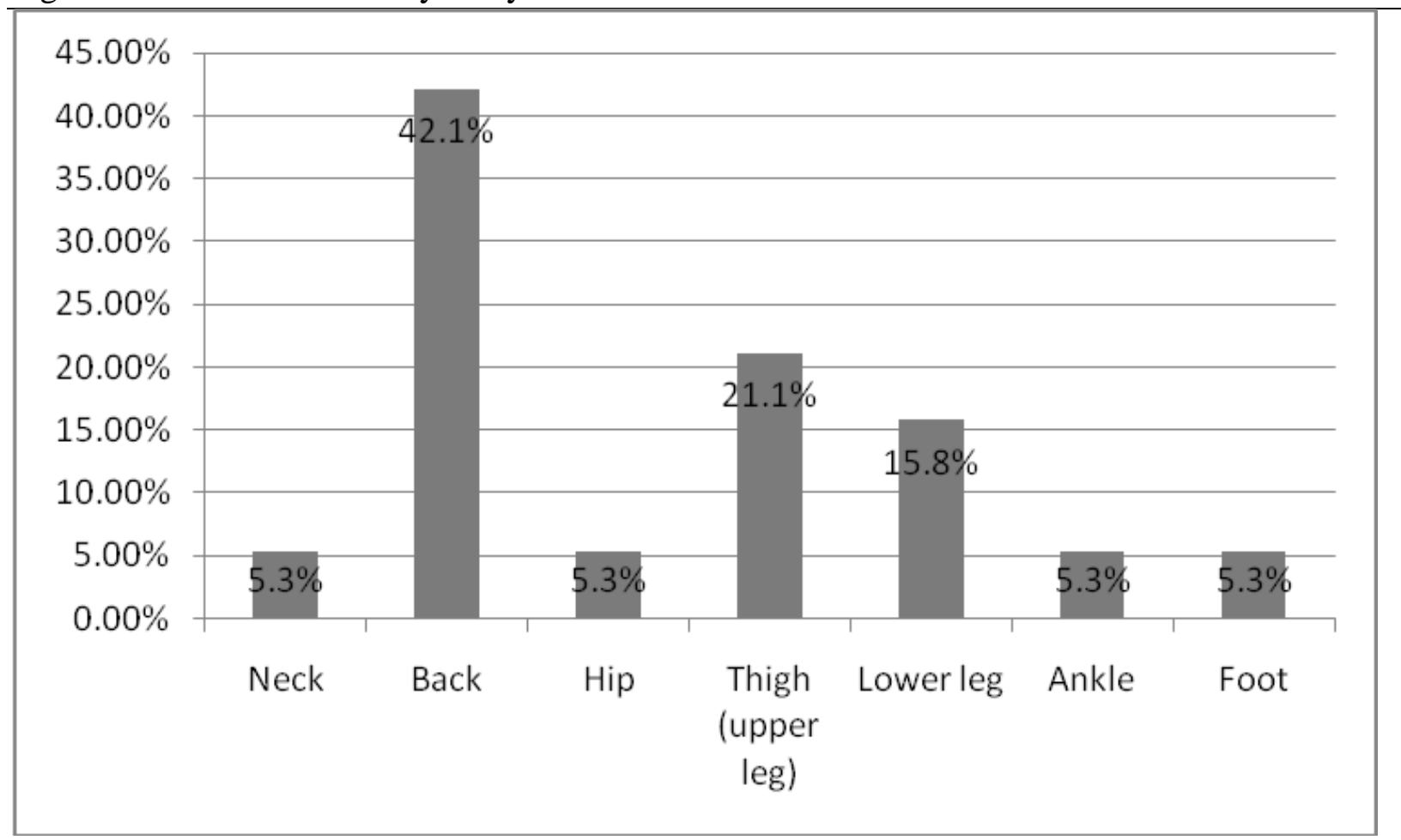


Figure D16. Fracture by Body Part

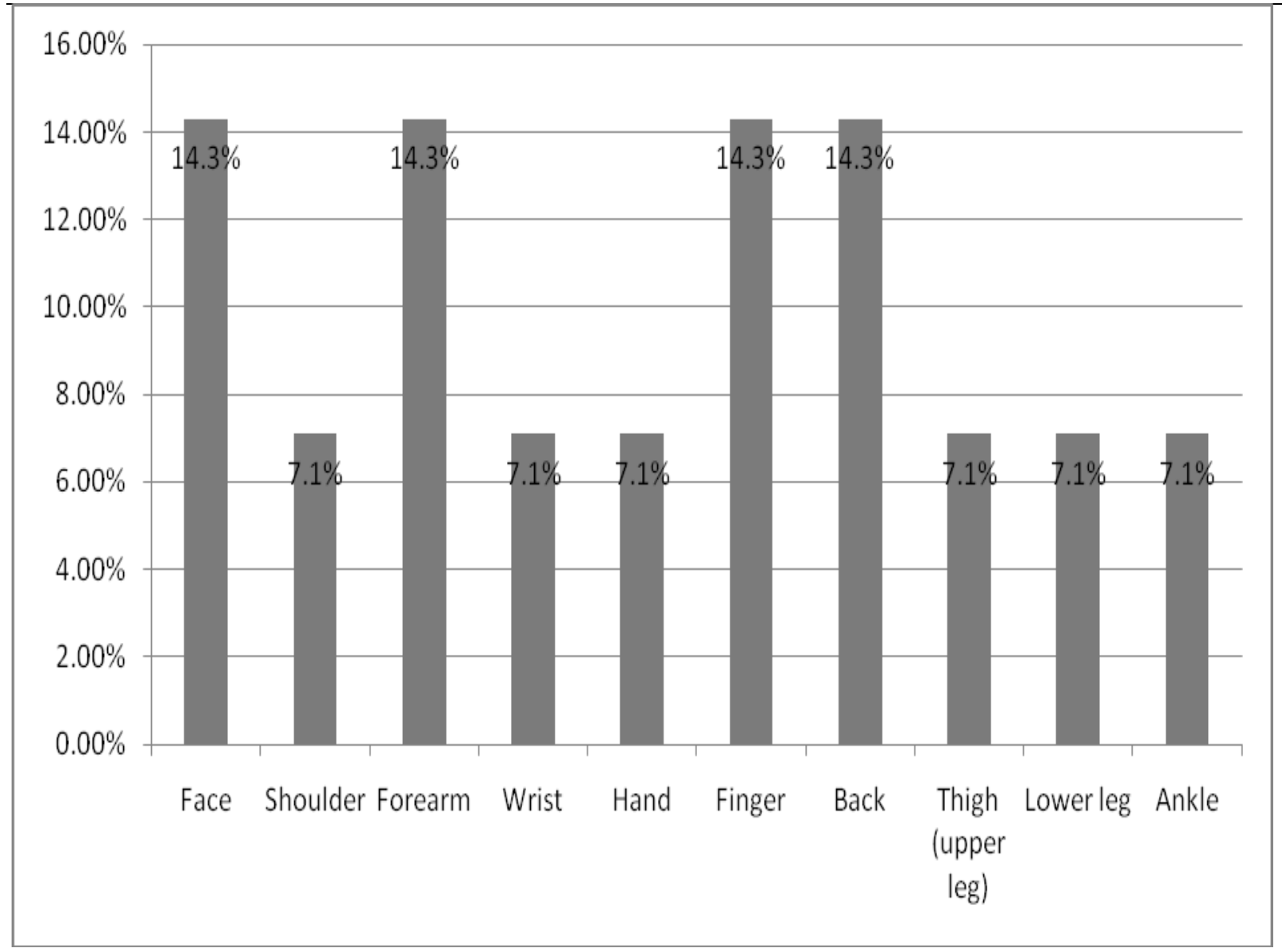

Figure D17. Dislocation by Body Part

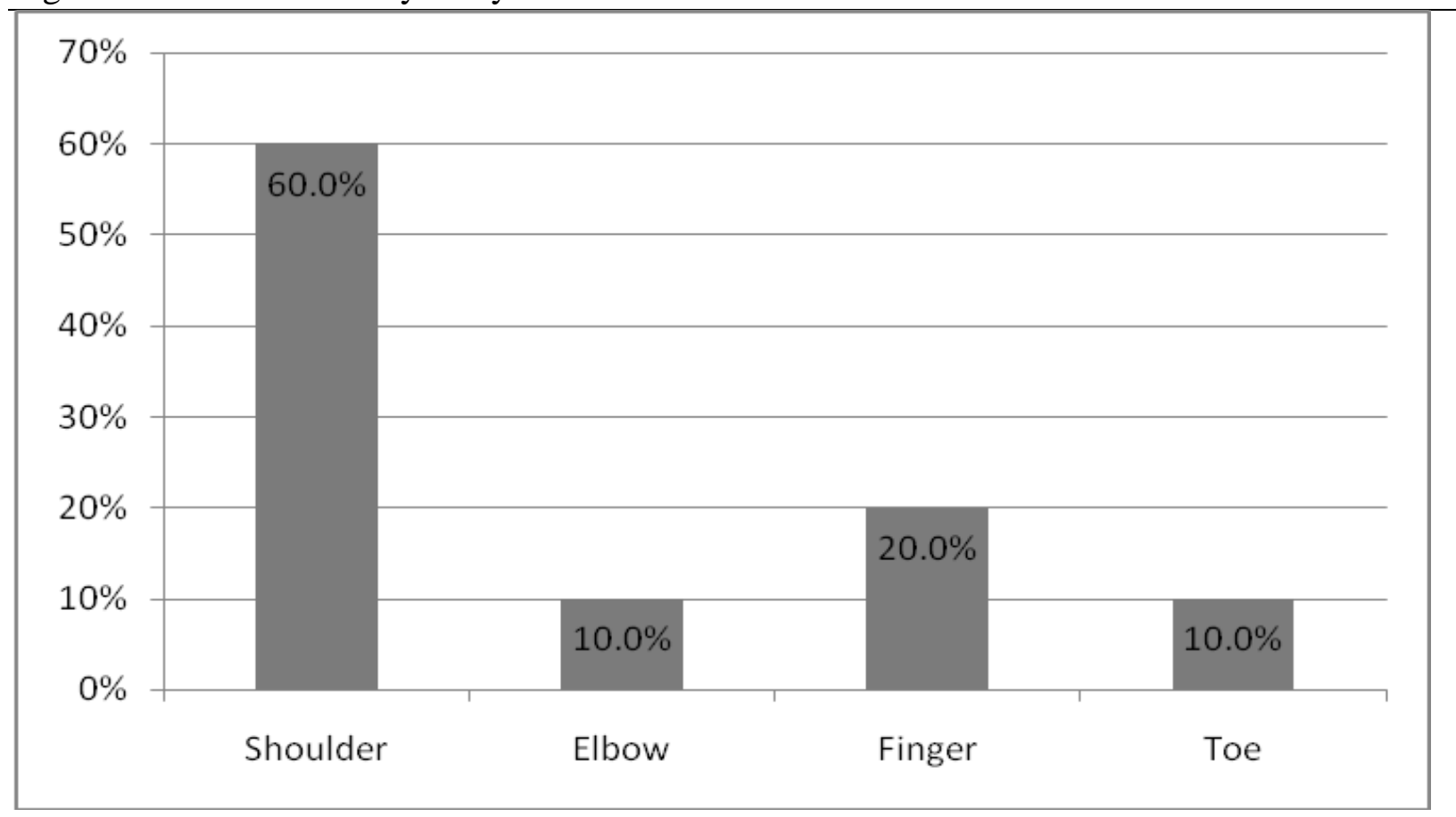


Figure D18. Tendinitis by Body Part

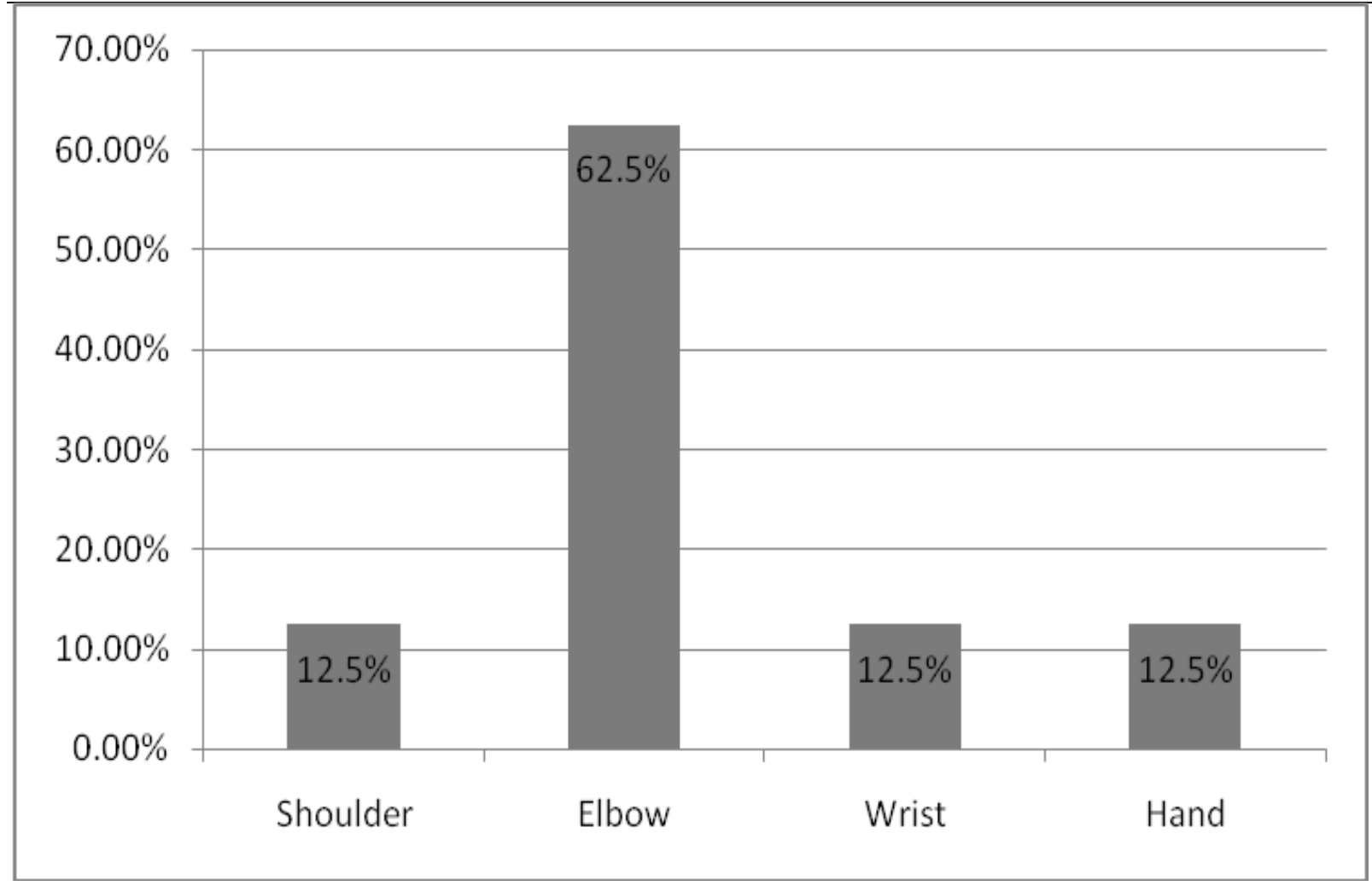

Figure D19. Tear/Rupture by Body Part

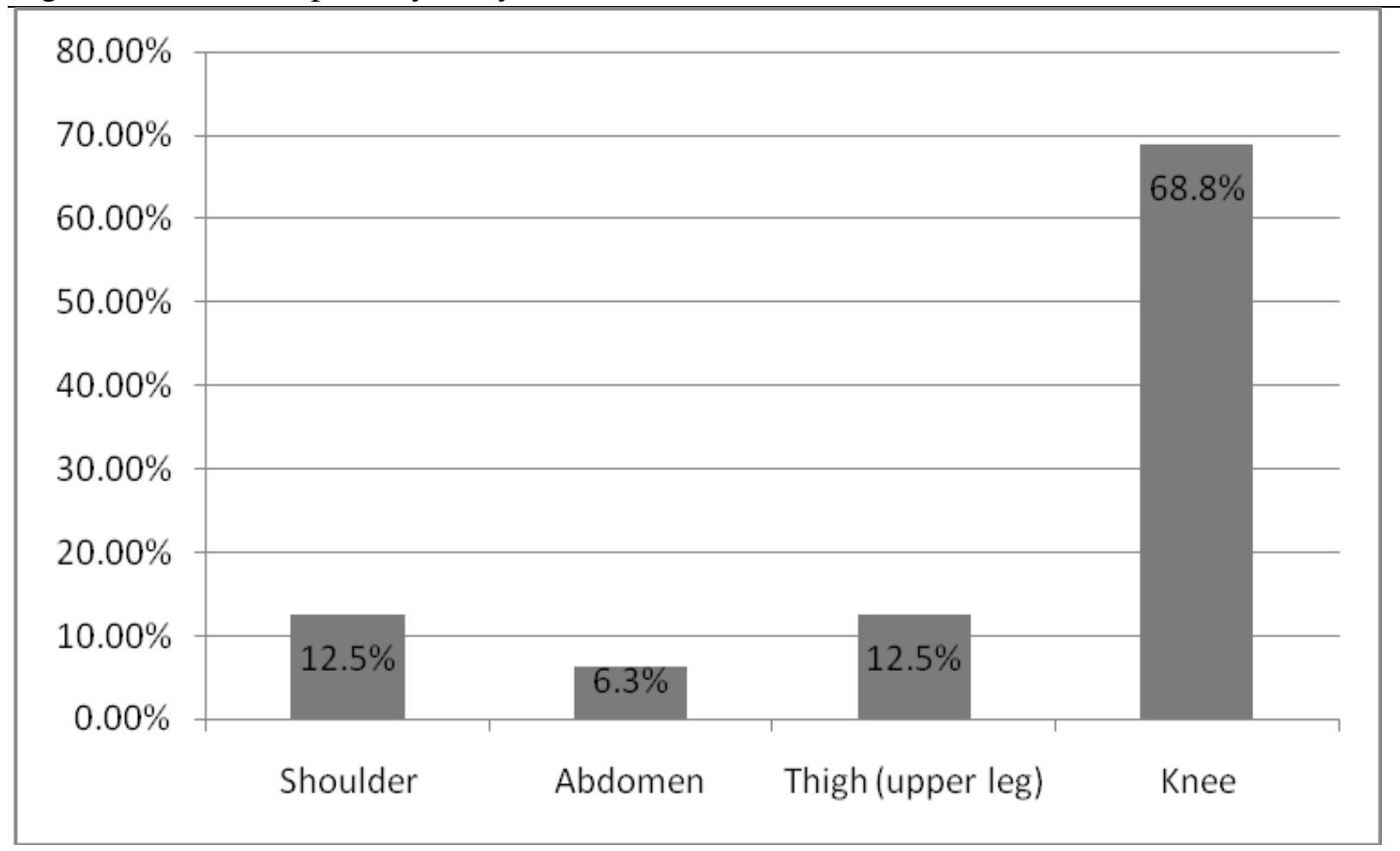


Figure D20. Vertebral Disc Involvement by Body Part

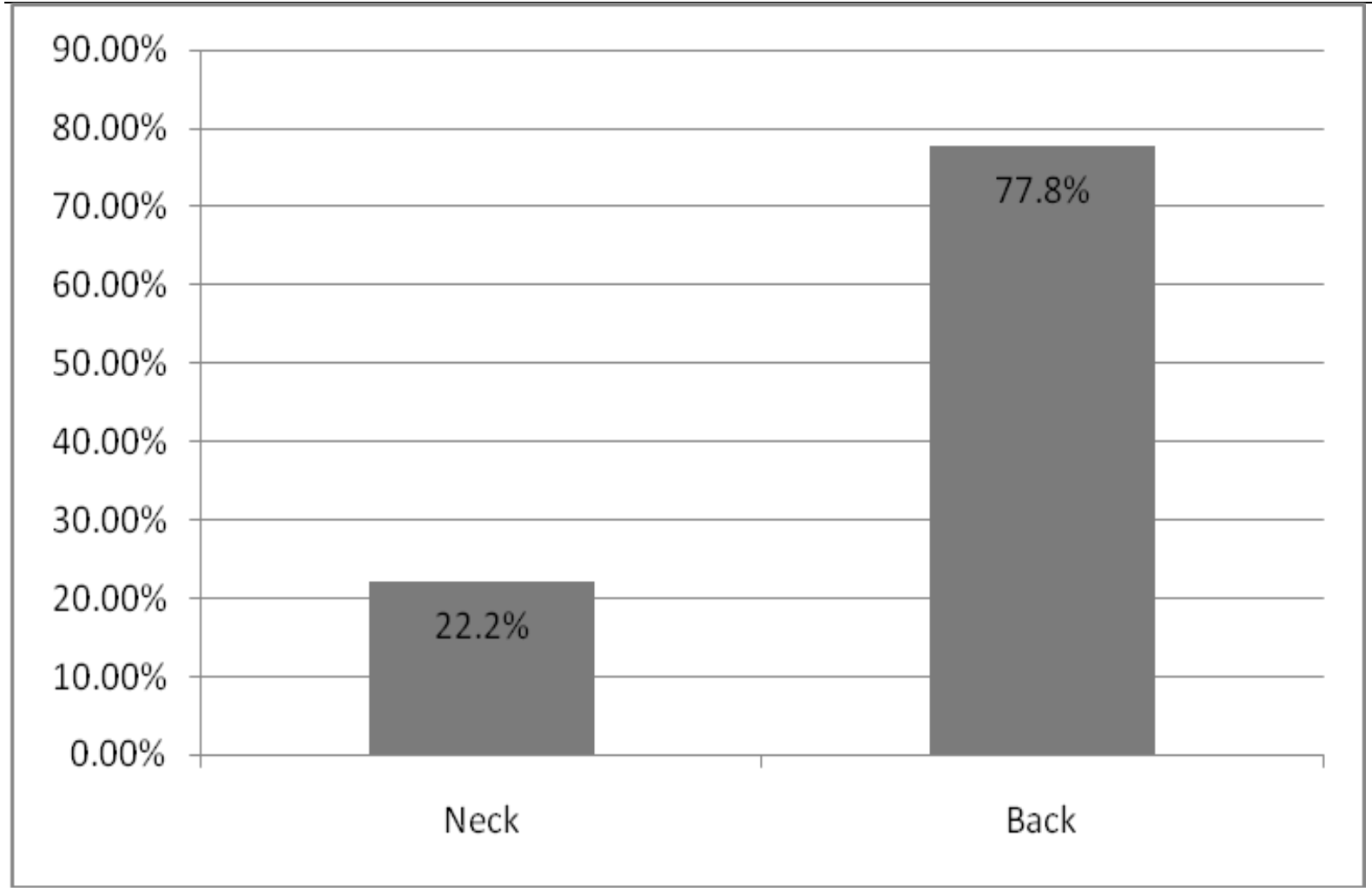

Figure D21. Contusion by Body Part

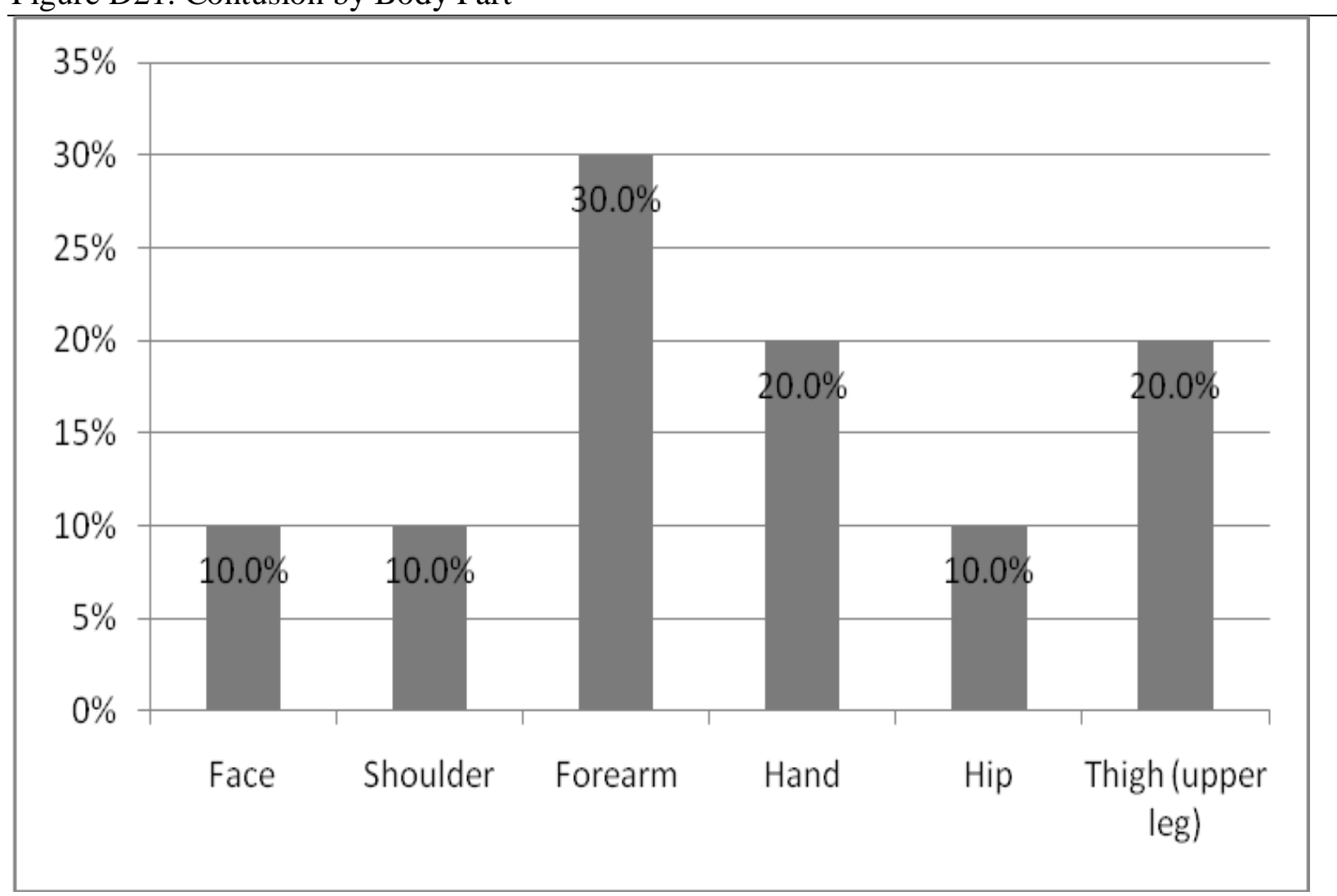


Figure D22. Laceration by Body Part

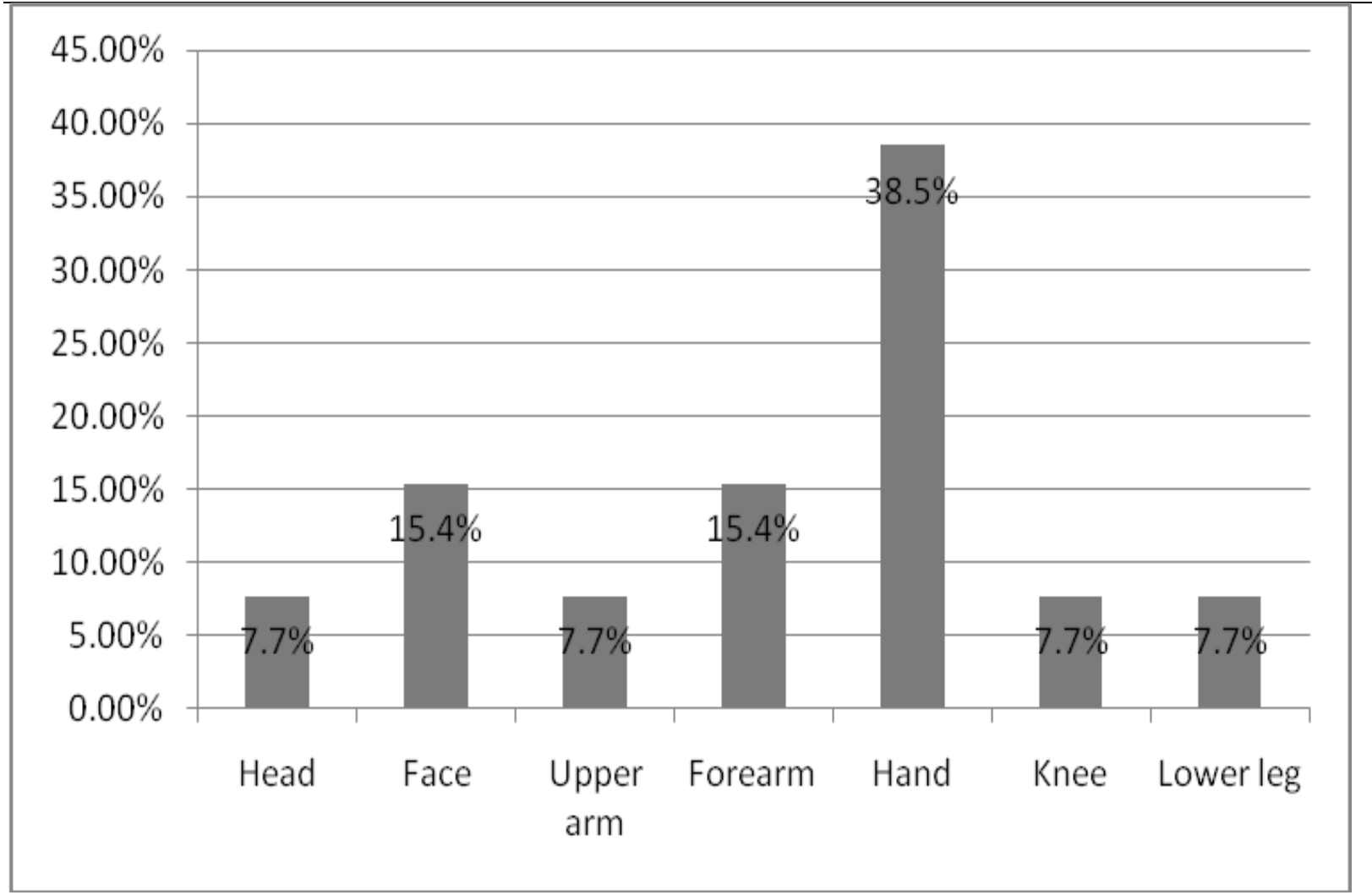

Figure D23. General Pain/Discomfort by Body Part

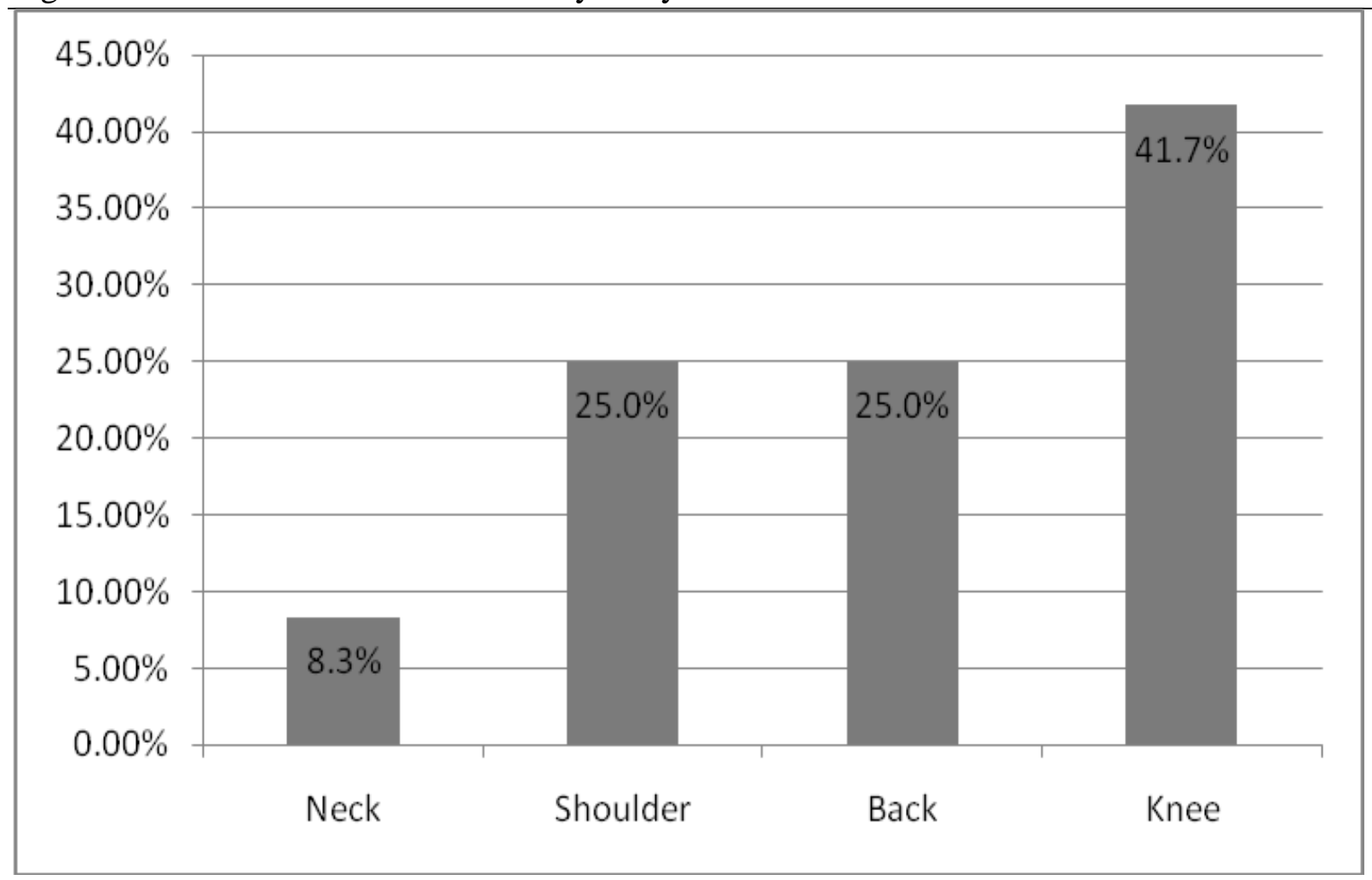


Figure D24. Pre-Employment Injury Medical Care

Of the injuries that you incurred prior to tactical officer employment,who was responsible for managing your injuries? Check all that apply.

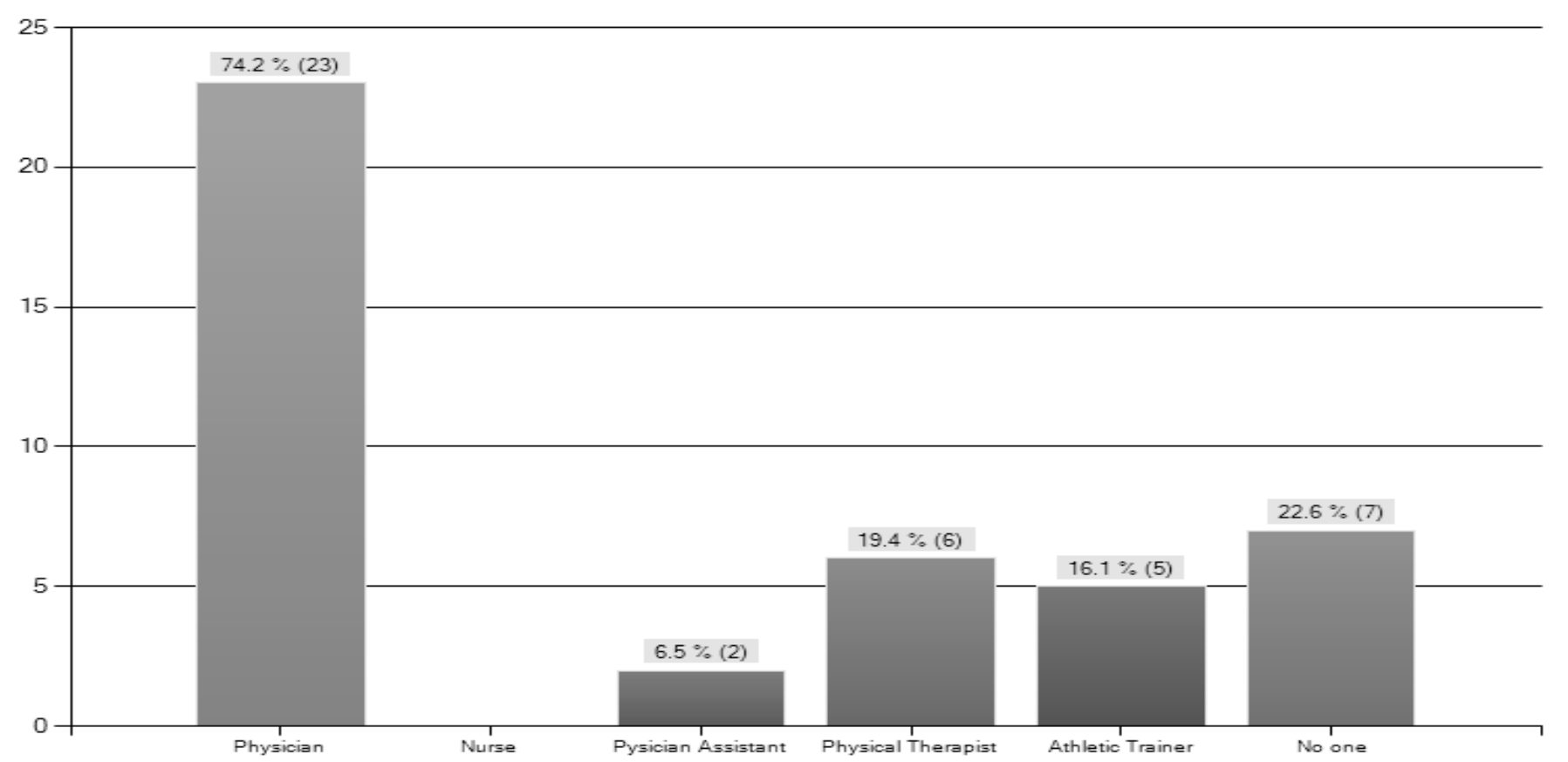

Figure D25. Time Lost Due to Pre-employment Injuries

Did any of the pre-tactical officer employment injuries cause you to miss work as a tactical officer?

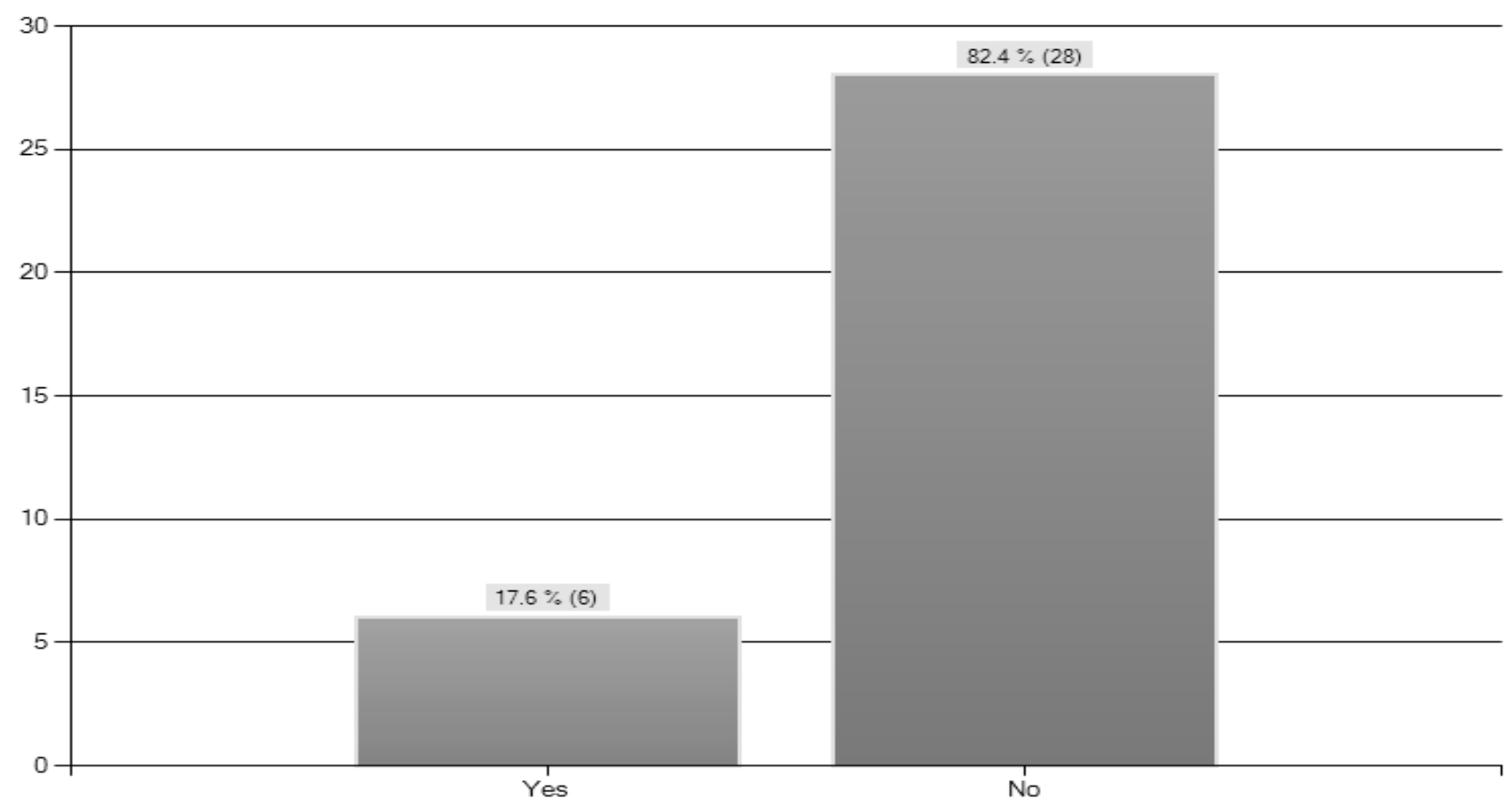


Figure D26. Weeks of Work Missed Due to Pre-Employment Injuries

If so, approximately how many weeks of work have you missed related to injuries that you sustained before you became a tactical officer?

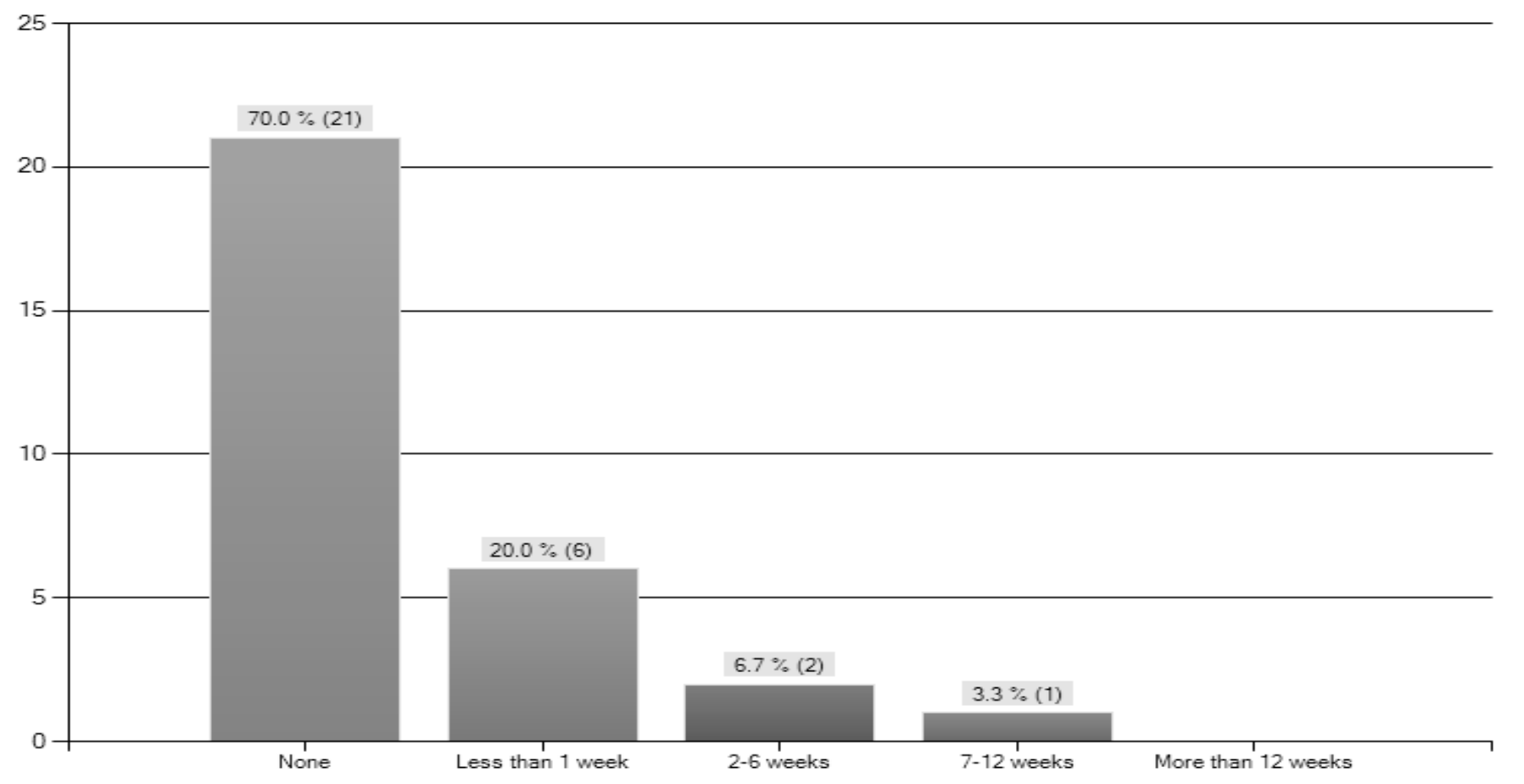

Figure D27. Work Related Injury Medical Care

Of the injuries that you incurred from work related activities, who was responsible for managing your injuries? Check all that apply.

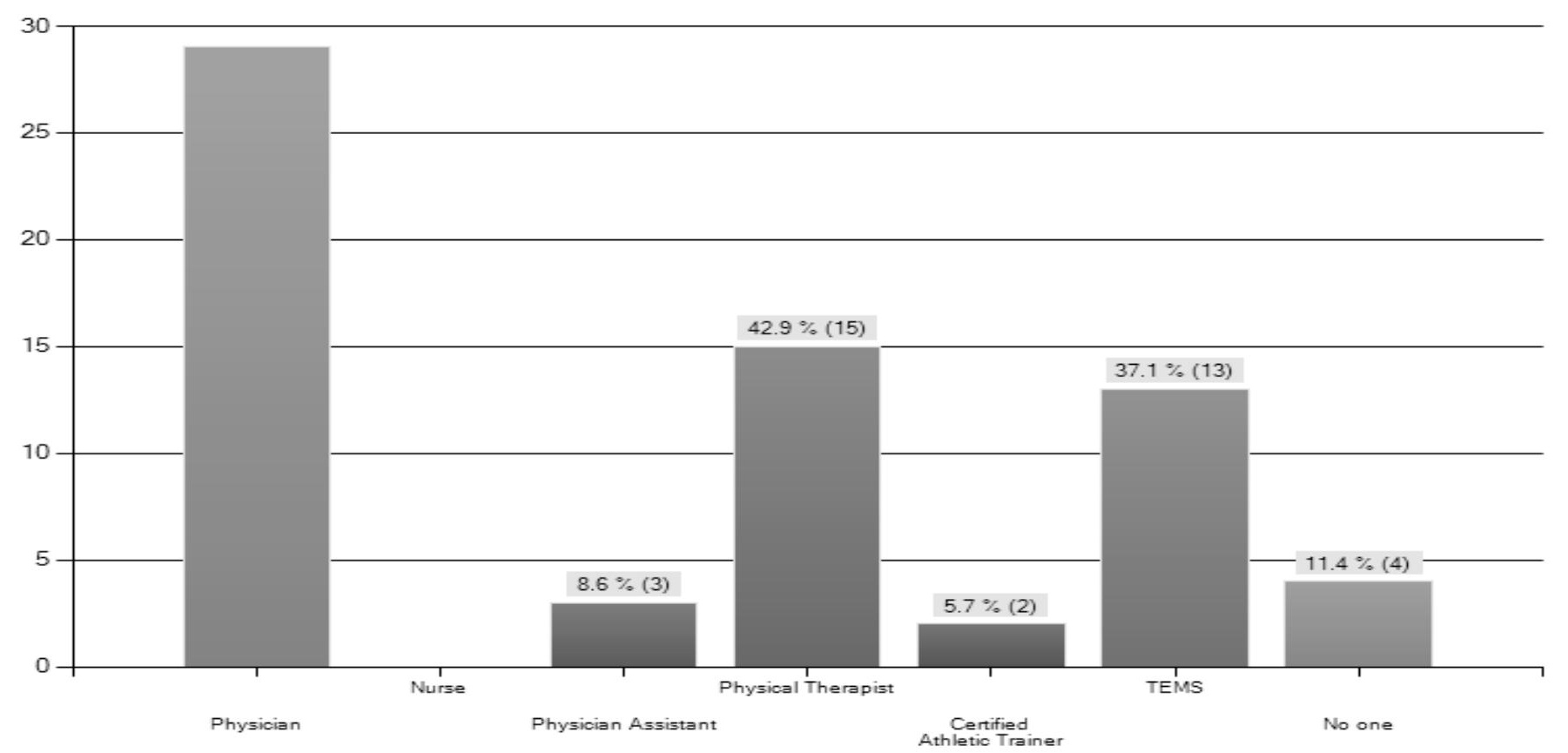


Figure D28. Time Lost Due to Work Related Injuries

Did any of the work related injuries cause you to miss work as a tactical officer?

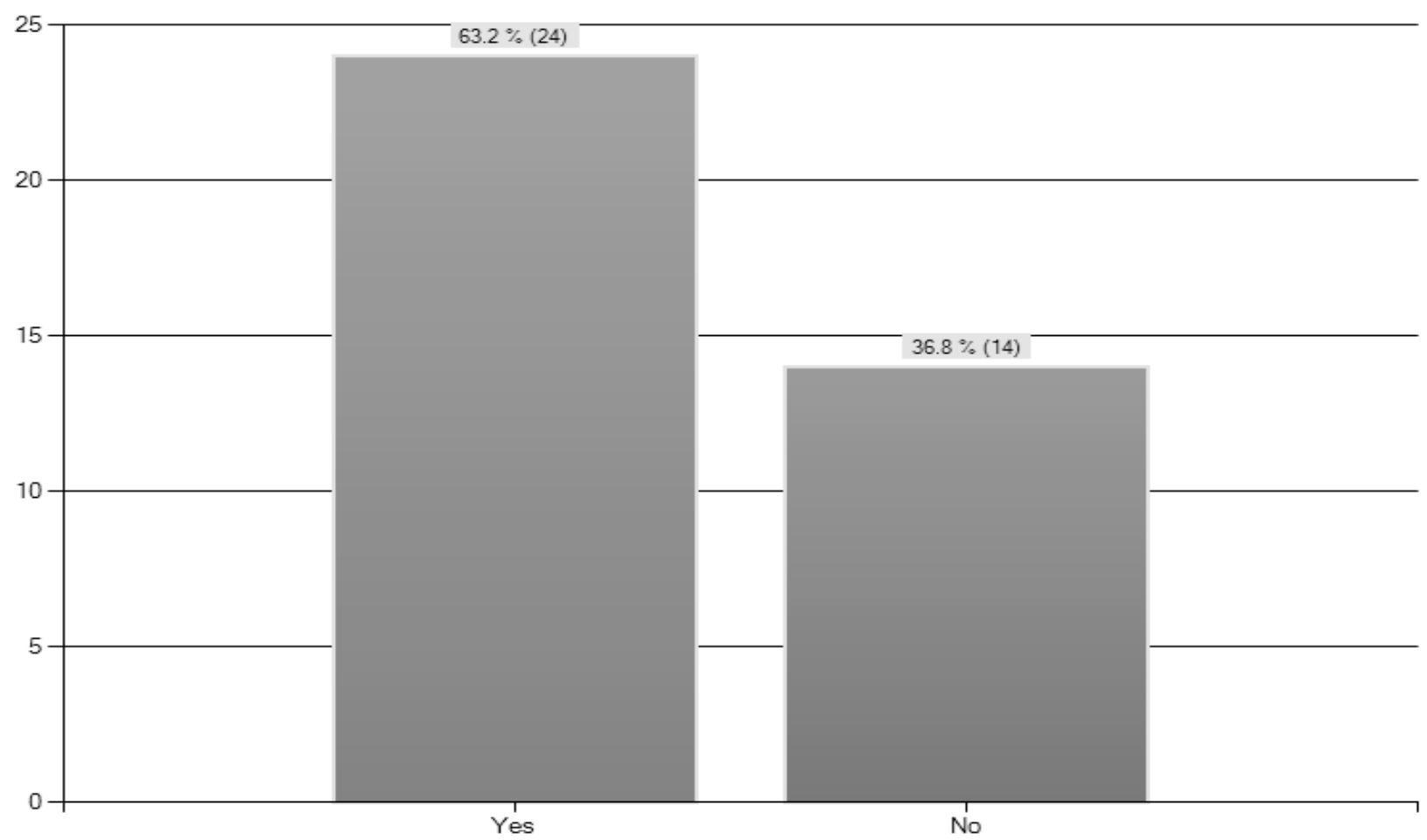

Figure D29. Weeks of Work Missed Due to Work Related Injuries

If so, approximately how many weeks of work have you missed associated with work related injuries?

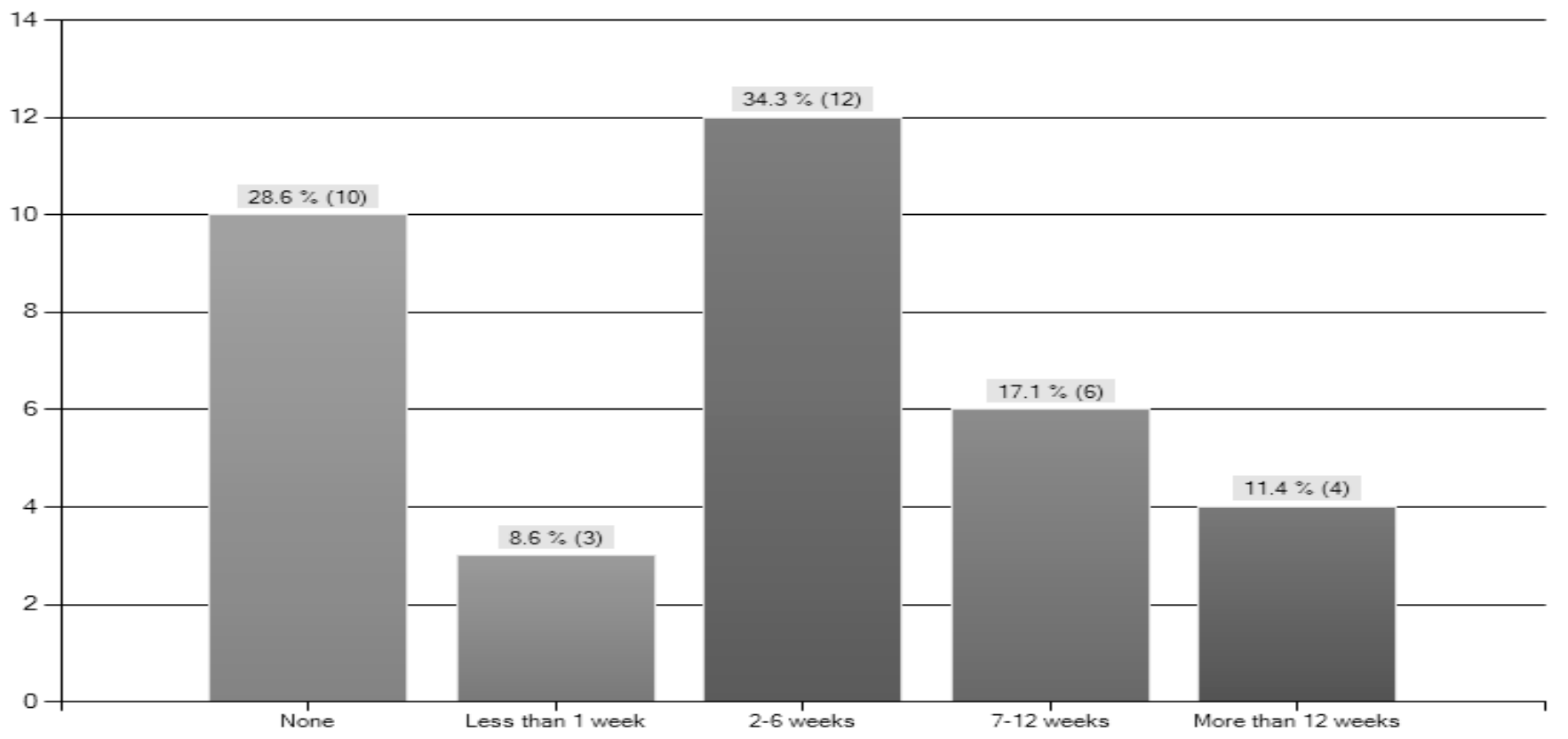


Figure D30. Outside of Work Injury Medical Care

Of the injuries that you incurred from outside of work (recreational) activities during your employment as a tactical officer, who was responsible for managing your injuries? Check all that apply.

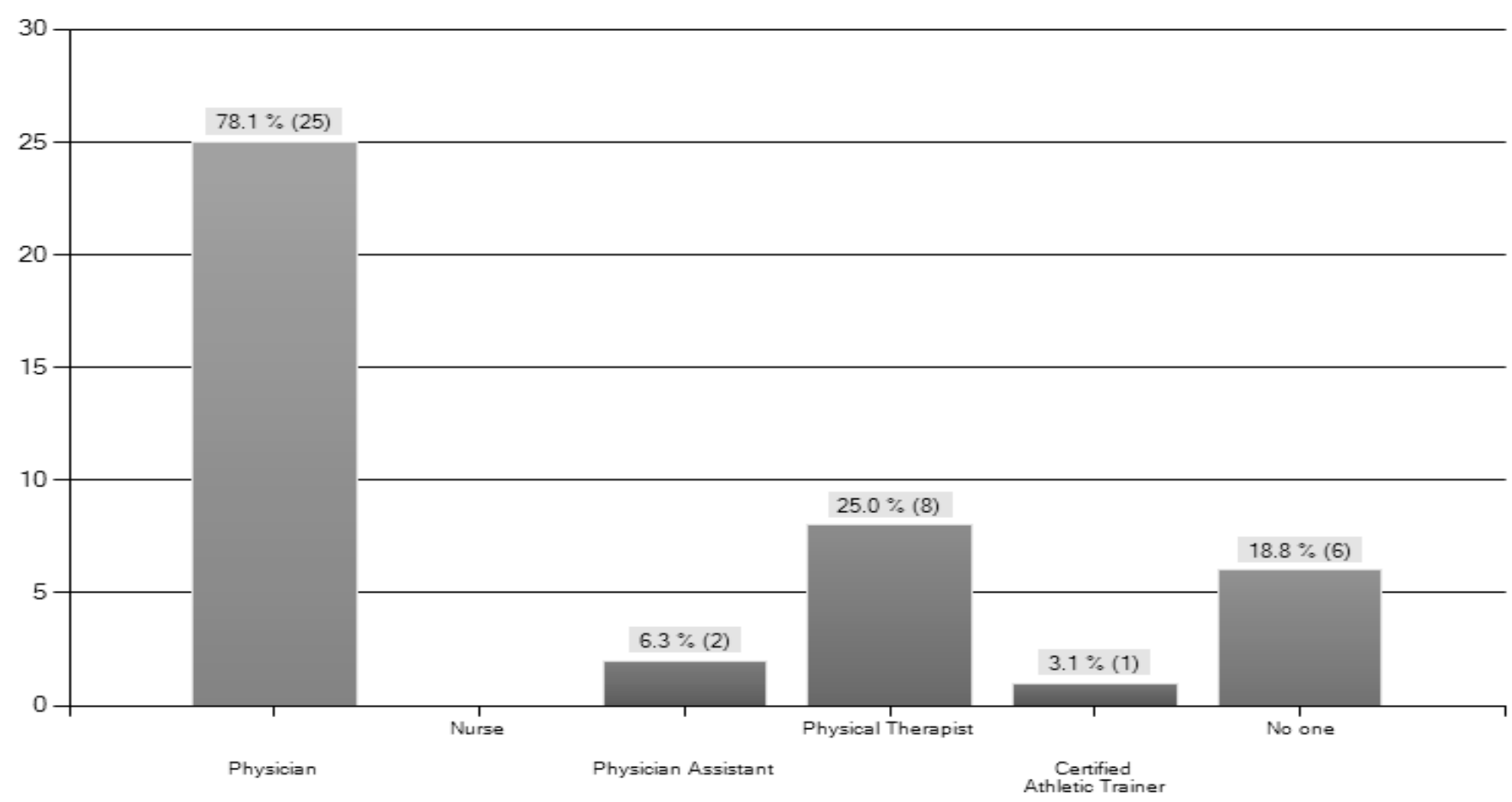

Figure D31. Time Lost Due to Outside of Work Injuries

Did any of your outside of work (recreational) activity injuries while a tactical officer cause you to miss work as a tactical officer?

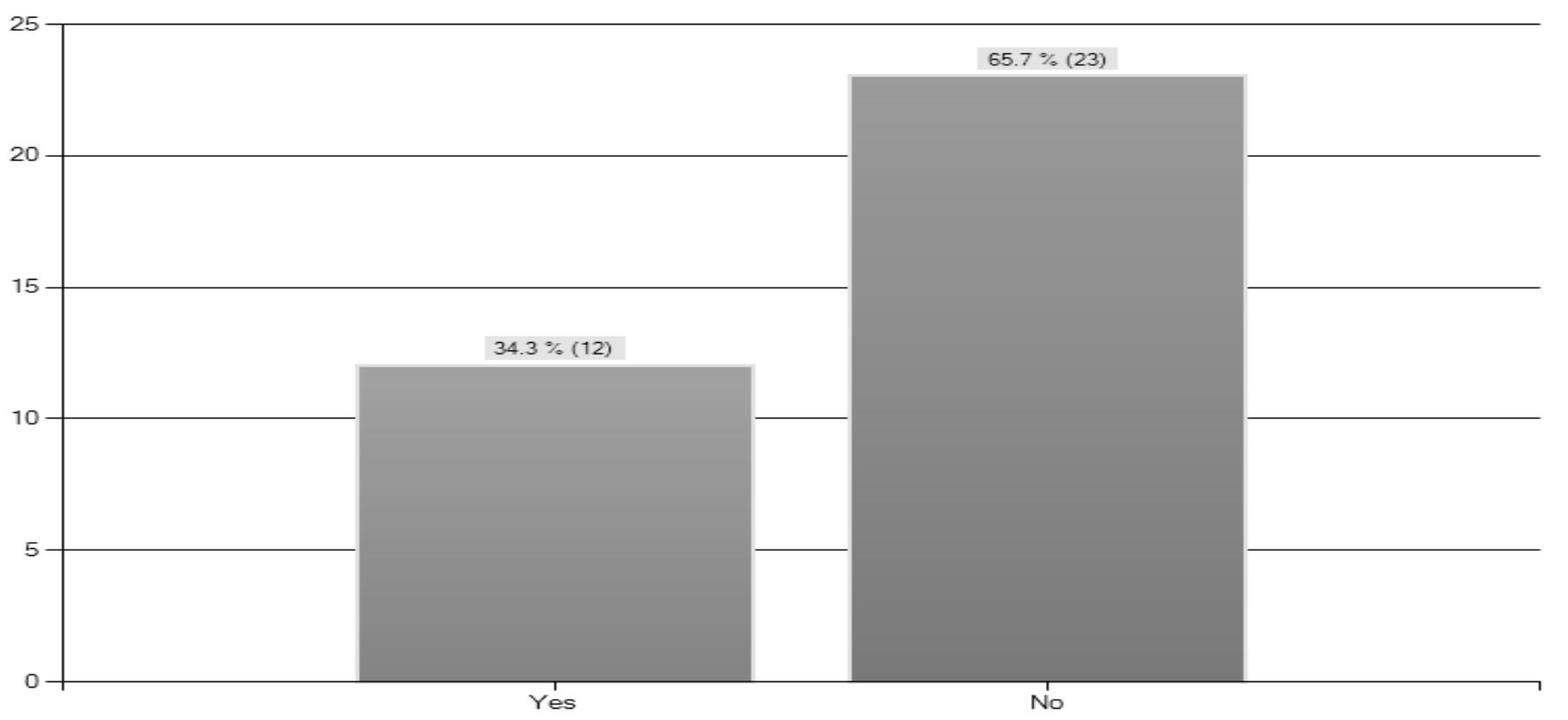


Figure D32. Weeks of Work Missed Due to Outside of Work Injuries

If so, approximately how many weeks of work have you missed related to injuries that you sustained during outside of work (recreational) activities?

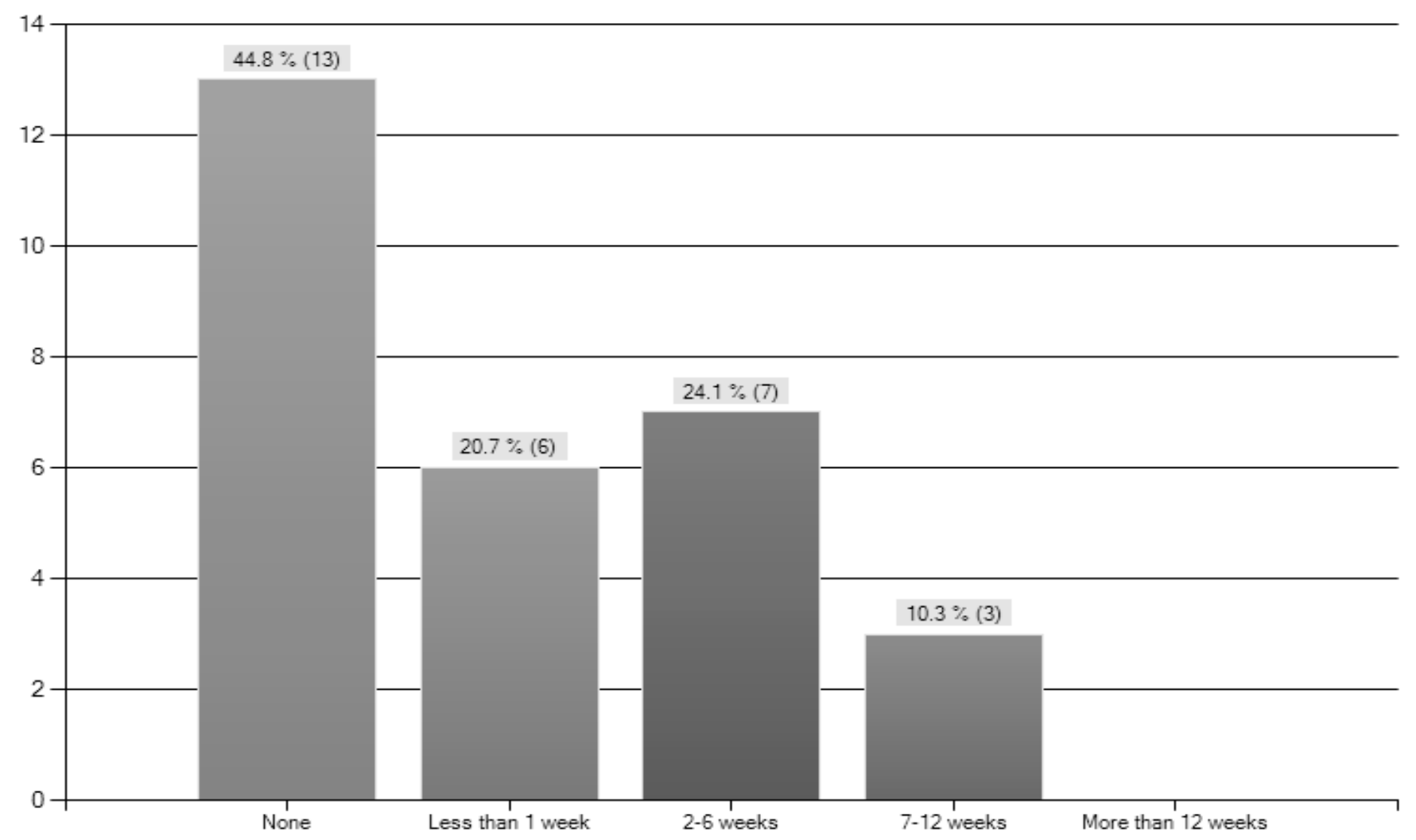




\section{APPENDIX E}

\section{RECOMMENDATIONS FOR FUTURE RESEARCH}

1. Gaining approval from all 27 state and regional tactical associations is recommended. The number of participants would have been higher if all 27 associations would have agreed to participate in the study. This could have been achieved by removing the initial association letter of interest, and initially providing associations with the cover letter containing the internet link to the survey. Many tactical associations agreed to forward the association letter of interest to all of their members. However this letter did not contain the link to the Tactical Officer Questionnaire. Providing the link in the first letter would cut down on the amount of work the participants would have to do in order to access the questionnaire, therefore increasing responses.

2. Individually contacting members electronically is also recommended. Although membership information is kept confidential, a direct email would increase response rates.

3. Conducting data collection during the Tactical Operations Conference and Vendor Show held in September every year is recommended. This would allow personal contact with tactical officers, and increase responses.

4. Narrowing the focus of the data collected is also recommended. Focusing on three primary factors as opposed to three primary factors and three secondary factors would dramatically reduce the confusion among participants during data collection and the analysis of the data collected. Looking at work related injuries only would allow the researcher to determine if the majority of injuries are a result of training exercises or call outs, which is more important than injuries sustain previous to tactical officer employment and outside of work (recreational) injuries. 


\section{ADDITIONAL REFERENCES}

16. Prentice WE. Arnheim's Principles of Athletic Training: A Competency-Based Approach. $11^{\text {th }}$ ed. New York, NY. McGraw-Hill Higher Education. 2003.

17. Heck JJ, Pierluisi G. National association of EMS physicians Position Paper: Law enforcement special operations medical support. Prehosp Emerg Care. 2001;5(4):403406.

18. Starkey C, Ryan J. Evaluation of Orthopedic and Athletic Injuries. $2^{\text {nd }}$ ed. Philadelphia, PA. F.A. Davis Company. 2002:610-652.

19. Moore KL, Dalley AF, Agur AM. Clinically Oriented Anatomy. $5^{\text {th }}$ ed. Baltimore, MD. Lippincott Williams \& Wilkins. 2006:886-1043.

20. Bailes JE, Petschauer M, Guskiewicz KM, Marano G. Management of cervical spine injuries in athletes. J Athl Train. 2007;42(1):126-134.

21. Sweitzer M. Injury surveillance of amateur motocross associated injuries over a six race series: concussions versus musculoskeletal injuries. West Virginia University ETD. 2009.

22. Parker S. The Human Body Book. New York, NY. DK Publishing. 2007.

23. Devereaux MW. Anatomy and examination of the spine. Neurol Clin. 2007;25:331-351.

24. Sieg KW, Adams SP. Illustrated Essentials of Musculoskeletal Anatomy. $3^{\text {rd }}$ ed. Gainesville, FL. Megabooks, Inc. 1996.

25. Saladin KS, Miller L. Anatomy \& Physiology the unity of form and function. $3^{\text {rd }}$ ed. New York, NY. McGraw-Hill. 2004.

26. Young DY, Papp S, Giachino A. Physical examination of the wrist. Orthop Clin N Am. 2007;38:149-165.

27. Yu JS, Habib PA. Normal MR imaging anatomy of the wrist and hand. Radiol Clin N Am. 2006;44:569-581.

28. Fowler KAB, Chung CB. Normal MR imaging anatomy of the elbow. Radiol Clin N Am. 2006;44:553-567.

29. Veillette CJH, Steinmann SP. Olecranon fractures. Orthop Clin N Am. 2008;39:229-236.

30. Bryce CD, Armstrong AD. Anatomy and biomechanics of the elbow. Orthop Clin N Am. 2008;39:141-154.

31. Patel DR, Baker RJ. Musculoskeletal injuries in sports. Prim Care Clin Office Pract. 2006;33:545-579. 
32. Johnson RJ. Acromioclavicular joint injuries: identifying and treating 'separated shoulder and other conditions. Phys Sports Med. 2001;29(11):1-7.

33. Rooks YL, Corwell B. Common urgent musculoskeletal injuries in primary care. Prim Care Clin Office Pract. 2006;33:751-777.

34. Beaty JH. Fractures of the hip in children. Orthop Clin N Am. 2006;37:223-232.

35. Armfield DR, Kim DHM, Towers JD, Bradley JP, Robertson DD. Sports-related muscle injury in the lower extremity. Clin Sports Med. 2006;25:803-842.

36. Pimentel L. Orthopedic trauma: office management of major joint trauma. Med Clin Am. 2006;90:355-382.

37. Roberts CC, Towers JD, Spangehl MJ, Carrino JA, Morrison WB. Advanced MR imaging of the cruciate ligaments. Radiol Clin N Am. 2007;45:1003-1016.

38. Beall DP, Googe JD, Moss JT, Ly JQ, Greer BJ, Stapp AM, Martin HD. Magnetic resonance imaging of the collateral ligaments and the anatomic quadrants of the knee. Radiol Clin N Am. 2007;45:983-1002.

39. Ivins D. Acute ankle sprain: an update. Am Fam Phys. 2006;74:1714-1720.

40. Cerezal L, Llopis E, Canga A, Rolon A. MR arthrography of the ankle: indications and technique. Radiol Clin N Am. 2008;46:973-994.

41. Craig JG. Ultrasound of ligaments and bone. Ultrasound Clin. 2007;2:617-637.

42. Hatem SF. Imaging of Lisfranc injury and midfoot sprain. Radiol Clin N Am. 2008;46:1045-1060.

43. Potter RN, Gardner JW, Deuster PA, Jenkins P, McKee K Jr, Jones BK,. Musculoskeletal injuries in an Army airborne population. Mil Med. 2002;167:1033-1040.

44. Davidson PL, Chalmers DJ, Wilson BD, McBride D. Lower limb injuries in New Zealand Defence Force personnel: descriptive epidemiology. Aust Nz J Publ Heal. 2008;32(2):167-173.

45. Gyi DE, Porter JM. Musculoskeletal problems and driving in police officers. Occup Med. 1998;48(3):153-160.

46. Suyama J, Rittenberger JC, Patterson PD, Holster D. Comparison of public safety provider injury rates. Prehosp Emerg Care. 2009;13(4):451-455.

47. Nabeel I, Baker BA, McGrail MP, Flottemesch TJ. Correlation between physical activity, fitness, and musculoskeletal injuries in police officers. Minn Med. 2007;9.

48. C2. National Tactical Officers Association Page. http://site.ntoa.org. Updated Dec 5, 2009. Accessed Dec. 5, 2009. 